\title{
Gold-Catalyzed Highly Enantioselective Synthesis of Axially Chiral Allenes
}

\author{
Vanessa Kar-Yan Lo, Man-Kin Wong, * and Chi-Ming Che* \\ Department of Chemistry and Open Laboratory of Chemical Biology of the Institute of \\ Molecular Technology for Drug Discovery and Synthesis, The University of Hong Kong, \\ Pokfulam Road, \\ Hong Kong, China
}

cmche@hku.hk, mkwong@hkusua.hku.hk

\section{Supporting Information}


Table S1. Effect of Catalysts on the Synthesis of Axially Chiral Allene 2a ${ }^{a}$

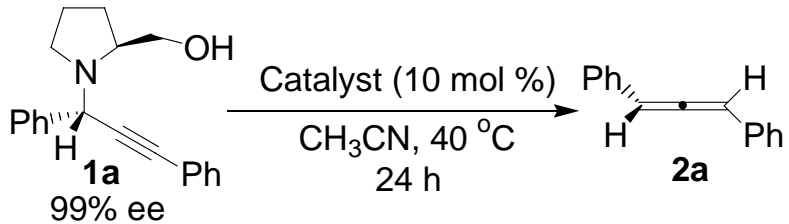

\begin{tabular}{ccccc}
\hline entry & catalyst & convn $^{b}$ & yield $^{c}$ & ee $^{d}$ \\
\hline 1 & $\mathrm{KAuCl}_{4}$ & 91 & 82 & 93 \\
$2^{e}$ & $\mathrm{KAuCl}_{4}$ & 55 & 85 & 95 \\
$3^{e, f}$ & $\mathrm{KAuCl}_{4}$ & 68 & 79 & 84 \\
$4^{g}$ & $\mathrm{KAuCl}_{4}$ & 49 & 75 & 95 \\
$5^{h}$ & $\mathrm{KAuCl}_{4}$ & 70 & 83 & 90 \\
6 & $\mathrm{KAuCl}_{4} / \mathrm{AgNO}_{3}$ & 91 & 65 & 87 \\
7 & $\mathrm{Au}(\mathrm{Salen}) \mathrm{Cl}$ & trace & - & - \\
$8^{i}$ & $\mathrm{Au}(\mathrm{TPP}) \mathrm{Cl}$ & 0 & - & - \\
$9^{i}$ & $\mathrm{AuCl}$ & 91 & 84 & 92 \\
10 & $\mathrm{Pd}(\mathrm{OAc})_{2}$ & 8 & - & - \\
11 & $\mathrm{TfOH}$ & 0 & - & - \\
12 & $\mathrm{ZnCl}_{2}$ & 0 & - & - \\
13 & $\mathrm{CuBr}$ & 0 & - & - \\
14 & $\mathrm{CuCl}$ & - & - \\
15 & $\mathrm{RuCl}$ & & - & - \\
16 & $\mathrm{~K}_{2} \mathrm{PtCl}$ & 0 & - & - \\
17 & $\mathrm{Yb}(\mathrm{OTf})_{3}$ & 0 & - &
\end{tabular}

${ }^{a}$ 1a $:$ catalyst $=1: 0.1 .{ }^{b}$ Determined by ${ }^{1} \mathrm{H}$ NMR analysis of the crude reaction mixture. ${ }^{c}$ Isolated yield based on conversion. ${ }^{d}$ Determined by HPLC using Chiralcel-OD column. ${ }^{e}$ Reaction performed at rt. ${ }^{f}$ Reaction time $=72 \mathrm{~h} .{ }^{g} \mathrm{H}_{2} \mathrm{O}$ as solvent. ${ }^{h}$ Reaction performed in $3 \mathrm{mmol}$ scale. ${ }^{i} \mathbf{1 a}:$ catalyst $=1: 0.3$. 


\section{General Procedure for Synthesis of Propargylamines 1a-p}

A mixture of $\mathrm{Au}(\mathrm{Salen}) \mathrm{Cl}(0.02 \mathrm{mmol})$, aldehyde $(2.0 \mathrm{mmol})$, amine $(2.2 \mathrm{mmol})$ and alkyne $(3.0 \mathrm{mmol})$ in water $(1 \mathrm{~mL})$ was stirred at $40{ }^{\circ} \mathrm{C}$ for $24 \mathrm{~h}$ under $\mathrm{N}_{2}$ atmosphere in the absence of light. The reaction mixture was extracted with diethyl ether. The combined organic layers were dried over anhydrous $\mathrm{Na}_{2} \mathrm{SO}_{4}$, filtered, and concentrated under reduced pressure. The product was purified by flash column chromatography on silica gel using ethyl acetate-hexane as eluent [Lo, V. K.-Y.; Liu, Y.; Wong, M.-K.; Che, C.-M. Org. Lett. 2006, 8, 1529.]

\section{General Procedure for Gold-Catalyzed Synthesis of Axially Chiral Allenes}

A mixture of propargylamine $(0.1 \mathrm{mmol})$ and $\mathrm{KAuCl}_{4}(0.01 \mathrm{mmol})$ in $\mathrm{CH}_{3} \mathrm{CN}(2$ $\mathrm{mL}$ ) was stirred at $40{ }^{\circ} \mathrm{C}$ for $24 \mathrm{~h}$. Solvent was removed under reduced pressure. The product was purified by flash column chromatography on silica gel using ethyl acetatehexane as eluent. The \% ee was determined by HPLC using Chiralcel-OD column using IPA-hexane as eluent.

\section{General Procedure for Preparation of Racemic Allenes for Chiral HPLC}

\section{Analysis}

Achiral propargylamines 1p, 1b'-f', 1h'-l' were synthesized as described above, despite using pyrrolidine as the amine component. The achiral propargylamines were converted into racemic allenes using the procedure described above. 
Racemic $\mathbf{2 g}$ was prepared by reacting equal amount of $\mathbf{1 g}$ and its enantiomer, which was synthesized by three-component coupling reaction using $(R)$-prolinol as the amine component.

\section{Preparation of Propargylamine-Modified Artemisinin 3a-d}

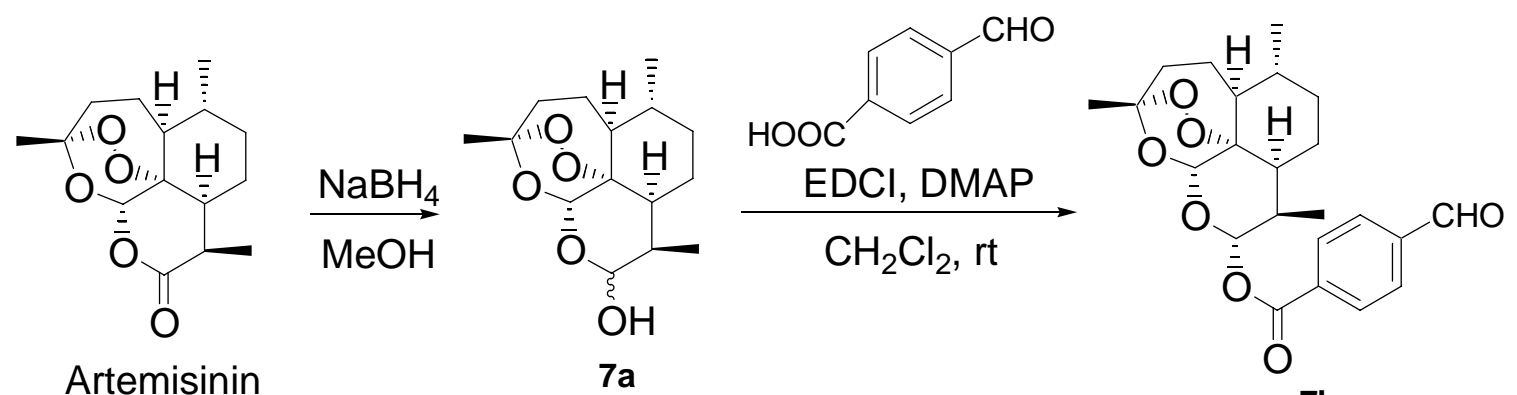

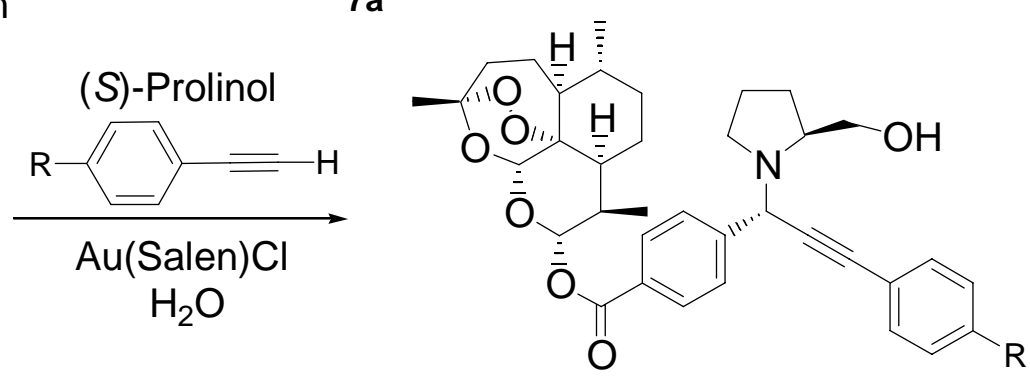

7a was synthesized according to a reported procedure: [Liu, Y.; Wong, V. K.-W.; Ko, B. C.-B.; Wong, M.-K.; Che, C.-M. Org. Lett. 2005, 7, 1561.]

To a solution of 4-carboxybenzaldehyde $(519 \mathrm{mg}, 3.46 \mathrm{mmol})$ in $\mathrm{CH}_{2} \mathrm{Cl}_{2}(50 \mathrm{~mL})$ was added EDCI (576 mg, $3.0 \mathrm{mmol}$ ) at $\mathrm{rt}$ under $\mathrm{N}_{2}$ atmosphere. The mixture was stirred for $5 \mathrm{~min}$ and then treated with DMAP $(70 \mathrm{mg}, 0.57 \mathrm{mmol})$ and $7 \mathbf{a}(327.4 \mathrm{mg}, 1.15$ mmol). After stirring overnight at rt, the mixture was washed with $\mathrm{NH}_{4} \mathrm{Cl}, \mathrm{H}_{2} \mathrm{O}$ and brine. The organic layer was dried over anhydrous $\mathrm{MgSO}_{4}$, filtered and concentrated under reduced pressure. Purification by flash column chromatography on silica gel using ethyl acetate-hexane as eluent afforded $\mathbf{7 b}(447.3 \mathrm{mg}, 93 \%)$ as a white solid. ${ }^{1} \mathrm{H}$ NMR (300 $\left.\mathrm{MHz}, \mathrm{CDCl}_{3}\right) \delta 10.12(\mathrm{~s}, 1 \mathrm{H}), 8.27-8.26(\mathrm{~m}, 2 \mathrm{H}), 7.99-7.96(\mathrm{~m}, 2 \mathrm{H}), 6.03(\mathrm{~d}, J=9.8 \mathrm{~Hz}$, 
1H), $5.55(\mathrm{~s}, 1 \mathrm{H}), 2.81-2.74(\mathrm{~m}, 1 \mathrm{H}), 2.40(\mathrm{td}, J=13.9,3.8 \mathrm{~Hz}, 1 \mathrm{H}), 2.08-2.04(\mathrm{~m}, 1 \mathrm{H})$, 1.97-1.68 (m, 4H), 1.58-1.49 (m, 2H), $1.43(\mathrm{~s}, 3 \mathrm{H}), 1.38-1.31(\mathrm{~m}, 2 \mathrm{H}), 1.12-1.03(\mathrm{~m}, 1 \mathrm{H})$, $0.99(\mathrm{~d}, J=5.8 \mathrm{~Hz}, 3 \mathrm{H}), 0.95(\mathrm{~d}, J=7.1 \mathrm{~Hz}, 3 \mathrm{H}) ;{ }^{13} \mathrm{C} \mathrm{NMR}\left(75 \mathrm{MHz}, \mathrm{CDCl}_{3}\right) \delta 191.52$, $164.13,139.27,134.41,130.51,129.30,104.32,92.93,91.49,79.78,51.45,45.14,37.11$, $36.08,33.94,31.80,25.77,24.43,21.88,20.08,12.09$; IR ( $\mathrm{NaCl}$, neat, $\left.\mathrm{cm}^{-1}\right) 2362,2343$, 1996, 1736, 1705; ESI-MS m/z $471\left(\mathrm{M}+\mathrm{CH}_{3} \mathrm{OH}+\mathrm{Na}^{+}\right)$.

A mixture of $\mathrm{Au}(\mathrm{Salen}) \mathrm{Cl}(7.5 \mathrm{mg}, 0.015 \mathrm{mmol}), 7 \mathbf{b}(124.8 \mathrm{mg}, 0.3 \mathrm{mmol}),(S)-$ prolinol $(32.5 \mu \mathrm{L}, 0.33 \mathrm{mmol})$ and alkyne $(0.45 \mathrm{mmol})$ in water $(1 \mathrm{~mL})$ were stirred at 40 ${ }^{\circ} \mathrm{C}$ for $24 \mathrm{~h}$ under $\mathrm{N}_{2}$ atmosphere in the absence of light. The reaction mixture was extracted with diethyl ether. The combined organic layers were dried over anhydrous $\mathrm{MgSO}_{4}$, filtered and concentrated under reduced pressure. The product was purified by flash column chromatography on silica gel using ethyl acetate-hexane as eluent. (86.1 $153.5 \mathrm{mg}, 57-84 \%$ yield)

\section{Preparation of Deuterium-Labeled Propargylamine 5a}

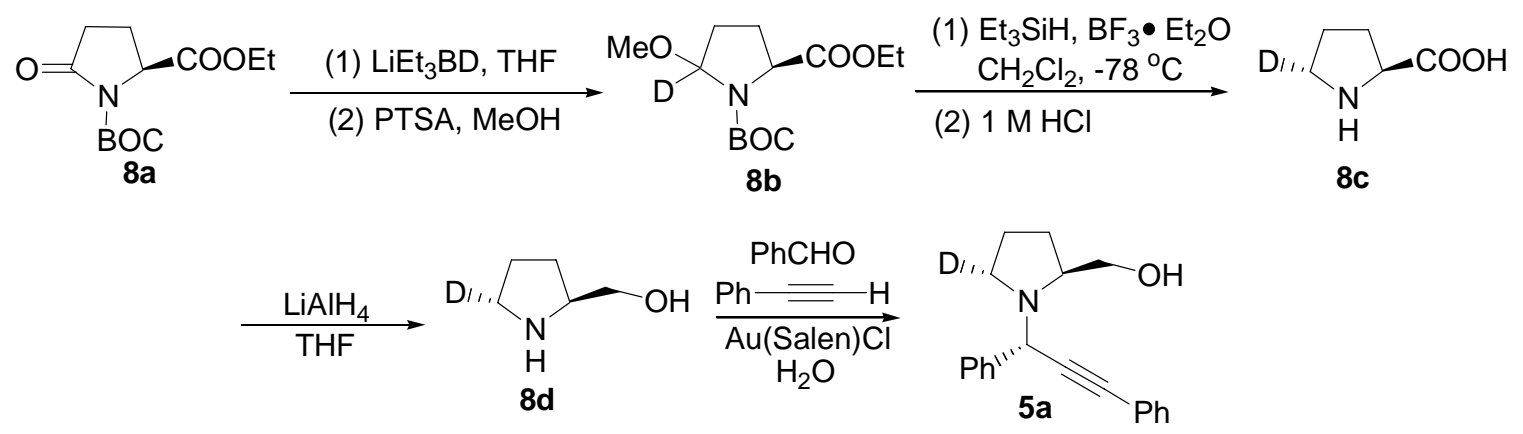

To a solution of $\mathbf{8 a}(1.28 \mathrm{~g}, 4.96 \mathrm{mmol})$ in THF $(50 \mathrm{~mL})$ was added a solution of $\mathrm{LiEt}_{3} \mathrm{BD}(1 \mathrm{M}$ in THF, $6.0 \mathrm{~mL}, 6.00 \mathrm{mmol})$ at $-78{ }^{\circ} \mathrm{C}$ under $\mathrm{N}_{2}$ atmosphere. After stirring for $0.5 \mathrm{~h}$, the reaction was quenched with saturated aqueous $\mathrm{NaHCO}_{3}(6 \mathrm{~mL})$ at $-78{ }^{\circ} \mathrm{C}$ 
and the reaction was warmed up to $0{ }^{\circ} \mathrm{C}$. After addition of $30 \% \mathrm{H}_{2} \mathrm{O}_{2}(1 \mathrm{~mL})$, the mixture was stirred for additional $20 \mathrm{~min}$ and concentrated under reduced pressure. The residue was extracted with diethyl ether and washed with $\mathrm{H}_{2} \mathrm{O}$. The organic layer was dried over anhydrous $\mathrm{MgSO}_{4}$, filtered and concentrated under reduced pressure. The crude product was directly treated with $\mathrm{MeOH}(30 \mathrm{~mL})$ in the presence of PTSA $(8.6 \mathrm{mg}, 0.05 \mathrm{mmol})$ overnight. The mixture was diluted with $\mathrm{CHCl}_{3}$ and washed with saturated aqueous $\mathrm{NaHCO}_{3}$. The organic layer was dried over anhydrous $\mathrm{MgSO}_{4}$, filtered and concentrated under reduced pressure. Purification by flash column chromatography on silica gel using ethyl acetate-hexane as eluent afforded $\mathbf{8 b}(1.08 \mathrm{~g}, 80 \%)$ as a colorless oil as inseparable diastereoisomers. ${ }^{1} \mathrm{H}$ NMR (300 MHz, $\left.\mathrm{CDCl}_{3}\right) \delta$ 4.29-4.14 (m, 3H), 3.43-3.35 (m, 3H), 2.34-1.75 (m, 4H), 1.49-1.42 (m, 9H), 1.32-1.23 (m, 3H); ${ }^{13} \mathrm{C}$ NMR $\left(75 \mathrm{MHz}, \mathrm{CDCl}_{3}\right) \delta$ $172.35,172.00,153.76,153.55,80.22,80.07,79.99,60.51,60.45,59.29,59.02,58.70$, $58.63,55.70,55.43,54.83,54.52,32.47,31.80,30.62,29.64,29.32,27.94,27.77,27.68$, 26.74, 26.64; EIMS m/z 243 (M-OMe); HRMS (EI) for $\mathrm{C}_{12} \mathrm{H}_{19} \mathrm{DNO}_{4}$, found 243.1461.

To a solution of $\mathbf{8 b}(273.6 \mathrm{mg}, 1.00 \mathrm{mmol})$ in $\mathrm{CH}_{2} \mathrm{Cl}_{2}(20 \mathrm{~mL})$ was added $\mathrm{Et}_{3} \mathrm{SiH}$ $(0.3 \mathrm{~mL}, 1.91 \mathrm{mmol})$ and $\mathrm{BF}_{3} \cdot \mathrm{Et}_{2} \mathrm{O}(0.3 \mathrm{~mL}, 2.43 \mathrm{mmol})$ in two portions at intervals of $0.5 \mathrm{~h}$ at $-78{ }^{\circ} \mathrm{C}$ under $\mathrm{N}_{2}$ atmosphere. After stirring for $2 \mathrm{~h}$, the reaction was quenched with saturated aqueous $\mathrm{Na}_{2} \mathrm{CO}_{3}(2 \mathrm{~mL})$. The organic layer was dried over anhydrous $\mathrm{MgSO}_{4}$, filtered and concentrated under reduced pressure. Deprotection of the resulting BOC-protected D-labeled proline was carried out by refluxing in $1 \mathrm{M} \mathrm{HCl}(20 \mathrm{~mL})$ for 3 h. Then the mixture was neutralized to $\mathrm{pH} \sim 6-7$ by $20 \%$ aqueous $\mathrm{KOH}$ solution and concentrated under reduced pressure. The product was extracted by $\mathrm{MeOH}$. Removal of the solvent under reduced pressure afforded 8c (109.1 mg, 94\%) as a pale yellow solid. 
${ }^{1} \mathrm{H}$ NMR (300 MHz, D $\left.2 \mathrm{O}\right) \delta$ 4.19-4.14 (m, 1H), 3.44-3.38 (m, 1.21H), 2.41-2.32 (m, 1H), 2.16-2.02 (m, $3 \mathrm{H}) ;{ }^{13} \mathrm{C}$ NMR $\left(150 \mathrm{MHz}, \mathrm{D}_{2} \mathrm{O}\right) \delta 61.15,45.75(\mathrm{t}, J=22.2 \mathrm{~Hz}), 28.90$, 23.57; EIMS m/z $71\left(\mathrm{M}^{+}-\mathrm{COOH}\right)$; HRMS (EI) for $\mathrm{C}_{4} \mathrm{H}_{7} \mathrm{DN}$, found 71.0719 .

To a solution of $8 \mathrm{c}(207 \mathrm{mg}, 1.78 \mathrm{mmol})$ suspended in THF $(20 \mathrm{~mL}), \mathrm{LiAlH}_{4}(240$ mg, $6.32 \mathrm{mmol}$ ) was added slowly at $0{ }^{\circ} \mathrm{C}$ under $\mathrm{N}_{2}$ atmosphere. The resulting mixture was refluxed for $2 \mathrm{~h}$. After cooling to $0{ }^{\circ} \mathrm{C}$, the reaction was quenched by ethyl acetate $(10 \mathrm{~mL})$ followed by $30 \%$ aqueous $\mathrm{KOH}$ solution $(4 \mathrm{~mL})$. The organic layer was collected and the residue was refluxed with a new portion of THF $(30 \mathrm{~mL})$ for $30 \mathrm{~min}$. The combined THF layers were dried with anhydrous $\mathrm{Na}_{2} \mathrm{SO}_{4}$, filtered and concentrated under reduced pressure to yield $\mathbf{8 d}(103.2 \mathrm{mg}, 57 \%)$ as pale yellow oil, which was then used without further purification.

A mixture of $\mathrm{Au}(\mathrm{Salen}) \mathrm{Cl}$, benzaldehyde, $\mathbf{8 d}$ and phenylacetylene in water $(1 \mathrm{~mL})$ were stirred at $40{ }^{\circ} \mathrm{C}$ for $24 \mathrm{~h}$ in the absence of light under $\mathrm{N}_{2}$ atmosphere. The reaction mixture was extracted with diethyl ether. The combined organic layers were dried over anhydrous $\mathrm{MgSO}_{4}$, filtered and concentrated under reduced pressure. Purification by flash column chromatography on silica gel using ethyl acetate-hexane as eluent afforded 5a as yellowish oil. ${ }^{1} \mathrm{H}$ NMR $\left(300 \mathrm{MHz}, \mathrm{CDCl}_{3}\right) \delta$ 7.62-7.59 (m, 2H), 7.54-7.50 (m, 2H), 7.40-7.26 (m, 6H), $5.11(\mathrm{~s}, 1 \mathrm{H}), 3.84(\mathrm{dd}, J=10.9,3.5 \mathrm{~Hz}, 1 \mathrm{H}), 3.54(\mathrm{dd}, J=10.9,2.3$ $\mathrm{Hz}, 1 \mathrm{H}), 3.32-3.25(\mathrm{~m}, 1 \mathrm{H}), 2.83-2.77(\mathrm{~m}, 0.21 \mathrm{H}), 2.61(\mathrm{dd}, J=6.8,2.8 \mathrm{~Hz}, 0.89 \mathrm{H})$, 2.02-1.60 (m, 5H); ${ }^{13} \mathrm{C}$ NMR (125 MHz, $\left.\mathrm{CDCl}_{3}\right) \delta 139.17,131.85,128.37,128.34$, $128.31,128.09,127.62,122.98,87.80,85.39,61.82,61.77,56.25,47.55$ (t, $J=20 \mathrm{~Hz})$, 29.71, 28.04, 23.50; EIMS m/z $292\left(\mathrm{M}^{+}\right)$. 


\section{Preparation of Deuterium-Labeled Propargylamine 5b}

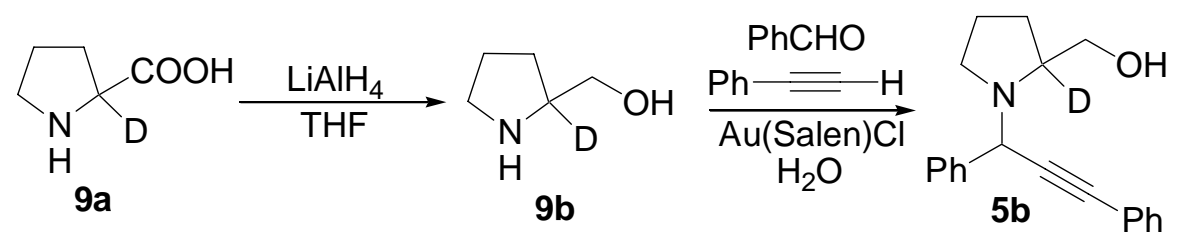

To a solution of DL-proline-2- $\mathrm{d}_{1}$ 9a $(120.6 \mathrm{mg}, 1.04 \mathrm{mmol})$ suspended in THF $(10 \mathrm{~mL}), \mathrm{LiAlH}_{4}(114 \mathrm{mg}, 3.00 \mathrm{mmol})$ was added slowly at $0{ }^{\circ} \mathrm{C}$ under $\mathrm{N}_{2}$ atmosphere. The resulting mixture was refluxed for $5 \mathrm{~h}$. After cooling to $0{ }^{\circ} \mathrm{C}$, the reaction was quenched by ethyl acetate $(5 \mathrm{~mL})$ followed by $30 \%$ aqueous $\mathrm{KOH}$ solution $(10 \mathrm{~mL})$. The organic layer was collected and the residue was refluxed with a new portion of THF (30 $\mathrm{mL}$ ) for $30 \mathrm{~min}$. The combined THF layers were dried with anhydrous $\mathrm{Na}_{2} \mathrm{SO}_{4}$, filtered and concentrated under reduced pressure to yield $\mathbf{9 b}(71 \mathrm{mg}, 67 \%)$ as yellowish oil, which was then used without further purification.

A mixture of $\mathrm{Au}($ Salen $) \mathrm{Cl}(10 \mathrm{mg}, 0.02 \mathrm{mmol})$, benzaldehyde $(0.2 \mathrm{~mL}, 2 \mathrm{mmol})$, 9b $(0.21 \mathrm{~mL}, 2.2 \mathrm{mmol})$ and phenylacetylene $(0.3 \mathrm{~mL}, 3 \mathrm{mmol})$ in water $(1 \mathrm{~mL})$ were stirred at $40{ }^{\circ} \mathrm{C}$ for $24 \mathrm{~h}$ in the absence of light under $\mathrm{N}_{2}$ atmosphere. The reaction mixture was extracted with diethyl ether. The combined organic layers were dried over anhydrous $\mathrm{MgSO}_{4}$, filtered and concentrated under reduced pressure. Purification by flash column chromatography on silica gel using ethyl acetate-hexane as eluent afforded 5b (26.1 mg, 45\% yield based on $10 \%$ conversion of benzaldehyde) as yellowish oil. ${ }^{1} \mathrm{H}$ NMR $\left(300 \mathrm{MHz}, \mathrm{CDCl}_{3}\right) \delta$ 7.62-7.59 (m, 2H), 7.53-7.50 (m, 2H), 7.39-7.27 (m, 6H), $5.11(\mathrm{~s}, 1 \mathrm{H}), 3.83(\mathrm{~d}, J=10.9 \mathrm{~Hz}, 1 \mathrm{H}), 3.53(\mathrm{~d}, J=10.9 \mathrm{~Hz}, 1 \mathrm{H}), 2.86-2.77(\mathrm{~m}, 1 \mathrm{H}), 2.65-$ $2.59(\mathrm{~m}, 1 \mathrm{H}), 1.98-1.65(\mathrm{~m}, 4 \mathrm{H}) ;{ }^{13} \mathrm{C} \mathrm{NMR}\left(75 \mathrm{MHz}, \mathrm{CDCl}_{3}\right) \delta 139.16,131.83,128.36$, 
128.32, 128.08, 127.60, 87.78, 85.38, 61.78, 56.20, 47.88, 27.93, 23.61; EIMS m/z 292

$\left(\mathrm{M}^{+}\right)$; HRMS (EI) for $\mathrm{C}_{20} \mathrm{H}_{20} \mathrm{DNO}$, found 292.1675.

\section{Cytotoxicity Studies (MTT Assay)}

Human hepatocellular carcinoma (HepG2) was maintained in a minimum essential medium with Earle's balanced salts (MEM). All the media were supplemented with 2 $\mathrm{mM} L$-glutamine and $10 \%$ fetal boviene serum. Penicillin $(100 \mathrm{U} / \mathrm{mL})$ and Streptomycin $(100 \mu \mathrm{g} / \mathrm{mL})$ were added to all media. Cultures were incubated at $37{ }^{\circ} \mathrm{C}$ in a $5 \% \mathrm{CO}_{2} /$ 95\% air humidified atmosphere.

Assays on the cytotoxic effects were conducted in 96-well flat-bottomed microtitre plates. The supplemented culture medium $(100 \mu \mathrm{L})$ with cells $\left(4 \times 10^{4}\right.$ cells/ $\left.\mathrm{mL}\right)$ was added into each well and was incubated $\left(37^{\circ} \mathrm{C}, 5 \% \mathrm{CO}_{2} / 95 \%\right.$ air $)$ for $24 \mathrm{~h}$. All the media were then removed and fresh supplemented medium $(100 \mu \mathrm{L})$ was added into each well. Compounds 4a-d dissolved in the culture medium (100 $\mu \mathrm{L}+<1 \%$ ethanol) were added into a set of wells. After mixing, the sample-containing media $(100 \mu \mathrm{L})$ were drawn and added to another set of wells. Such processes were repeated to provide a set of two-fold dilution series. Controlled wells only contained $100 \mu \mathrm{L}$ of supplemented media. Microtitre plates were incubated at $37{ }^{\circ} \mathrm{C}$ in a $5 \% \mathrm{CO}_{2} / 95 \%$ air humidified atmosphere for further 6 days. All the cytotoxicity assays were run in parallel with a negative control (i.e., untreated population). Assessment of the cytotoxicity was carried out using a modified method of Mosmann based 3-(4, 5-Dimethylthiazol-2-yl)-2, 5diphenyltetrazolium bromide (MTT) Assay [Mosmann, T. J. Immunol. Methods 1983, 65, 55-63.]. At the end of each incubation period, $10 \mu \mathrm{L}$ of the MTT solution (Cell Proliferation Kit I, Roche) were added into each well and the cultures were further incubated for $4 \mathrm{~h}$ at $37{ }^{\circ} \mathrm{C}$ in a $5 \% \mathrm{CO}_{2} / 95 \%$ air humidified atmosphere. Then $100 \mu \mathrm{L}$ of 
the solubilization solution was added into the wells to lyse the cells and solubilize the formazan complex formed. The microtitre plates were maintained in a dark and humidified chamber overnight. The formation of formazan was measured with a microtitre plate reader at $550 \mathrm{~nm}$, and the percentages of cell survival were determined. The cytotoxicity was evaluated based on the percentage cell survival in a dosedependence manner relative to the negative control.

\section{Literature References of Chiral Propargylamines 1a, 1j and 1n}

\begin{tabular}{|l|l|}
\hline & $\begin{array}{l}\text { Lo, V. K.-Y.; Liu, Y.; Wong, M.-K.; Che, C.-M. Org. Lett. } \\
\text { 2006, 8, 1529. }\end{array}$ \\
\hline Lo, V. K.-Y.; Liu, Y.; Wong, M.-K.; Che, C.-M. Org. Lett. \\
2006, 8, 1529.
\end{tabular}

\section{Literature References of Chiral Propargylamines 1j’ and 1p}

\begin{tabular}{|l|l|}
\hline & $\begin{array}{l}\text { Lett. 2006, 8, 1529. } \\
\text { (1) }\end{array}$ \\
\hline
\end{tabular}




\section{Literature References of Chiral Allenes 2a-d, 2f and 2j}

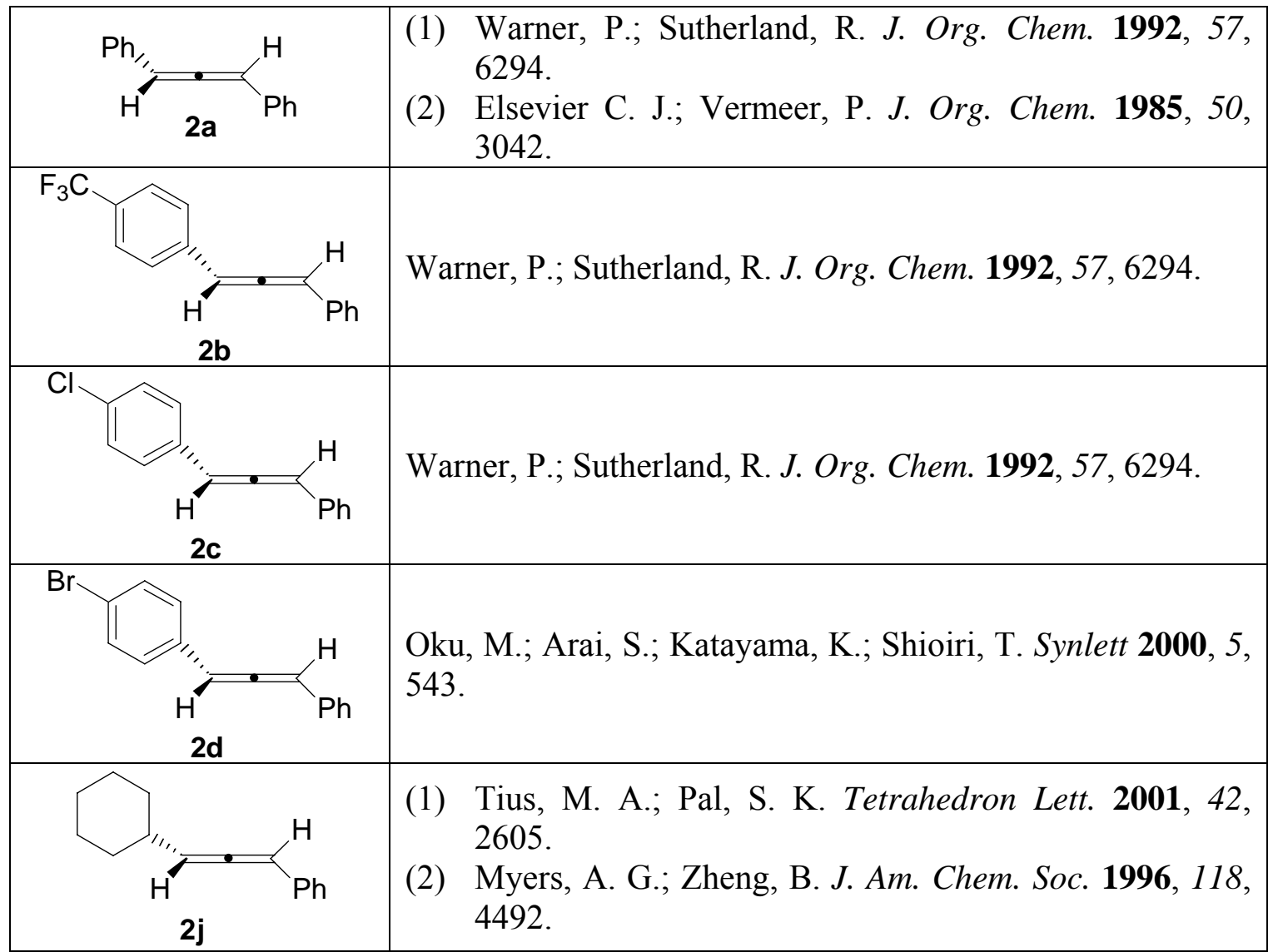

\section{Characterization Data of Propargylamines 1b-i, 1k-l, 10}

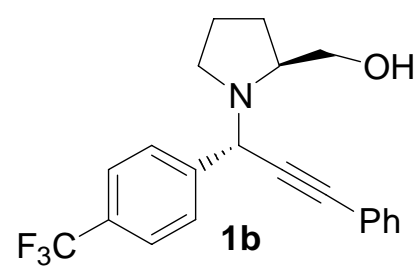

Pale yellow oil; analytical TLC (silica gel 60) (30\% EtOAc in hexane) $\mathrm{R}_{f}=0.43 ;{ }^{1} \mathrm{H}$ NMR $\left(300 \mathrm{MHz}, \mathrm{CDCl}_{3}\right) \delta$ 7.76-7.73 (m, 2H), 7.62-7.59 (m, 2H), 7.53-7.50 (m, 2H), 7.34-7.32 (m, 3H), $5.20(\mathrm{~s}, 1 \mathrm{H}), 3.81(\mathrm{dd}, J=11.0,3.7 \mathrm{~Hz}, 1 \mathrm{H}), 3.58(\mathrm{dd}, J=10.5,2.9$ $\mathrm{Hz}, 1 \mathrm{H}), 3.32-3.25(\mathrm{~m}, 1 \mathrm{H}), 2.84-2.75(\mathrm{~m}, 2 \mathrm{H}), 2.60-2.54(\mathrm{~m}, 1 \mathrm{H}), 2.01-1.62(\mathrm{~m}, 4 \mathrm{H})$;

${ }^{13} \mathrm{C}$ NMR $\left(100 \mathrm{MHz}, \mathrm{CDCl}_{3}\right) \delta 143.21,131.80,129.70(\mathrm{q}, J=32.1 \mathrm{~Hz}), 128.42,128.32$, 
$125.15(\mathrm{q}, J=3.7 \mathrm{~Hz}), 124.10(\mathrm{q}, J=270.0 \mathrm{~Hz}), 122.55,88.33,84.42,62.46,61.94$, 56.17, 47.81, 27.83, 23.44; IR ( $\mathrm{NaCl}$, neat, $\left.\mathrm{cm}^{-1}\right)$ 3421, 2225, 1620; EIMS m/z $359\left(\mathrm{M}^{+}\right)$; HRMS (EI) for $\mathrm{C}_{21} \mathrm{H}_{20} \mathrm{~F}_{3} \mathrm{NO}$, calcd 359.1497, found 359.1482.

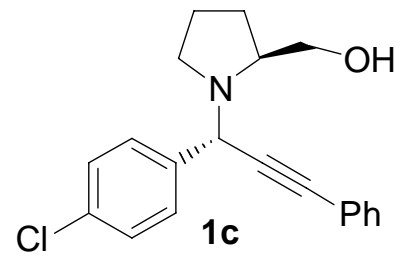

Yellowish oil; analytical TLC (silica gel 60) (30\% EtOAc in hexane) $\mathrm{R}_{f}=0.40 ;{ }^{1} \mathrm{H}$ NMR $\left(400 \mathrm{MHz}, \mathrm{CDCl}_{3}\right) \delta$ 7.54-7.48 (m, 4H), 7.32-7.29 (m, 5H), $5.10(\mathrm{~s}, 1 \mathrm{H}), 3.76(\mathrm{dd}, J=$ 11.0, $3.9 \mathrm{~Hz}, 1 \mathrm{H}), 3.55(\mathrm{dd}, J=11.0,3.0 \mathrm{~Hz}, 1 \mathrm{H}), 3.27-3.22(\mathrm{~m}, 1 \mathrm{H}), 2.79-2.73(\mathrm{~m}, 1 \mathrm{H})$, 2.59-2.54 (m, 1H), 1.95-1.82 (m, 1H), 1.80-1.64 (m, 3H); ${ }^{13} \mathrm{C}$ NMR (100 MHz, $\left.\mathrm{CDCl}_{3}\right) \delta$ $137.59,133.11,131.64,129.29,128.21,128.19,128.14,122.54,87.94,84.75,62.27$, 61.72, 55.76, 47.69, 27.79, 23.32; IR (NaCl, neat, $\left.\mathrm{cm}^{-1}\right)$ 3426, 2360, 2341; EIMS m/z 325 $\left(\mathrm{M}^{+}\right)$; HRMS (EI) for $\mathrm{C}_{20} \mathrm{H}_{20} \mathrm{ClNO}$, calcd 325.1233, found 325.1224.

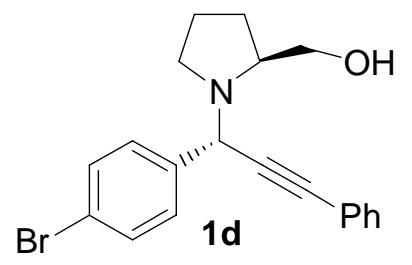

Light yellow oil; analytical TLC (silica gel 60) (10\% EtOAc in hexane) $\mathrm{R}_{f}=0.09 ;{ }^{1} \mathrm{H}$ NMR (300 MHz, $\left.\mathrm{CDCl}_{3}\right) \delta$ 7.52-7.48 (m, 6H), 7.36-7.33 (m, 3H), 5.07 (s, 1H), 3.80 (dd, $J=11.0,3.5 \mathrm{~Hz}, 1 \mathrm{H}), 3.54(\mathrm{dd}, J=11.0,2.6 \mathrm{~Hz}, 1 \mathrm{H}), 3.30-3.16(\mathrm{~m}, 1 \mathrm{H}), 2.79-2.75(\mathrm{~m}$, 1H), 2.00-1.65 (m, 4H); ${ }^{13} \mathrm{C}$ NMR (75 MHz, $\left.\mathrm{CDCl}_{3}\right) \delta 138.26,131.82,131.52,131.39$, $129.96,129.78,128.44,128.38,122.68,121.50,88.15,87.71,62.05,61.80,55.83,47.83$, 27.93, 23.53; IR $\left(\mathrm{NaCl}\right.$, neat, $\left.\mathrm{cm}^{-1}\right)$ 3430, 2359; EIMS m/z $369\left(\mathrm{M}^{+}\right)$; HRMS (EI) for $\mathrm{C}_{20} \mathrm{H}_{20} \mathrm{BrNO}$, calcd 369.0728, found 369.0710. 


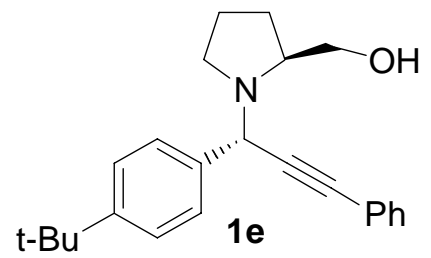

Yellowish oil; analytical TLC (silica gel 60) $\left(10 \%\right.$ EtOAc in hexane) $\mathrm{R}_{f}=0.10 ;{ }^{1} \mathrm{H}$ NMR $\left(300 \mathrm{MHz}, \mathrm{CDCl}_{3}\right) \delta$ 7.54-7.48 (m, 4H), 7.39-7.36 (m, 2H), 7.32-7.30 (m, 3H), $5.08(\mathrm{~s}$, 1H), $3.80(\mathrm{dd}, J=10.9,3.6 \mathrm{~Hz}, 1 \mathrm{H}), 3.52(\mathrm{dd}, J=10.9,2.2 \mathrm{~Hz}, 1 \mathrm{H}), 3.29-3.23(\mathrm{~m}, 1 \mathrm{H})$, 2.87-2.78 (m, 1H), 2.69-2.62 (m, 1H), 1.96-1.67 (m, 4H), $1.32(\mathrm{~s}, 9 \mathrm{H}) ;{ }^{13} \mathrm{C}$ NMR $(75$ $\left.\mathrm{MHz}, \mathrm{CDCl}_{3}\right) \delta 150.45,136.14,131.76,128.27,128.15,127.95,127.70,125.16,123.03$, $87.49,85.68,61.90,61.67,55.88,47.88,34.44,31.32,28.02,23.53$; IR ( $\mathrm{NaCl}$, neat, $\left.\mathrm{cm}^{-1}\right)$ 3430, 2361; EIMS m/z $347\left(\mathrm{M}^{+}\right)$; HRMS (EI) for $\mathrm{C}_{24} \mathrm{H}_{29} \mathrm{NO}$, calcd 347.2249, found 347.2243 .

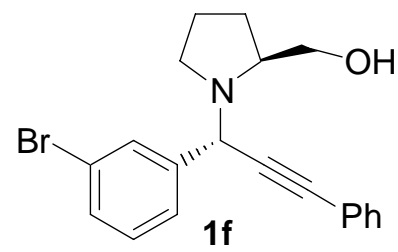

Yellowish oil; analytical TLC (silica gel 60) (30\% EtOAc in hexane), $\mathrm{R}_{f}=0.28 ;{ }^{1} \mathrm{H}$ NMR $\left.300 \mathrm{MHz}, \mathrm{CDCl}_{3}\right) \delta 7.76(\mathrm{~s}, 1 \mathrm{H}), 7.56-7.49(\mathrm{~m}, 3 \mathrm{H}), 7.42(\mathrm{~d}, J=8.0 \mathrm{~Hz}, 1 \mathrm{H}), 7.34-7.32$ (m, 3H), 7.22 (d, $J=7.6 \mathrm{~Hz}, 1 \mathrm{H}), 5.12(\mathrm{~s}, 1 \mathrm{H}), 3.80$ (dd, $J=11.0,3.7 \mathrm{~Hz}, 1 \mathrm{H}), 3.56$ (dd, $J=11.0,2.8 \mathrm{~Hz}, 1 \mathrm{H}), 3.30-3.23(\mathrm{~m}, 1 \mathrm{H}), 1.98-1.67(\mathrm{~m}, 4 \mathrm{H}) ;{ }^{13} \mathrm{C} \mathrm{NMR}\left(125 \mathrm{MHz}, \mathrm{CDCl}_{3}\right)$ $\delta 141.59,131.89,131.08,130.76,129.89,128.49,128.42,126.77,122.69,122.48,88.30$ 84.53, 62.10, 61.89, 55.93, 47.92, 27.92, 23.59; IR ( $\mathrm{NaCl}$, neat, $\left.\mathrm{cm}^{-1}\right)$ 3430, 2210; EIMS m/z $369\left(\mathrm{M}^{+}\right)$; HRMS (EI) for $\mathrm{C}_{20} \mathrm{H}_{20} \mathrm{BrNO}$, calcd 369.0728, found 369.0708. 


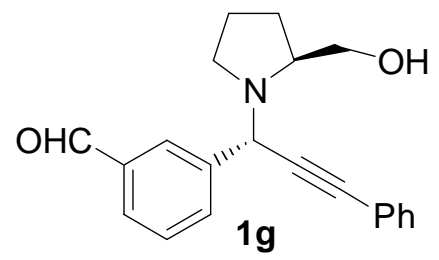

Yellowish oil; analytical TLC (silica gel 60) (30\% EtOAc in hexane) $\mathrm{R}_{f}=0.19 ;{ }^{1} \mathrm{H}$ NMR $\left(300 \mathrm{MHz}, \mathrm{CDCl}_{3}\right) \delta 10.04(\mathrm{~s}, 1 \mathrm{H}), 8.14(\mathrm{~s}, 1 \mathrm{H}), 7.90(\mathrm{dd}, J=7.7,0.6 \mathrm{~Hz}, 1 \mathrm{H}), 7.83(\mathrm{~d}, J$ $=7.6 \mathrm{~Hz}, 1 \mathrm{H}), 7.56-7.51(\mathrm{~m}, 3 \mathrm{H}), 7.36-7.34(\mathrm{~m}, 3 \mathrm{H}), 5.24(\mathrm{~s}, 1 \mathrm{H}), 3.84(\mathrm{dd}, J=11.0,3.7$ Hz, 1H), 3.60 (dd, $J=11.0,2.8 \mathrm{~Hz}, 1 \mathrm{H}), 3.34-3.27$ (m, 1H), 2.85-2.77 (m, 1H), 2.61-2.55 (m, 2H), 1.91-1.64 (m, 4H); ${ }^{13} \mathrm{C}$ NMR $\left(75 \mathrm{MHz}, \mathrm{CDCl}_{3}\right) \delta 192.15,140.50,136.48$, $134.15,131.81,129.33,128.97,128.82,128.44,128.34,122.55,88.39,84.45,62.42$, 61.94, 56.12, 47.83, 27.84, 23.45; IR (NaCl, neat, $\left.\mathrm{cm}^{-1}\right)$ 3421, 2361, 1699; EIMS m/z 319 $\left(\mathrm{M}^{+}\right)$; HRMS (EI) for $\mathrm{C}_{21} \mathrm{H}_{21} \mathrm{NO}_{2}$, calcd 319.1572, found 319.1570.

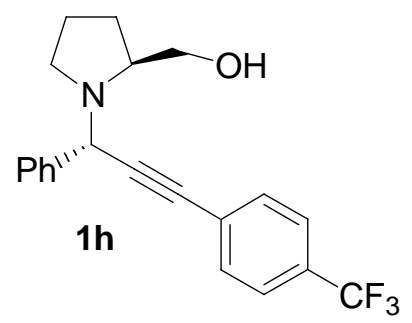

Yellowish oil; analytical TLC (silica gel 60) (30\% EtOAc in hexane) $\mathrm{R}_{f}=0.33 ;{ }^{1} \mathrm{H}$ NMR $\left(300 \mathrm{MHz}, \mathrm{CDCl}_{3}\right) \delta$ 7.63-7.57 (m, 6H), 7.41-7.29 (m, 3H), $5.38(\mathrm{~s}, 1 \mathrm{H}), 3.83(\mathrm{dd}, J=$ 11.0, 3.6 Hz, 1H), $3.56(\mathrm{dd}, J=11.0,2.5 \mathrm{~Hz}, 1 \mathrm{H}), 3.33-3.23(\mathrm{~m}, 1 \mathrm{H}), 2.87-2.75(\mathrm{~m}, 1 \mathrm{H})$, 2.69-2.60 (m, 1H), 1.95-1.67 (m, 4H); ${ }^{13} \mathrm{C}$ NMR (75 MHz, $\left.\mathrm{CDCl}_{3}\right) \delta 138.69,132.09$, 128.41, 128.00, 127.77, 126.74, 125.29 (q, $J=5.0 \mathrm{~Hz}), 123.89$ (q, $J=359 \mathrm{~Hz}), 88.29$, 86.51, 62.05, 61.86, 56.39, 48.04, 28.01, 23.56; IR ( $\mathrm{NaCl}$, neat, $\left.\mathrm{cm}^{-1}\right) 3401,2362,2335$, 1615; EIMS m/z $359\left(\mathrm{M}^{+}\right)$; HRMS (EI) for $\mathrm{C}_{21} \mathrm{H}_{20} \mathrm{~F}_{3} \mathrm{NO}$, calcd 359.1496, found 359.1485. 


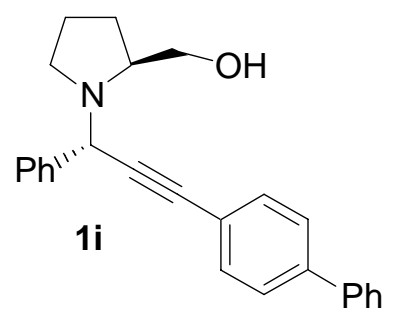

Yellowish solid; analytical TLC (silica gel 60) (30\% EtOAc in hexane) $\mathrm{R}_{f}=0.37 ;{ }^{1} \mathrm{H}$ NMR (300 MHz, $\left.\mathrm{CDCl}_{3}\right) \delta$ 7.65-7.57 (m, 8H), 7.51-7.27 (m, 6H), 5.37 (s, 1H), 3.84 (dd, $J=10.9,3.5 \mathrm{~Hz}, 1 \mathrm{H}), 3.55(\mathrm{dd}, J=10.9,2.2 \mathrm{~Hz}, 1 \mathrm{H}), 3.33-3.26(\mathrm{~m}, 1 \mathrm{H}), 2.87-2.79(\mathrm{~m}$, 1H), 2.67-2.60 (m, 1H), 2.01-1.62 (m, 4H); ${ }^{13} \mathrm{C}$ NMR (75 MHz, $\left.\mathrm{CDCl}_{3}\right) \delta 141.10,140.32$, $139.16,132.52,128.87,128.33,128.08,127.67,127.61,127.04,127.02,121.83,87.66$, 86.09, 61.87, 61.74, 56.30, 47.91, 28.04, 23.59; IR ( $\mathrm{NaCl}$, neat, $\left.\mathrm{cm}^{-1}\right)$ 3459, 2306; EIMS m/z $336\left(\mathrm{M}^{+}-\mathrm{CH}_{2} \mathrm{OH}\right)$; HRMS (EI) for $\mathrm{C}_{25} \mathrm{H}_{22} \mathrm{~N}$, calcd 336.1752, found 336.1739.

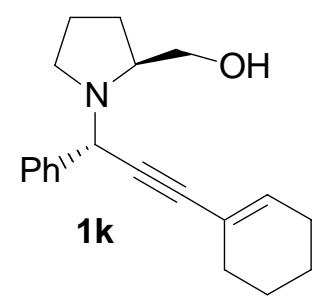

Yellowish oil; analytical TLC (silica gel 60) (30\% EtOAc in hexane) $\mathrm{R}_{f}=0.26 ;{ }^{1} \mathrm{H}$ NMR (400 MHz, $\left.\mathrm{CDCl}_{3}\right) \delta$ 7.54-7.52 (m, 2H), 7.32-7.28 (m, 2H), 7.24-7.21 (m, 1H), 6.16-6.13 (m, 1H), 4.99 (s, 1H), 3.73 (dd, $J=10.9,3.8 \mathrm{~Hz}, 1 \mathrm{H}), 3.49$ (dd, $J=10.9,2.5 \mathrm{~Hz}, 1 \mathrm{H}$ ), 3.19-3.13 (m, 1H), 2.89 (br, s, 1H), 2.73-2.67 (m, 1H), 2.55-2.50 (m, 1H), 2.19-2.18 (m, $2 \mathrm{H}), 2.10-2.08(\mathrm{~m}, 2 \mathrm{H}), 1.96-1.76(\mathrm{~m}, 2 \mathrm{H}), 1.67-1.49(\mathrm{~m}, 6 \mathrm{H}) ;{ }^{13} \mathrm{C}$ NMR $(100 \mathrm{MHz}$, $\left.\mathrm{CDCl}_{3}\right) \delta 139.34,134.32,127.99,127.94,127.15,120.25,89.43,82.14,61.90,61.49$, 56.01, 47.49, 29.46, 27.85, 25.39, 23.30, 22.14, 13.91; IR ( $\mathrm{NaCl}$, neat, $\left.\mathrm{cm}^{-1}\right) 3412,2361$, 1602; EIMS m/z $264\left(\mathrm{M}^{+}-\mathrm{CH}_{2} \mathrm{OH}\right)$. 


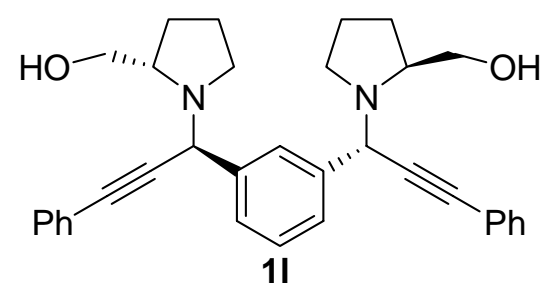

Pale yellow solid; analytical TLC (silica gel 60) (30\% EtOAc in hexane) $\mathrm{R}_{f}=0.03 ;{ }^{1} \mathrm{H}$ NMR (400 MHz, $\left.\mathrm{CDCl}_{3}\right) \delta 7.92(\mathrm{~s}, 1 \mathrm{H}), 7.54-7.51(\mathrm{~m}, 2 \mathrm{H}), 7.48-7.45(\mathrm{~m}, 4 \mathrm{H}), 7.37$ (t, $J$ $=7.6 \mathrm{~Hz}, 1 \mathrm{H}), 7.33-7.24(\mathrm{~m}, 4 \mathrm{H}), 5.14(\mathrm{~s}, 2 \mathrm{H}), 3.82(\mathrm{dd}, J=10.9,3.5 \mathrm{~Hz}, 2 \mathrm{H}), 3.54(\mathrm{dd}$, $J=11.0,2.3 \mathrm{~Hz}, 2 \mathrm{H}), 3.31-3.26(\mathrm{~m}, 2 \mathrm{H}), 2.85-2.79(\mathrm{~m}, 2 \mathrm{H}), 2.67-2.56(\mathrm{~m}, 2 \mathrm{H}), 2.00-$ $1.83(\mathrm{~m}, 5 \mathrm{H}), 1.76-1.64(\mathrm{~m}, 5 \mathrm{H}) ;{ }^{13} \mathrm{C} \mathrm{NMR}\left(100 \mathrm{MHz}, \mathrm{CDCl}_{3}\right) \delta 139.35,131.82,128.32$, $128.22,127.68,127.33,122.89,87.84,85.40,62.02,61.81,56.35,48.01,28.03,23.61$; IR $\left(\mathrm{NaCl}\right.$, neat, $\left.\mathrm{cm}^{-1}\right)$ 3435, 2336; EIMS m/z $473\left(\mathrm{M}^{+}-\mathrm{CH}_{2} \mathrm{OH}\right)$; HRMS (EI) for $\mathrm{C}_{33} \mathrm{H}_{33} \mathrm{~N}_{2} \mathrm{O}$, calcd 473.2593 , found 473.2599 .

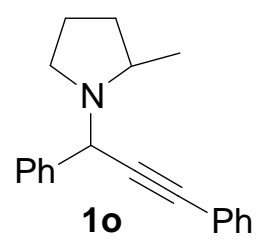

Yellowish oil; analytical TLC (silica gel 60) $\left(10 \%\right.$ EtOAc in hexane) $\mathrm{R}_{f}=0.37 ;{ }^{1} \mathrm{H}$ NMR $\left(300 \mathrm{MHz}, \mathrm{CDCl}_{3}\right) \delta$ 7.65-7.63 (m, 2H), 7.50-7.46 (m, 2H), 7.34-7.20 (m, 6H), $5.12(\mathrm{~s}$, 1H), 2.95-2.92 (m, 1H), $2.65(\mathrm{q}, J=8.7 \mathrm{~Hz}, 1 \mathrm{H}), 2.58-2.51(\mathrm{~m}, 1 \mathrm{H}), 1.97-1.90(\mathrm{~m}, 1 \mathrm{H})$, 1.68-1.58 (m, 2H), 1.51-1.42 (m, 1H), $1.21(\mathrm{~d}, J=6.0 \mathrm{~Hz}, 3 \mathrm{H}) ;{ }^{13} \mathrm{C}$ NMR $(75 \mathrm{MHz}$, $\left.\mathrm{CDCl}_{3}\right) \delta 139.69,131.74,128.17,128.08,128.04,127.92,127.18,123.22,87.69,85.37$, 56.40, 55.34, 47.08, 32.80, 21.56, 18.99; IR ( NaCl, neat, $\left.\mathrm{cm}^{-1}\right)$ 2358; EIMS m/z $275\left(\mathrm{M}^{+}\right)$; HRMS (EI) for $\mathrm{C}_{20} \mathrm{H}_{21} \mathrm{~N}$, calcd 275.1674, found 275.1678. 


\section{Characterization Data of Propargylamines 1b'-1i', 1k'-l'}

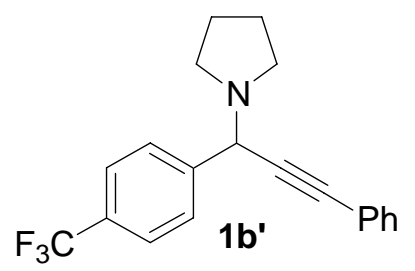

Yellowish oil; analytical TLC (silica gel 60) $\left(10 \%\right.$ EtOAc in hexane) $\mathrm{R}_{f}=0.31 ;{ }^{1} \mathrm{H}$ NMR $\left(300 \mathrm{MHz}, \mathrm{CDCl}_{3}\right) \delta$ 7.75-7.72 (m, 2H), 7.61-7.58 (m, 2H), 7.50-7.47 (m, 2H), 7.28-7.27 (m, 3H), $4.93(\mathrm{~s}, 1 \mathrm{H}), 2.67-2.66(\mathrm{~m}, 4 \mathrm{H}), 1.82-1.76(\mathrm{~m}, 4 \mathrm{H}) ;{ }^{13} \mathrm{C} \mathrm{NMR}\left(100 \mathrm{MHz}, \mathrm{CDCl}_{3}\right)$ $\delta 143.62,131.76,129.68(\mathrm{q}, J=32 \mathrm{~Hz}), 128.46,128.25,125.11(\mathrm{q}, J=4 \mathrm{~Hz}), 124.20(\mathrm{q}, J$ $=270 \mathrm{~Hz}), 122.82,87.65,85.46,58.46,53.28,50.00,23.55 ; \mathrm{IR}\left(\mathrm{NaCl}\right.$, neat, $\left.\mathrm{cm}^{-1}\right) 2351$; EIMS m/z $329\left(\mathrm{M}^{+}\right)$; HRMS (EI) for $\mathrm{C}_{20} \mathrm{H}_{18} \mathrm{~F}_{3} \mathrm{~N}$, calcd 329.1391, found 329.1381.

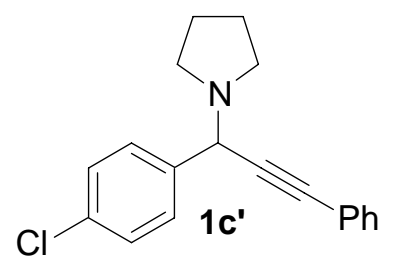

Yellowish oil; analytical TLC (silica gel 60) $\left(10 \%\right.$ EtOAc in hexane) $\mathrm{R}_{f}=0.21 ;{ }^{1} \mathrm{H}$ NMR (400 MHz, $\left.\mathrm{CDCl}_{3}\right) \delta$ 7.55-7.52 (m, 2H), 7.48-7.45 (m, 2H), 7.30-7.26 (m, 2H), 7.26-7.23 (m, 3H), $4.85(\mathrm{~s}, 1 \mathrm{H}), 2.67-2.63(\mathrm{~m}, 4 \mathrm{H}), 1.77-1.74(\mathrm{~m}, 4 \mathrm{H}) ;{ }^{13} \mathrm{C} \mathrm{NMR}\left(100 \mathrm{MHz}, \mathrm{CDCl}_{3}\right)$ $\delta 137.80,133.06,131.54,129.35,128.12,128.06,128.00,122.71,87.22,85.70,58.00$, 49.80, 23.32; IR ( $\mathrm{NaCl}$, neat, $\left.\mathrm{cm}^{-1}\right)$ 2349; EIMS $\mathrm{m} / \mathrm{z} 295\left(\mathrm{M}^{+}\right)$; HRMS (EI) for $\mathrm{C}_{19} \mathrm{H}_{18} \mathrm{ClN}$, calcd 295.1128, found 295.1123. 


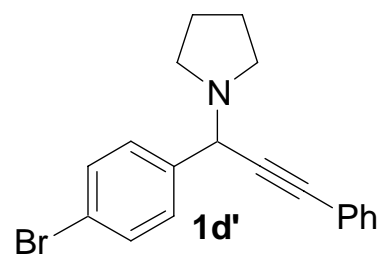

Yellowish oil; analytical TLC (silica gel 60) (10\% EtOAc in hexane) $\mathrm{R}_{f}=0.38 ;{ }^{1} \mathrm{H}$ NMR $\left(300 \mathrm{MHz}, \mathrm{CDCl}_{3}\right) \delta$ 7.49-7.44 (m, 6H), 7.3-7.29 (m, 3H), $4.87(\mathrm{~s}, 1 \mathrm{H}), 2.68-2.67(\mathrm{~m}$, 4H), 1.80-1.77 (m, 4H); ${ }^{13} \mathrm{C}$ NMR (75 MHz, $\left.\mathrm{CDCl}_{3}\right) \delta 138.46,131.74,131.30,129.93$, 128.26, 122.88, 121.46, 87.37, 85.78, 58.33, 50.05, 23.47; IR ( $\mathrm{NaCl}$, neat, $\left.\mathrm{cm}^{-1}\right) 2358$; EIMS m/z $339\left(\mathrm{M}^{+}\right)$; HRMS (EI) for $\mathrm{C}_{19} \mathrm{H}_{18} \mathrm{BrN}$, calcd 339.0623, found 339.0606.

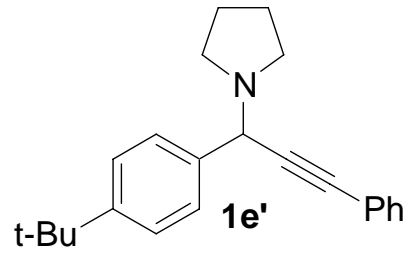

Yellowish oil; analytical TLC ( ilica gel 60) (10\% EtOAc in hexane) $\mathrm{R}_{f}=0.32 ;{ }^{1} \mathrm{H}$ NMR $\left(300 \mathrm{MHz}, \mathrm{CDCl}_{3}\right) \delta$ 7.54-7.51 (m, 2H), 7.48-7.45 (m, 2H), 7.37-7.35 (m, 2H), 7.28-7.25 (m, 3H), $4.84(\mathrm{~s}, 1 \mathrm{H}), 2.68-2.66(\mathrm{~m}, 4 \mathrm{H}), 1.79-1.77(\mathrm{~m}, 4 \mathrm{H}), 1.31(\mathrm{~s}, 9 \mathrm{H})$; IR (NaCl, neat, $\mathrm{cm}^{-1}$ ) 2361; EIMS m/z $317\left(\mathrm{M}^{+}\right)$; HRMS (EI) for $\mathrm{C}_{23} \mathrm{H}_{27} \mathrm{~N}$, calcd 317.2144, found 317.2139 .

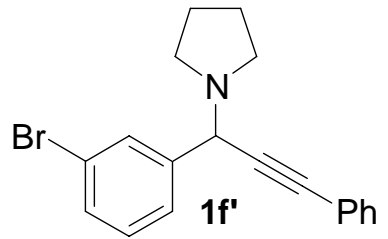

Yellowish oil; analytical TLC (silica gel 60) (10\% EtOAc in hexane) $\mathrm{R}_{f}=0.23 ;{ }^{1} \mathrm{H}$ NMR $\left(300 \mathrm{MHz}, \mathrm{CDCl}_{3}\right) \delta$ 7.81-7.76 (s, 1H), 7.54-7.52 (d, $\left.J=7.7 \mathrm{~Hz}, 1 \mathrm{H}\right), 7.48-7.45(\mathrm{~m}, 2 \mathrm{H})$, 7.37-7.32 (m, 2H), 7.27-7.23 (m, 3H), 7.17-7.12 (t, J=7.8 Hz, 1H), $4.84(\mathrm{~s}, 1 \mathrm{H}), 2.70-$ $2.63(\mathrm{~m}, 4 \mathrm{H}), 1.79-1.68(\mathrm{~m}, 4 \mathrm{H}) ;{ }^{13} \mathrm{C} \mathrm{NMR}\left(75 \mathrm{MHz}, \mathrm{CDCl}_{3}\right) \delta 141.88,131.68,131.05$, 
$130.50,129.65,128.17,128.12,126.68,122.81,122.30,87.38,85.61,58.28,49.96,23.43$;

IR ( $\mathrm{NaCl}$, neat, $\left.\mathrm{cm}^{-1}\right)$ 2334; EIMS m/z $339\left(\mathrm{M}^{+}\right)$; HRMS (EI) for $\mathrm{C}_{19} \mathrm{H}_{18} \mathrm{BrN}$, calcd 339.0622, found 339.0611.

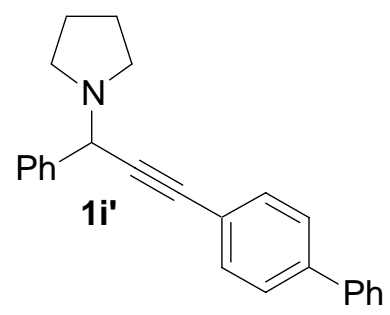

Brown oil; analytical TLC (silica gel 60) (30\% EtOAc in hexane) $\mathrm{R}_{f}=0.62 ;{ }^{1} \mathrm{H}$ NMR $\left(400 \mathrm{MHz}, \mathrm{CDCl}_{3}\right) \delta$ 7.63-7.61 (m, 2H), 7.55-7.52 (m, 6H), 7.41-7.28 (m, 6H), $4.91(\mathrm{~s}$, 1H), 2.75-2.67 (m, 4H), 1.80-1.77 (m, 4H); ${ }^{13} \mathrm{C}$ NMR (100 MHz, $\left.\mathrm{CDCl}_{3}\right) \delta$ 140.75, $140.23,139.26,132.11,128.74,128.71,128.21,128.20,127.54,127.49,126.88,126.85$, 121.98, 87.25, 86.76, 59.06, 50.17, 23.41; IR ( $\mathrm{NaCl}$, neat, $\left.\mathrm{cm}^{-1}\right)$ 2198; EIMS m/z 337 $\left(\mathrm{M}^{+}\right)$, HRMS (EI) for $\mathrm{C}_{25} \mathrm{H}_{23} \mathrm{~N}$, calcd 337.1830, found 337.1818

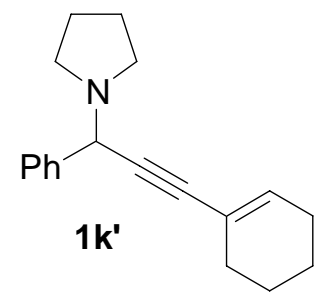

Yellowish oil; analytical TLC (silica gel 60) (20\% EtOAc in hexne) $\mathrm{R}_{f}=0.44 ;{ }^{1} \mathrm{H}$ NMR (400 MHz, $\left.\mathrm{CDCl}_{3}\right) \delta$ 7.54-7.52 (m, 2H), 7.34-7.30 (m, 2H), 7.27-7.24 (m, 1H), 6.14-6.12 (m, 1H), $4.76(\mathrm{~s}, 1 \mathrm{H}), 2.62-2.59(\mathrm{~m}, 4 \mathrm{H}), 2.19-2.15(\mathrm{~m}, 2 \mathrm{H}), 2.12-2.09(\mathrm{~m}, 2 \mathrm{H}), 1.78-$ $1.75(\mathrm{~m}, 4 \mathrm{H}), 1.67-1.57(\mathrm{~m}, 4 \mathrm{H}) ;{ }^{13} \mathrm{C} \mathrm{NMR}\left(100 \mathrm{MHz}, \mathrm{CDCl}_{3}\right) \delta$ 139.97, 134.35, 128.25, $128.15,127.37,120.60,88.74,83.66,59.04,50.16,29.61,25.61,23.47,22.34,21.56$; IR $\left(\mathrm{NaCl}\right.$, neat, $\left.\mathrm{cm}^{-1}\right)$ 2365, 1655; EIMS m/z $265\left(\mathrm{M}^{+}\right)$. 


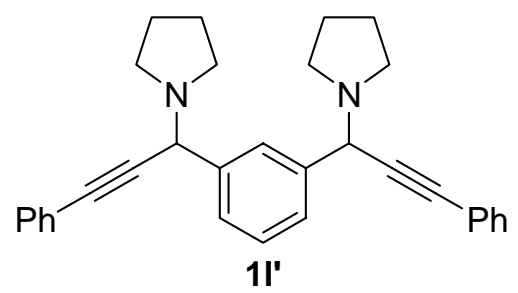

Yellowish oil; analytical TLC (silica gel 60) $\left(30 \%\right.$ EtOAc in hexane) $\mathrm{R}_{f}=0.36 ;{ }^{1} \mathrm{H}$ NMR (400 MHz, $\left.\mathrm{CDCl}_{3}\right) \delta$ 7.92-7.86 (m, 1H), 7.58-7.52 (m, 2H), 7.46-7.43 (m, 4H), 7.37-7.32 (m, 1H), 7.26-7.19 (m, 6H), $4.93(\mathrm{~s}, 1 \mathrm{H}), 4.91(\mathrm{~s}, 1 \mathrm{H}), 2.73-2.65(\mathrm{~m}, 8 \mathrm{H}), 1.82-1.76(\mathrm{~m}$, $8 \mathrm{H}) ;{ }^{13} \mathrm{C}$ NMR $\left(100 \mathrm{MHz}, \mathrm{CDCl}_{3}\right) \delta 139.38,139.32,131.64,128.08,127.96,127.85$, $127.45,127.32,123.12,86.83,86.79,86.69,86.65,58.87,58.83,50.05,50.12,23.39$; IR $\left(\mathrm{NaCl}\right.$, neat, $\left.\mathrm{cm}^{-1}\right)$ 2347; EIMS m/z $375\left(\mathrm{M}^{+}-\mathrm{C}_{4} \mathrm{H}_{7} \mathrm{~N}\right)$; HRMS (EI) for $\mathrm{C}_{28} \mathrm{H}_{25} \mathrm{~N}$, calcd 375.0987, found 375.1980.

\section{Characterization Data of Allenes 2e-g, 2i, 2k-1}

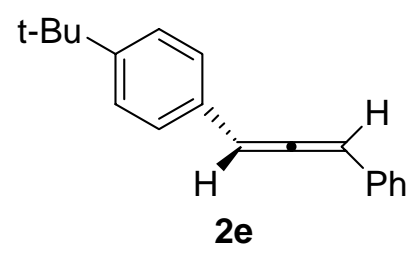

Yellowish solid; analytical TLC (silica gel 60) (10\% EtOAc in hexane) $\mathrm{R}_{f}=0.67 ;{ }^{1} \mathrm{H}$ NMR (300 MHz, $\left.\mathrm{CDCl}_{3}\right) \delta$ 7.36-7.24 (m, 9H), $6.58(\mathrm{~s}, 2 \mathrm{H}), 1.31(\mathrm{~s}, 9 \mathrm{H}) ;{ }^{13} \mathrm{C}$ NMR $(75$ $\left.\mathrm{MHz}, \mathrm{CDCl}_{3}\right) \delta 207.74,150.50,130.63,128.95,127.43,127.22,126.73,125.70,54.28$, 31.30; IR ( $\mathrm{NaCl}$, neat, $\mathrm{cm}^{-1}$ ) 1936; EIMS m/z $248\left(\mathrm{M}^{+}\right)$; HRMS (EI) for $\mathrm{C}_{19} \mathrm{H}_{20}$, calcd 248.1565 , found 248.1563 . 


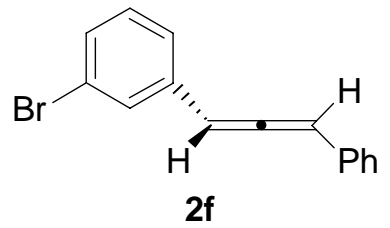

Light yellow solid; analytical TLC (silica gel 60) (10\% EtOAc in hexane) $\mathrm{R}_{f}=0.60 ;{ }^{1} \mathrm{H}$ NMR (300 MHz, $\left.\mathrm{CDCl}_{3}\right) \delta 7.49(\mathrm{t}, J=1.7 \mathrm{~Hz}, 1 \mathrm{H}), 7.35-7.32(\mathrm{~m}, 5 \mathrm{H}), 7.19-7.14(\mathrm{~m}, 3 \mathrm{H})$, 6.64-6.62 (d, $J=6.5 \mathrm{~Hz}, 1 \mathrm{H}), 6.53-6.51(\mathrm{~d}, J=6.5 \mathrm{~Hz}, 1 \mathrm{H}) ;{ }^{13} \mathrm{C} \mathrm{NMR}\left(125 \mathrm{MHz}, \mathrm{CDCl}_{3}\right)$ $\delta 208.02,135.96,133.06,130.23,130.18,129.73,128.81,127.58,127.10,125.58,122.91$, 98.91, 97.41; IR ( $\mathrm{NaCl}$, neat, $\mathrm{cm}^{-1}$ ) 1938; EIMS m/z $270\left(\mathrm{M}^{+}\right)$; HRMS (EI) for $\mathrm{C}_{15} \mathrm{H}_{11} \mathrm{Br}$, calcd 270.0044, found 270.0030 .

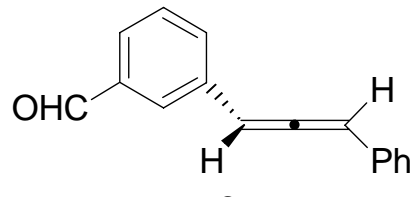

$2 \mathrm{~g}$

Orange solid; analytical TLC (silica gel 60$)\left(10 \%\right.$ EtOAc in hexane) $\mathrm{R}_{f}=0.37 ;{ }^{1} \mathrm{H}$ NMR $\left(300 \mathrm{MHz}, \mathrm{CDCl}_{3}\right) \delta 10.00(\mathrm{~s}, 1 \mathrm{H}), 7.84(\mathrm{~s}, 1 \mathrm{H}), 7.75-7.73(\mathrm{~d}, J=7.5 \mathrm{~Hz}, 1 \mathrm{H}), 7.63-7.60$ (d, $J=7.7 \mathrm{~Hz}, 1 \mathrm{H}), 7.50-7.45(\mathrm{t}, J=7.6 \mathrm{~Hz}, 1 \mathrm{H}), 7.39-7.27(\mathrm{~m}, 5 \mathrm{H}), 6.66(\mathrm{~s}, 2 \mathrm{H}) ;{ }^{13} \mathrm{C}$ NMR (75 MHz, $\left.\mathrm{CDCl}_{3}\right) \delta 208.20,192.19,135.00,132.73,129.43,128.86,128.5,128.07$, 127.67, 127.14, 99.11, 97.57; IR ( $\mathrm{NaCl}$, neat, $\left.\mathrm{cm}^{-1}\right)$ 2361, 2343, 1938, 1699; EIMS m/z $220\left(\mathrm{M}^{\dagger}\right)$; HRMS (EI) for $\mathrm{C}_{16} \mathrm{H}_{12} \mathrm{O}$, calcd 220.0888; found 220.0893 .

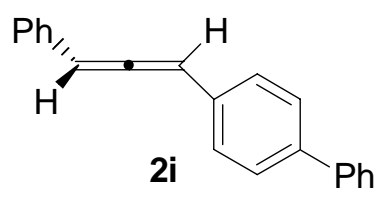

Yellowish solid; analytical TLC (silica gel 60) (10\% EtOAc in hexane) $\mathrm{R}_{f}=0.56 ;{ }^{1} \mathrm{H}$ NMR $\left(300 \mathrm{MHz}, \mathrm{CDCl}_{3}\right) \delta$ 7.60-7.54 (m, 4H), 7.44-7.33 (m, 10H), $6.64(\mathrm{~s}, 2 \mathrm{H}) ;{ }^{13} \mathrm{C}$ NMR $\left(75 \mathrm{MHz}, \mathrm{CDCl}_{3}\right) \delta 208.11,140.73,140.20,133.57,132.62,128.77,127.47$, 
127.42, 127.37, 127.30, 127.04, 126.95, 98.54, 98.13; IR ( $\mathrm{NaCl}$, neat, $\left.\mathrm{cm}^{-1}\right) 2361,2342$, 1936; EIMS m/z $268\left(\mathrm{M}^{+}\right)$, HRMS (EI) for $\mathrm{C}_{21} \mathrm{H}_{16}$, calcd 268.1252, found 268.1244.

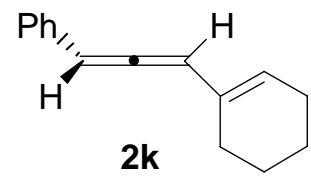

Yellowish oil; analytical TLC (silica gel 60) $\left(10 \%\right.$ EtOAc in hexane) $\mathrm{R}_{f}=0.60 ;{ }^{1} \mathrm{H}$ NMR $\left(400 \mathrm{MHz}, \mathrm{CDCl}_{3}\right) \delta$ 7.30-7.28 (m, 4H), 7.26-7.17 (m, 1H), 6.40-6.38 (dd, J=6.3, 1.2 Hz, $1 \mathrm{H}), 6.26-6.25(\mathrm{~d}, J=6.4 \mathrm{~Hz}, 1 \mathrm{H}), 5.77-5.76(\mathrm{~m}, 1 \mathrm{H}), 2.14-1.99(\mathrm{~m}, 2 \mathrm{H}), 1.67-1.58(\mathrm{~m}$, $4 \mathrm{H}) ;{ }^{13} \mathrm{C}$ NMR $\left(125 \mathrm{MHz}, \mathrm{CDCl}_{3}\right) \delta 206.48,134.77,131.85,128.61,127.12,126.91$, 126.74, 101.60, 97.55, 29.72, 25.95, 25.81, 22.48, 22.40; IR ( $\mathrm{NaCl}$, neat, $\left.\mathrm{cm}^{-1}\right)$ 1951, 1619; EIMS m/z $196\left(\mathrm{M}^{+}\right)$.

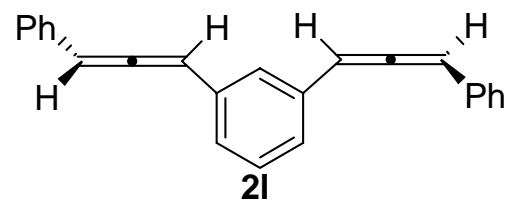

Yellowish oil; analytical TLC (silica gel 60) $\left(10 \%\right.$ EtOAc in hexane) $\mathrm{R}_{f}=0.55 ;{ }^{1} \mathrm{H}$ NMR $\left(300 \mathrm{MHz}, \mathrm{CDCl}_{3}\right) \delta$ 7.33-7.28 (m, 12H), 7.25-7.22 (m, 8H), $6.57(\mathrm{~s}, 4 \mathrm{H}) ;{ }^{13} \mathrm{C}$ NMR $(75$ $\left.\mathrm{MHz}, \mathrm{CDCl}_{3}\right) \delta 207.92,134.19,129.12,128.76,127.37,127.07,125.96,125.65,98.53$, 98.24; IR (NaCl, neat, $\left.\mathrm{cm}^{-1}\right)$ 2361, 2342, 1938; EIMS m/z $306\left(\mathrm{M}^{+}\right)$; HRMS (EI) for $\mathrm{C}_{24} \mathrm{H}_{18}$, calcd 306.1409, found 306.1422. 


\section{Characterization Data of Propargylamines 3a-d}

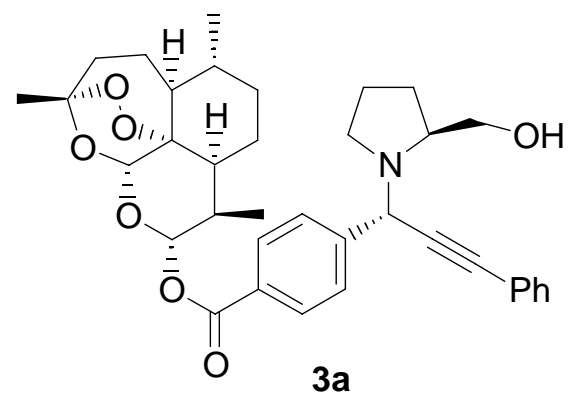

Pale yellow solid; analytical TLC (silica gel 60) (50\% EtOAc in hexane) $\mathrm{R}_{f}=0.48 ;{ }^{1} \mathrm{H}$ NMR (300 MHz, $\left.\mathrm{CDCl}_{3}\right) \delta$ 8.13-8.11 (m, 2H), 7.72-7.69 (m, 2H), 7.54-7.49 (m, 2H), 7.37-7.34 (m, 3H), $6.01(\mathrm{~d}, J=9.8 \mathrm{~Hz}, 1 \mathrm{H}), 5.53(\mathrm{~s}, 1 \mathrm{H}), 5.19(\mathrm{~s}, 1 \mathrm{H}), 3.83(\mathrm{dd}, J=11.0$, $3.6 \mathrm{~Hz}, 1 \mathrm{H}), 3.58$ (dd, $J=11.0,2.6 \mathrm{~Hz}, 1 \mathrm{H}), 3.33-3.27$ (m, 1H), 2.83-2.72 (m, 1H), 2.61$2.55(\mathrm{~m}, 1 \mathrm{H}), 2.44-2.34(\mathrm{~m}, 1 \mathrm{H}), 2.07-1.70(\mathrm{~m}, 9 \mathrm{H}), 1.67-1.25(\mathrm{~m}, 4 \mathrm{H}), 1.43(\mathrm{~s}, 3 \mathrm{H})$ 1.09-1.01 (m, 1H), $0.98(\mathrm{~d}, J=5.8 \mathrm{~Hz}, 3 \mathrm{H}), 0.93(\mathrm{~d}, J=7.1 \mathrm{~Hz}, 3 \mathrm{H}) ;{ }^{13} \mathrm{C} \mathrm{NMR}(75 \mathrm{MHz}$, $\left.\mathrm{CDCl}_{3}\right) \delta 165.03,144.65,131.82,130.15,128.93,128.43,128.36,128.00,122.63,104.38$, $92.54,91.55,88.28,84.57,80.14,62.14,61.91,56.25,51.60,47.93,45.30,37.22,36.22$, $34.08,31.95,29.64,27.86,25.90,24.55,23.55,22.01,20.20,12.19 ; \mathrm{IR}\left(\mathrm{NaCl}\right.$, neat, $\left.\mathrm{cm}^{-1}\right)$ 3459, 2362, 2345, 1996, 1730; EIMS m/z $601\left(\mathrm{M}^{+}\right)$; HRMS (EI) for $\mathrm{C}_{36} \mathrm{H}_{43} \mathrm{NO}_{7}$, calcd 601.3040, found 601.3043.

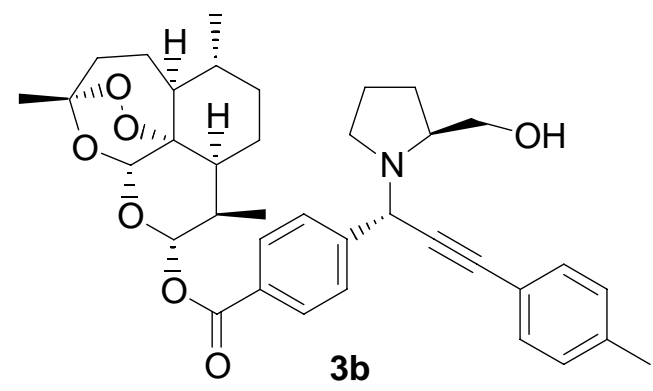

Pale yellow solid; analytical TLC (silica gel 60) (50\% EtOAc in hexane) $\mathrm{R}_{f}=0.54 ;{ }^{1} \mathrm{H}$ NMR (300 MHz, $\left.\mathrm{CDCl}_{3}\right) \delta$ 8.13-8.10 (m, 2H), 7.71-7.69 (m, 2H), 7.42-7.40 (m, 2H), 
7.17-7.14 (m, 2H), 6.01 (d, $J=9.8 \mathrm{~Hz}, 1 \mathrm{H}), 5.52(\mathrm{~s}, 1 \mathrm{H}), 5.17$ (s, 1H), $3.82(\mathrm{dd}, J=11.0$, $3.6 \mathrm{~Hz}, 1 \mathrm{H}), 3.57$ (dd, $J=11.0,2.5 \mathrm{~Hz}, 1 \mathrm{H}), 3.32-3.27$ (m, 1H), 2.82-2.72 (m, 2H), 2.60$2.53(\mathrm{~m}, 1 \mathrm{H}), 2.47-2.31(\mathrm{~m}, 1 \mathrm{H}), 2.37(\mathrm{~s}, 3 \mathrm{H}), 2.06-1.64(\mathrm{~m}, 9 \mathrm{H}), 1.56-1.26(\mathrm{~m}, 4 \mathrm{H}), 1.42$ (s, 3H), 1.09-0.97 (m, 1H), $0.98(\mathrm{~d}, J=5.8 \mathrm{~Hz}, 3 \mathrm{H}), 0.93(\mathrm{~d}, J=7.1 \mathrm{~Hz}, 3 \mathrm{H}) ;{ }^{13} \mathrm{C}$ NMR $\left(75 \mathrm{MHz}, \mathrm{CDCl}_{3}\right) \delta 165.01,144.81,138.52,131.67,130.10,129.07,128.84,127.98$, $119.54,104.34,92.49,91.51,88.32,83.78,80.11,62.11,61.83,56.20,51.57,47.86$, $45.27,37.19,36.19,34.06,31.92,29.62,27.84,25.87,24.52,23.52,21.98,21.42,20.17$, 12.17; IR (NaCl, neat, $\left.\mathrm{cm}^{-1}\right)$ 3467, 2361, 2342, 1996, 1729; EIMS m/z $615\left(\mathrm{M}^{+}\right)$; HRMS for $\mathrm{C}_{37} \mathrm{H}_{45} \mathrm{NO}_{7}$, calcd 615.3196, found 615.3191.

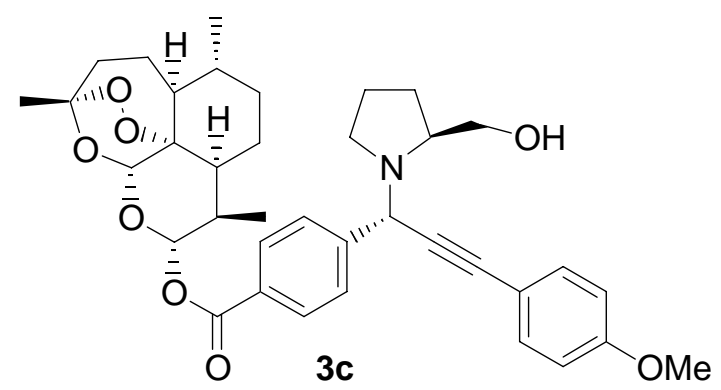

Pale yellow solid; analytical TLC (silica gel 60) (50\% EtOAc in hexane) $\mathrm{R}_{f}=0.46 ;{ }^{1} \mathrm{H}$ NMR $\left(300 \mathrm{MHz}, \mathrm{CDCl}_{3}\right) \delta 8.13-8.10(\mathrm{~m}, 2 \mathrm{H}), 7.71-7.68(\mathrm{~m}, 2 \mathrm{H})$, 7.47-7.44 (m, 2H), $6.88(\mathrm{~d}, J=8.8 \mathrm{~Hz}, 2 \mathrm{H}), 6.01(\mathrm{~d}, J=9.8 \mathrm{~Hz}, 1 \mathrm{H}), 5.53(\mathrm{~s}, 1 \mathrm{H}), 5.16(\mathrm{~s}, 1 \mathrm{H}), 3.85-3.75(\mathrm{~m}$, 1H), 3.83 (s, 3H), $3.56(\mathrm{dd}, J=11.0,2.3 \mathrm{~Hz}, 1 \mathrm{H}), 3.29(\mathrm{~m}, 1 \mathrm{H}), 3.82-2.70(\mathrm{~m}, 2 \mathrm{H}), 2.60-$ $2.54(\mathrm{~m}, 1 \mathrm{H}), 2.44-2.34(\mathrm{~m}, 1 \mathrm{H}), 2.06-1.64(\mathrm{~m}, 10 \mathrm{H}), 1.53-1.23(\mathrm{~m}, 4 \mathrm{H}), 1.43(\mathrm{~s}, 3 \mathrm{H})$ 1.06-0.86 (m, 1H), $0.98(\mathrm{~d}, J=5.8 \mathrm{~Hz}, 3 \mathrm{H}), 0.93(\mathrm{~d}, J=7.1 \mathrm{~Hz}, 3 \mathrm{H}) ;{ }^{13} \mathrm{C}$ NMR $(75 \mathrm{MHz}$, $\left.\mathrm{CDCl}_{3}\right) \delta 165.04,159.70,144.91,133.27,130.11,128.87,128.00,114.74,113.98,104.37$, $92.52,91.54,88.13,93.01,80.13,62.09,61.86,56.23,55.29,51.62,47.89,45.31,37.22$, $36.23,34.09,31.95,27.86,25.89,24.55,23.54,22.01,20.19,12.18$; IR ( $\mathrm{NaCl}$, neat, $\left.\mathrm{cm}^{-1}\right)$ 3514, 2361, 1996, 1729; ESI-MS m/z $654\left(\mathrm{M}+\mathrm{Na}^{+}\right)$. 


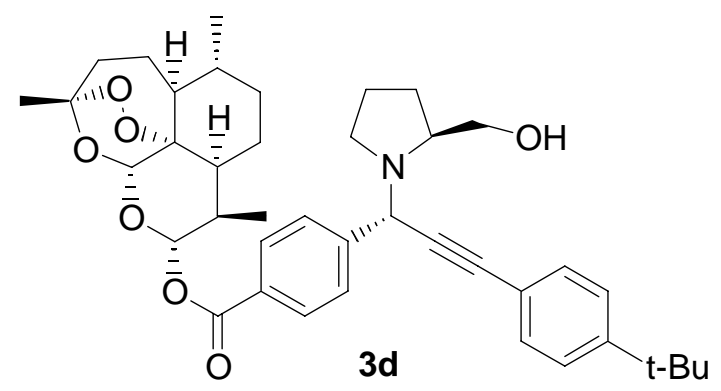

Pale yellow solid; analytical TLC (silica gel 60) (50\% EtOAc in hexane) $\mathrm{R}_{f}=0.45 ;{ }^{1} \mathrm{H}$ NMR (300 MHz, $\left.\mathrm{CDCl}_{3}\right) \delta$ 8.13-8.10 (m, 2H), 7.72-7.69 (m, 2H), 7.48-7.45 (m, 2H), 7.39-7.36 (m, 2H), $6.01(\mathrm{~d}, J=9.8 \mathrm{~Hz}, 1 \mathrm{H}), 5.53(\mathrm{~s}, 1 \mathrm{H}), 5.17(\mathrm{~s}, 1 \mathrm{H}), 3.82(\mathrm{dd}, J=11.0$, $3.5 \mathrm{~Hz}, 1 \mathrm{H}), 3.57$ (dd, $J=11.0,2.3 \mathrm{~Hz}, 1 \mathrm{H}), 3.31-3.27$ (m, 1H), 2.82-2.70 (m, 2H), $2.60-$ $2.53(\mathrm{~m}, 1 \mathrm{H}), 2.45-2.34(\mathrm{~m}, 1 \mathrm{H}), 2.06-1.72(\mathrm{~m}, 10 \mathrm{H}), 1.67-1.23(\mathrm{~m}, 4 \mathrm{H}), 1.42(\mathrm{~s}, 3 \mathrm{H})$ $1.32(\mathrm{~s}, 9 \mathrm{H}), 1.09-0.91(\mathrm{~m}, 1 \mathrm{H}), 0.98(\mathrm{~d}, J=5.7 \mathrm{~Hz}, 3 \mathrm{H}), 0.93(\mathrm{~d}, J=7.1 \mathrm{~Hz}, 3 \mathrm{H}) ;{ }^{13} \mathrm{C}$ NMR $\left(75 \mathrm{MHz}, \mathrm{CDCl}_{3}\right) \delta 165.08,144.85,131.60,130.17,128.92,128.02,125.39$, $119.66,104.41,92.55,91.59,88.36,83.86,80.17,62.07,61.87,56.23,51.66,47.90$, $45.36,37.27,36.26,34.13,31.99,31.16,27.89,25.94,24.59,23.60,22.06,20.23,12.23$; IR $\left(\mathrm{NaCl}\right.$, neat, $\left.\mathrm{cm}^{-1}\right)$ 3559, 2361, 2342, 1996, 1731; ESI-MS m/z $658\left(\mathrm{M}+\mathrm{H}^{+}\right)$.

\section{Characterization Data of Allenes 4a-d and 6a}

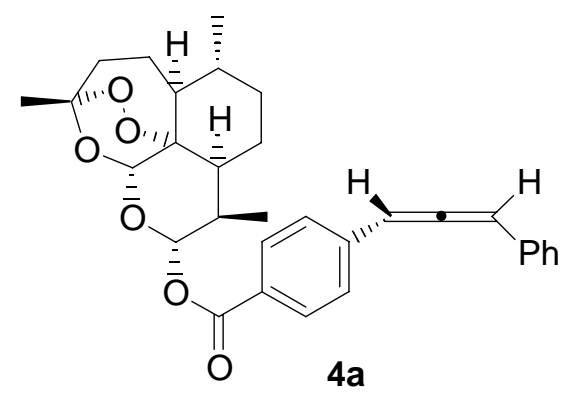

Yellowish solid; analytical TLC (silica gel 60) (30\% EtOAc in hexane) $\mathrm{R}_{f}=0.73 ;{ }^{1} \mathrm{H}$ NMR (300 MHz, $\left.\mathrm{CDCl}_{3}\right) \delta$ 8.07-8.05 (m, 2H), 7.42-7.39 (m, 2H), 7.38-7.27 (m, 4H), 
7.24-7.23 (m, 2H), 6.67-6.62 (m, 2H), $6.00(\mathrm{~d}, J=9.8 \mathrm{~Hz}, 1 \mathrm{H}), 5.52(\mathrm{~s}, 1 \mathrm{H}), 2.78-2.73$ (m, $1 \mathrm{H}), 2.44-2.34(\mathrm{~m}, 1 \mathrm{H}), 2.08-2.02(\mathrm{~m}, 1 \mathrm{H}), 1.95-1.63(\mathrm{~m}, 3 \mathrm{H}), 1.53-1.48(\mathrm{~m}, 2 \mathrm{H})$, $1.43(\mathrm{~s}, 3 \mathrm{H}), 1.31(\mathrm{~m}, 2 \mathrm{H}), 1.09-0.99(\mathrm{~m}, 1 \mathrm{H}), 0.98(\mathrm{~d}, J=5.9 \mathrm{~Hz}, 3 \mathrm{H}), 0.91(\mathrm{~d}, J=7.1$ $\mathrm{Hz}, 3 \mathrm{H}) ;{ }^{13} \mathrm{C}$ NMR $\left(125 \mathrm{MHz}, \mathrm{CDCl}_{3}\right) \delta 209.07,165.04,139.06,132.90,130.63,128.83$, $128.30,128.27,127.63,127.13,126.79,104.44,98.86,98.83,98.05,92.52,91.62,80.21$, $51.68,45.36,37.29,36.28,34.14,32.03,31.96,25.97,24.60,22.07,20.24,12.23$; IR $\left(\mathrm{NaCl}\right.$, neat, $\left.\mathrm{cm}^{-1}\right)$ 2361, 2342, 1996, 1728; ESI-MS m/z $525\left(\mathrm{M}+\mathrm{Na}^{+}\right)$.

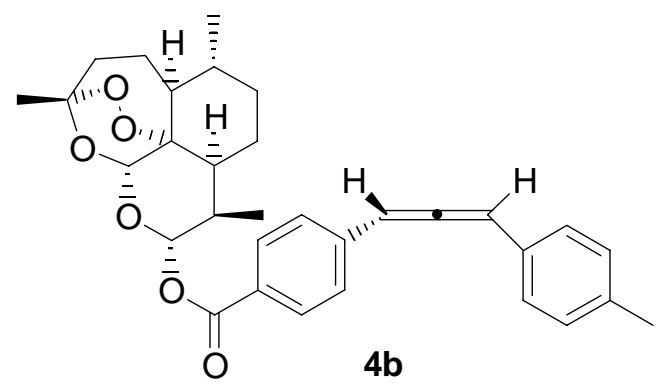

Yellowish solid; analytical TLC (silica gel 60) (30\% EtOAc in hexane) $\mathrm{R}_{f}=0.60 ;{ }^{1} \mathrm{H}$ NMR (300 MHz, $\left.\mathrm{CDCl}_{3}\right) \delta$ 8.07-8.04 (m, 2H), 7.41-7.38 (m, 2H), 7.26-7.23 (m, 2H), 7.15-7.12 (m, 2H), $6.62(\mathrm{dd}, J=8.7,6.6 \mathrm{~Hz}, 2 \mathrm{H}), 6.01(\mathrm{~s}, 1 \mathrm{H}), 2.78-2.69(\mathrm{~m}, 1 \mathrm{H}), 2.44-$ $2.38(\mathrm{~m}, 1 \mathrm{H}), 2.34(\mathrm{~s}, 3 \mathrm{H}), 2.11-2.00(\mathrm{~m}, 1 \mathrm{H}), 1.95-1.63(\mathrm{~m}, 6 \mathrm{H}), 1.52-1.23(\mathrm{~m}, 5 \mathrm{H}), 1.43$ (s, 3H), 1.09-0.85 (m, 1H), 0.98 (d, $J=5.9 \mathrm{~Hz}, 3 \mathrm{H}), 0.91(\mathrm{~d}, J=7.1 \mathrm{~Hz}, 3 \mathrm{H}) ;{ }^{13} \mathrm{C}$ NMR $\left(75 \mathrm{MHz}, \mathrm{CDCl}_{3}\right) \delta 208.93,165.07,139.28,137.53,130.61,129.84,129.56,128.21$, $127.04,126.75,104.43,98.64,97.95,92.51,91.62,80.21,51.68,45.37,37.29,36.28$, $34.15,32.03,29.70,25.96,24.60,22.07,21.22,20.24,12.22$; IR ( $\mathrm{NaCl}$, neat, $\left.\mathrm{cm}^{-1}\right) 2361$, 2342, 1935, 1727; ESI-MS m/z $539\left(\mathrm{M}+\mathrm{Na}^{+}\right)$. 


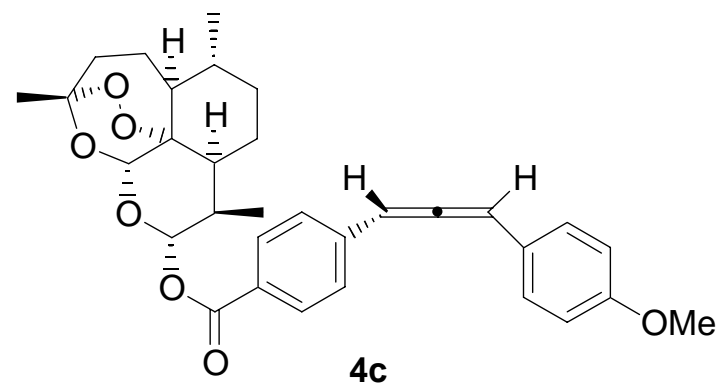

Yellowish solid; analytical TLC (silica gel 60) (30\% EtOAc in hexane) $\mathrm{R}_{f}=0.52 ;{ }^{1} \mathrm{H}$ NMR (300 MHz, $\left.\mathrm{CDCl}_{3}\right) \delta$ 8.07-8.04 (m, 2H), 7.41-7.38 (m, 2H), 7.29-7.26 (m, 2H), $6.87(\mathrm{~d}, J=8.6 \mathrm{~Hz}, 2 \mathrm{H}), 6.61(\mathrm{~s}, 2 \mathrm{H}), 3.81(\mathrm{~s}, 3 \mathrm{H}), 2.78-2.69(\mathrm{~m}, 1 \mathrm{H}), 2.44-2.34(\mathrm{~m}, 1 \mathrm{H})$, 2.06-2.00 (m, 1H), 1.94-1.62 (m, 5H), 1.56-1.31 (m, 2H), $1.42(\mathrm{~s}, 3 \mathrm{H}), 1.25(\mathrm{~s}, 3 \mathrm{H}), 1.09-$ $1.05(\mathrm{~m}, 1 \mathrm{H}), 0.98(\mathrm{~d}, J=5.8 \mathrm{~Hz}, 3 \mathrm{H}), 0.91(\mathrm{~d}, J=7.1 \mathrm{~Hz}, 3 \mathrm{H}) ;{ }^{13} \mathrm{C}$ NMR $(75 \mathrm{MHz}$, $\left.\mathrm{CDCl}_{3}\right) \delta 208.70,165.09,159.32,139.43,130.62,128.29,126.74,125.07,114.39,104.45$, $98.29,98.00,92.52,91.63,80.22,77.23,55.35,51.70,45.39,37.30,36.29,34.16,32.04$, 29.71, 25.97, 24.61, 22.09, 20.24, 12.23; IR ( $\mathrm{NaCl}$, neat, $\left.\mathrm{cm}^{-1}\right)$ 2361, 2342, 1996, 1727; ESI-MS $m / z 555\left(\mathrm{M}+\mathrm{Na}^{+}\right)$.

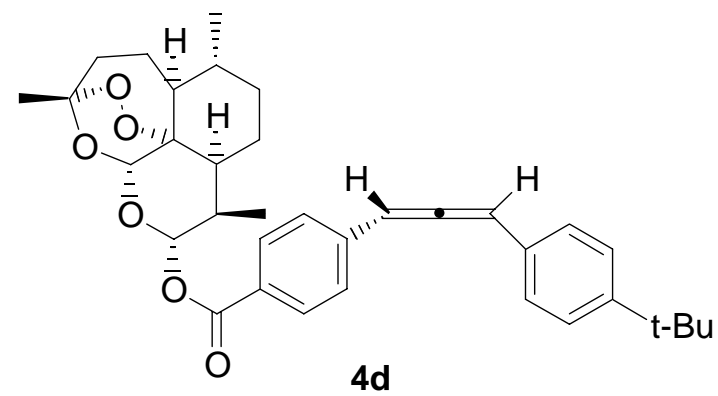

Yellowish solid; analytical TLC (silica gel 60) (30\% EtOAc in hexane) $\mathrm{R}_{f}=0.61 ;{ }^{1} \mathrm{H}$ NMR (300 MHz, $\left.\mathrm{CDCl}_{3}\right) \delta$ 8.06-8.04 (m, 2H), 7.41-7.26 (m, 6H), $6.63(\mathrm{dd}, J=10.6,6.5$ $\mathrm{Hz}, 2 \mathrm{H}), 6.00(\mathrm{~d}, J=9.8 \mathrm{~Hz}, 1 \mathrm{H}), 5.52(\mathrm{~s}, 1 \mathrm{H}), 2.78-2.71(\mathrm{~m}, 1 \mathrm{H}), 2.44-2.34(\mathrm{~m}, 1 \mathrm{H})$, 2.06-2.00 (m, 1H), 1.89-1.60 (m, 3H), 1.53-1.26 (m, 2H), $1.43(\mathrm{~s}, 3 \mathrm{H}), 1.31(\mathrm{~s}, 9 \mathrm{H}), 1.25$ (s, 3H), 1.10-0.86 (m, 1H), $0.98(\mathrm{~d}, J=5.9 \mathrm{~Hz}, 3 \mathrm{H}), 0.91(\mathrm{~d}, J=7.1 \mathrm{~Hz}, 3 \mathrm{H}) ;{ }^{13} \mathrm{C}$ NMR 
$\left(75 \mathrm{MHz}, \mathrm{CDCl}_{3}\right) \delta 209.14,165.09,150.86,139.30,130.62,129.90,128.22,126.88$, $126.77,125.82,104.45,98.51,97.91,92.52,91.64,80.22,51.71,45.39,37.31,36.30$, $34.17,32.05,31.29,29.71,25.98,24.62,22.10,20.26,12.24$; IR ( $\mathrm{NaCl}$, neat, $\left.\mathrm{cm}^{-1}\right) 2347$, 1996, 1934, 1729; ESI-MS m/z $581\left(\mathrm{M}+\mathrm{Na}^{+}\right)$.

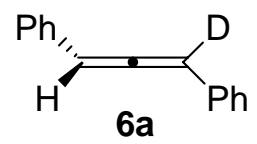

Pale yellow solid; analytical TLC (silica gel 60) $\left(10 \%\right.$ EtOAc in hexane) $\mathrm{R}_{f}=0.63 ;{ }^{1} \mathrm{H}$ NMR (300 MHz, $\left.\mathrm{CD}_{3} \mathrm{CN}\right) \delta$ 7.18-7.03 (m, 8.2H), $6.48(\mathrm{~s}, 1 \mathrm{H})$; IR $\left(\mathrm{NaCl}\right.$, neat, $\left.\mathrm{cm}^{-1}\right)$ 1936; EIMS m/z $193\left(\mathrm{M}^{+}\right)$; HRMS (EI) for $\mathrm{C}_{15} \mathrm{H}_{11} \mathrm{D}$, found 193.0994 . 


\section{GC-MS Spectra of Crossover Reaction between 5a and 1f}
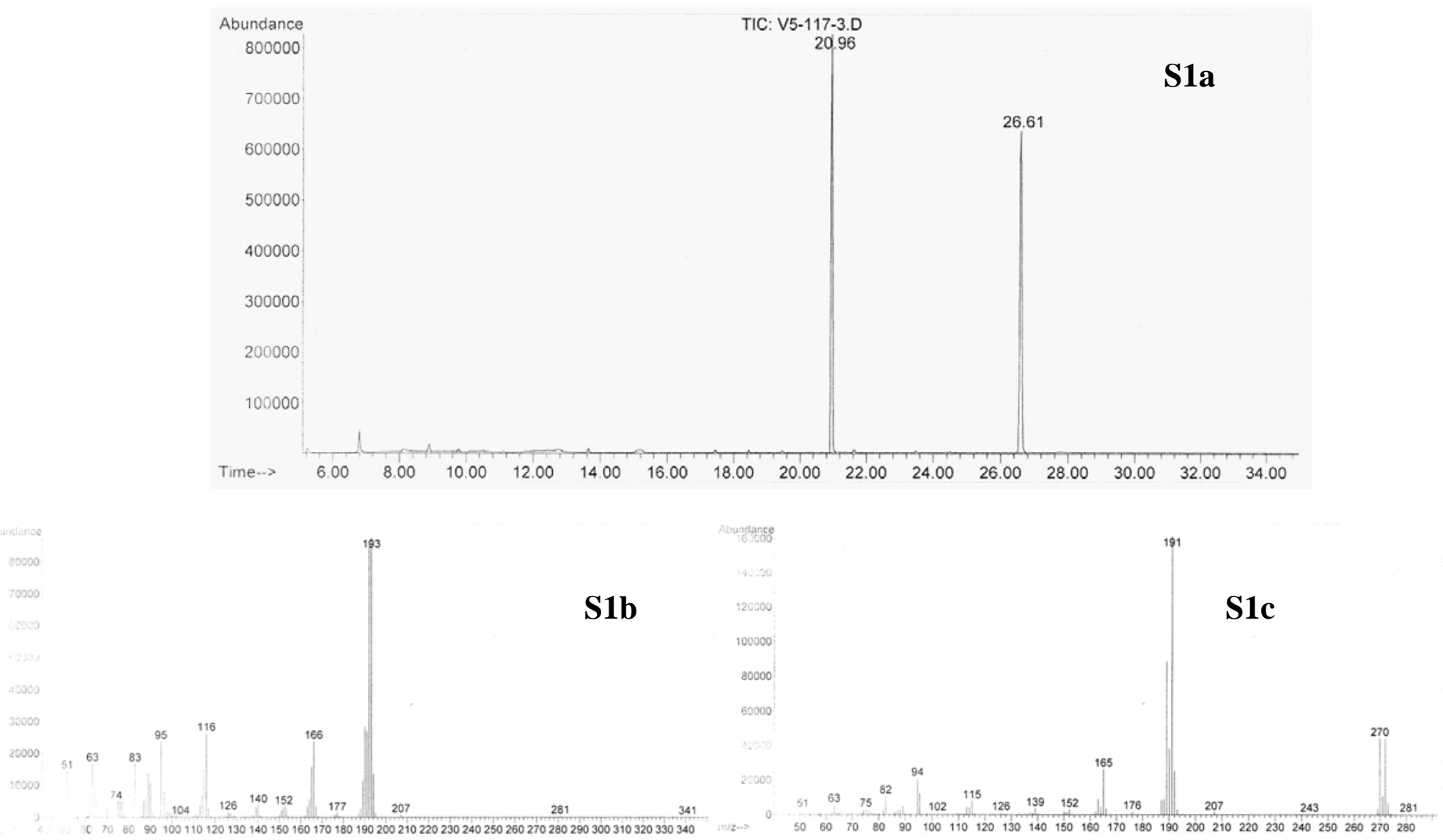

Figure S1a. GC-MS chromatograph of the crossover experiment. Figure S1b. MS spectrum of $\mathbf{6 a}(t=20.96 \mathrm{~min})\left(\mathrm{M}^{+}=193\right)$. Figure $\mathrm{S} 1 \mathrm{c}$. MS spectrum of $\mathbf{2 f}(\mathrm{t}=26.61 \mathrm{~min})$ $\left(\mathrm{M}^{+}=270\right)$. 


\section{ESI-MS Spectrum of 1a-Au Adduct}

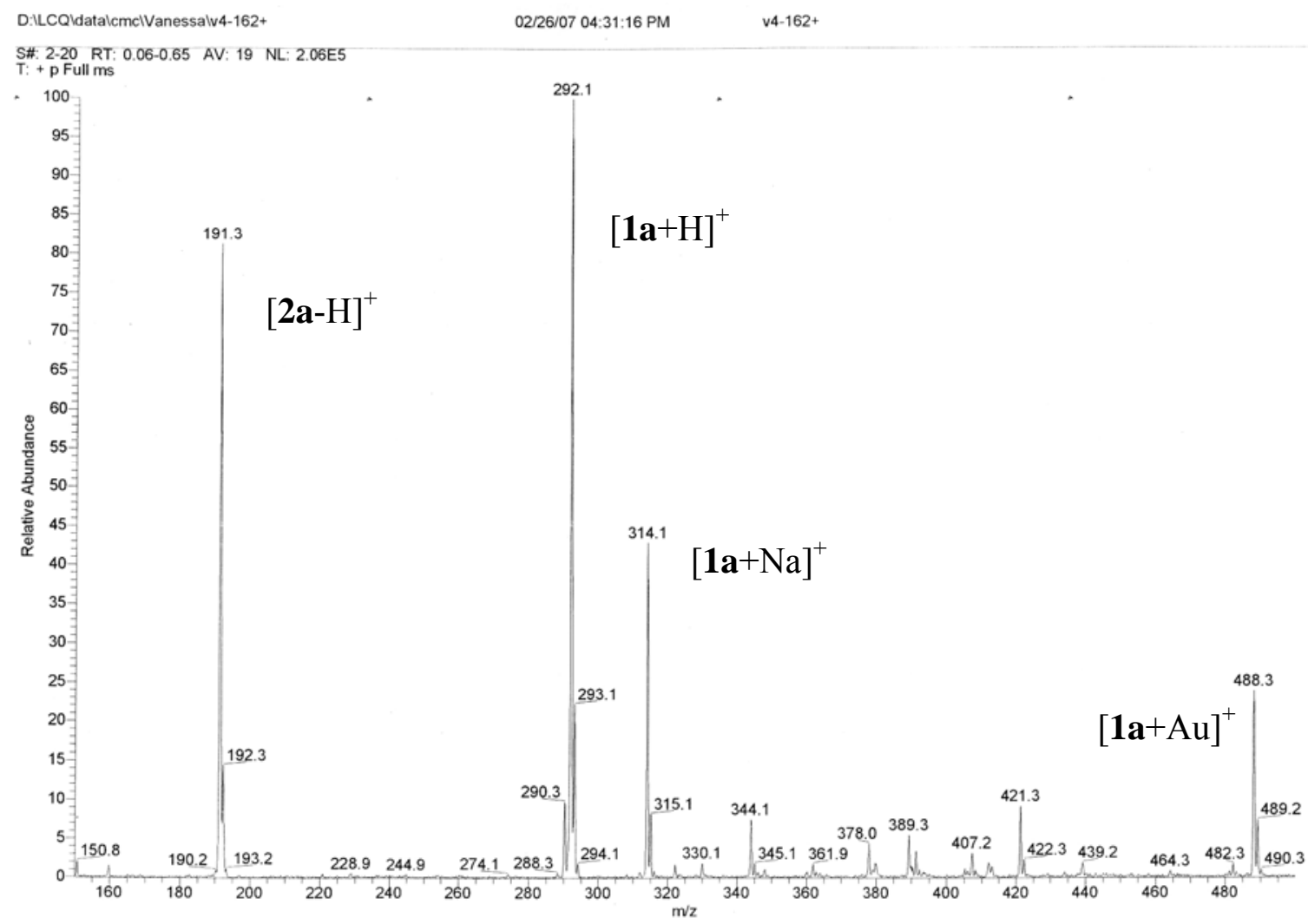

Figure S2. ESI-MS spectrum of adduct of $\mathbf{1 a}$ and $\mathrm{Au}^{+}$(peak at $m / z=488.3$ ) 


\section{XRD Data of Gold Residue}

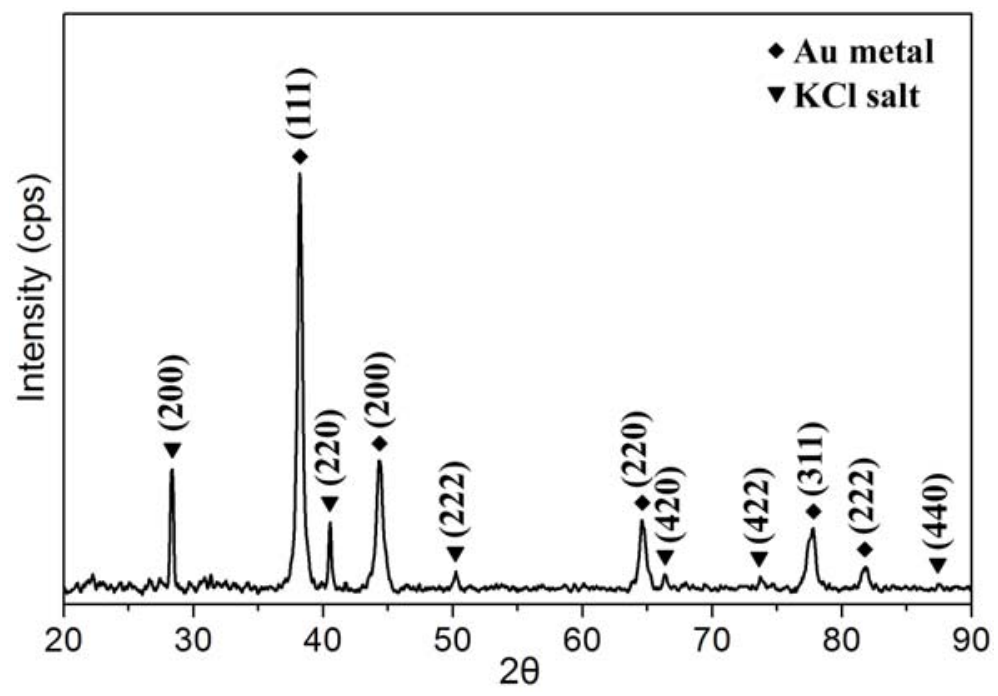

Figure S3. Powder XRD spectrum of the gold residue.

Powder X-ray diffraction (XRD) measurements were performed on Bruker AXS D8 ADVANCE powder X-ray diffractometer with parallel $\mathrm{Cu} \mathrm{K} \alpha$ radiation $(\lambda=1.5406$ $\AA)$. The scanning rate is $0.05^{\circ} / \mathrm{s}$ in the $2 \theta$ range from 20 to $90^{\circ}$. The XRD samples were prepared by placing dry gold residue onto glass slides.

Powder XRD pattern (Figure S3) showed two sets of diffraction peaks corresponding to the literature reported cubic metallic $\mathrm{Au}(0)$ (JCPDS no. 04-0784, a $=$ $4.078 \AA$ ) and cubic $\mathrm{KCl}$ salts (JCPDS no. $73-0380, \mathrm{a}=6.278 \AA$ ). $\mathrm{KCl}$ salts probably arise from the $\mathrm{K}^{+}$and $\mathrm{Cl}^{-}$in $\mathrm{KAuCl}_{4}$. 


\section{HPLC Spectra of 2a-I}

2a (Chiralcel OD column $0.46 \mathrm{~cm}$ x $25 \mathrm{~cm}, 1 \%$ IPA in hexane, $0.4 \mathrm{~mL} / \mathrm{min}$ )

\section{Racemic}

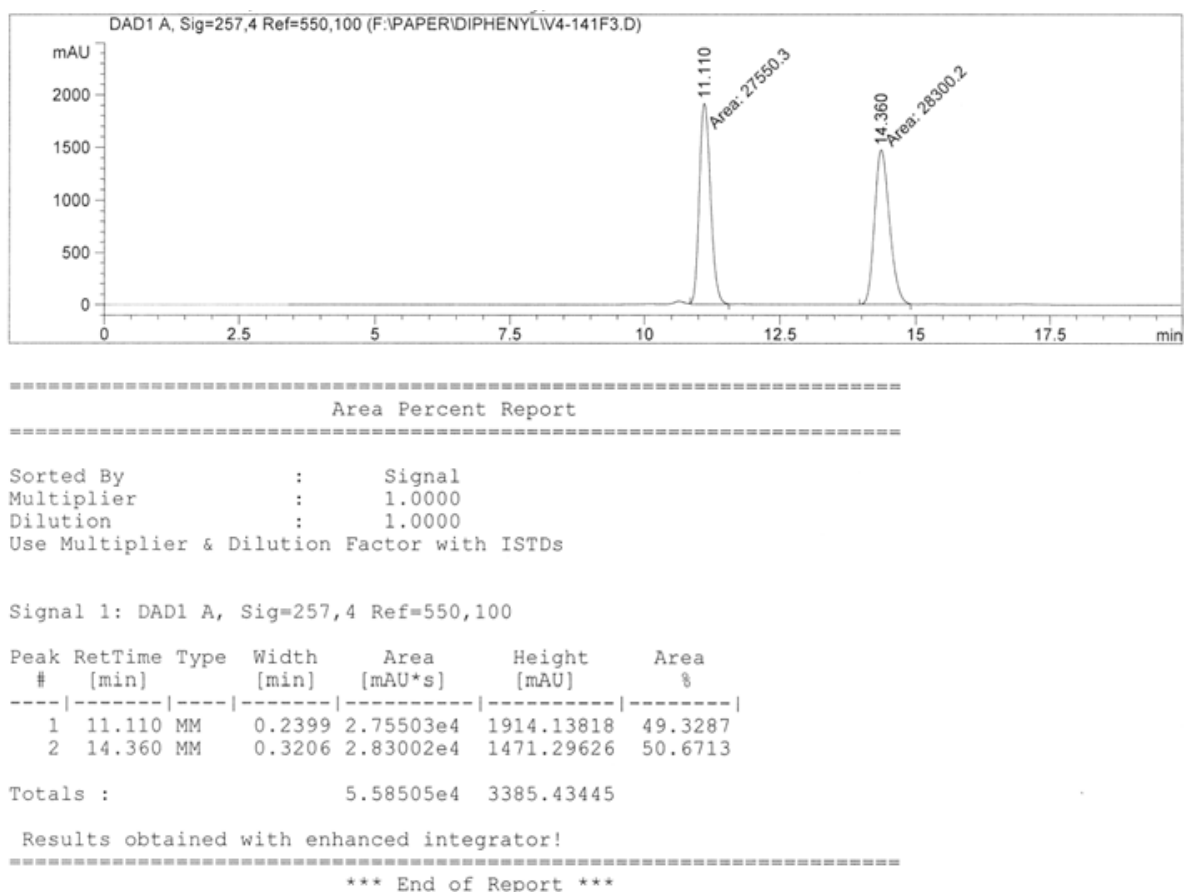

(R)-2a, for Table 1 , entry 1

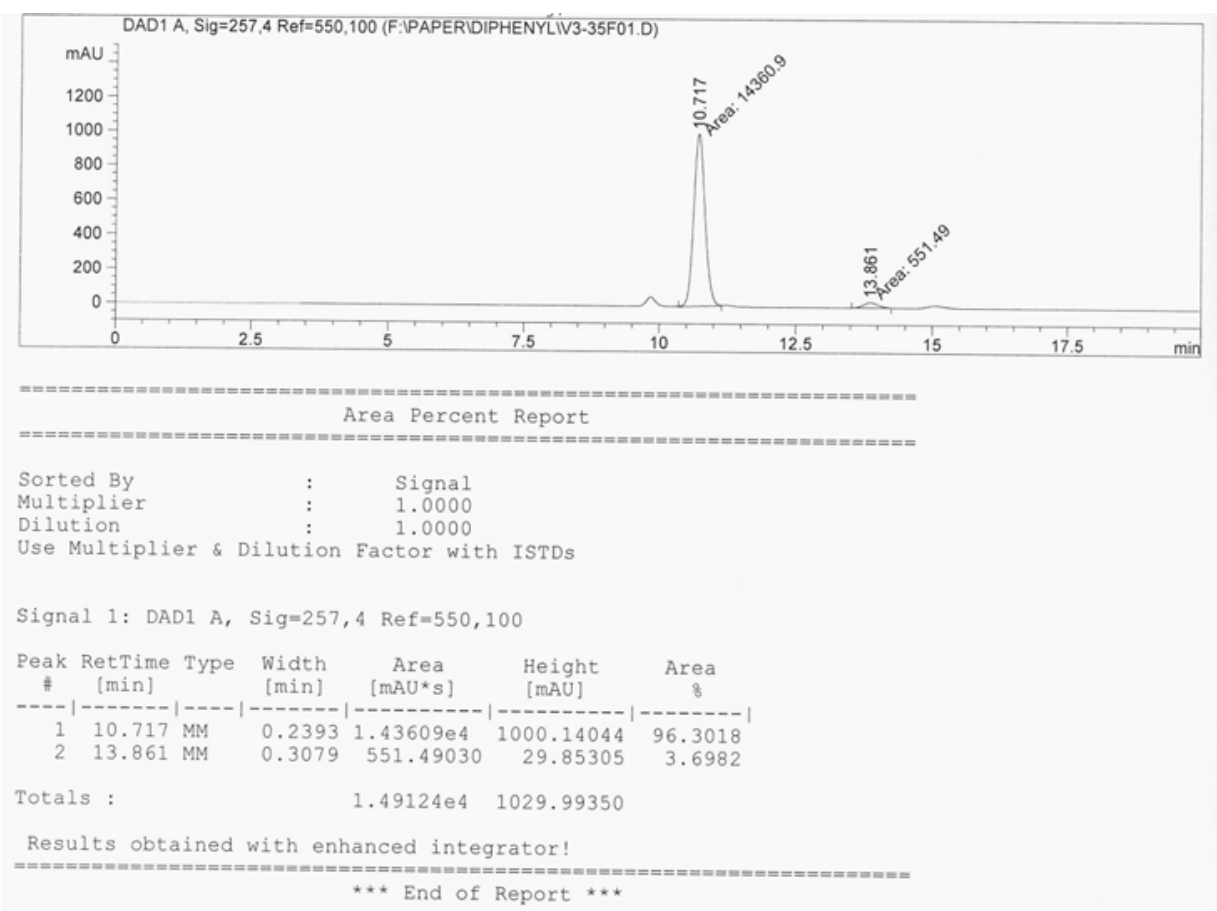


2b (Chiralcel OD column $0.46 \mathrm{~cm}$ x $25 \mathrm{~cm}, 1 \%$ IPA in hexane, $0.4 \mathrm{~mL} / \mathrm{min}$ )

\section{Racemic}
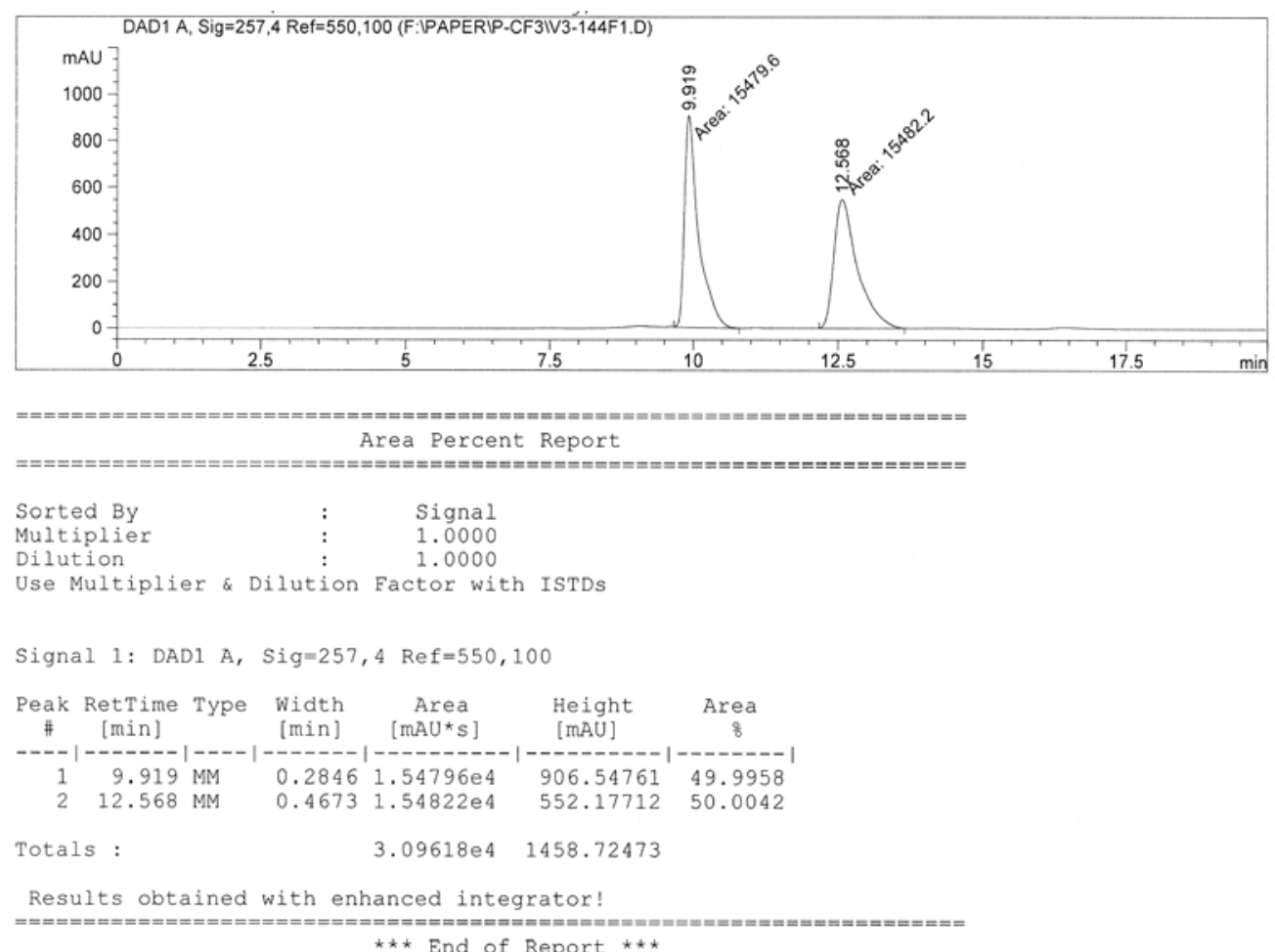

(R)-2b, for Table 1 , entry 2

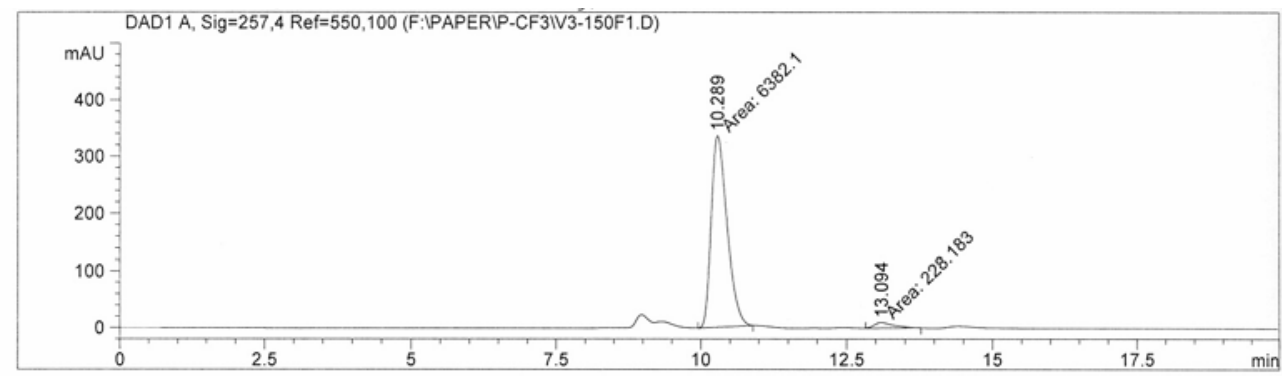

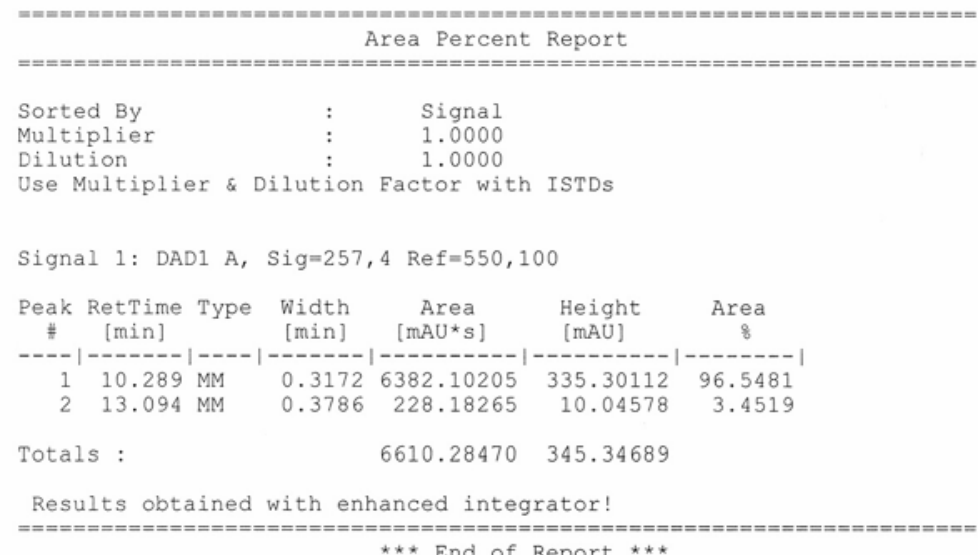


2c (Chiralcel OD column $0.46 \mathrm{~cm}$ x $25 \mathrm{~cm}, 1 \%$ IPA in hexane, $0.4 \mathrm{~mL} / \mathrm{min}$ )

\section{Racemic}

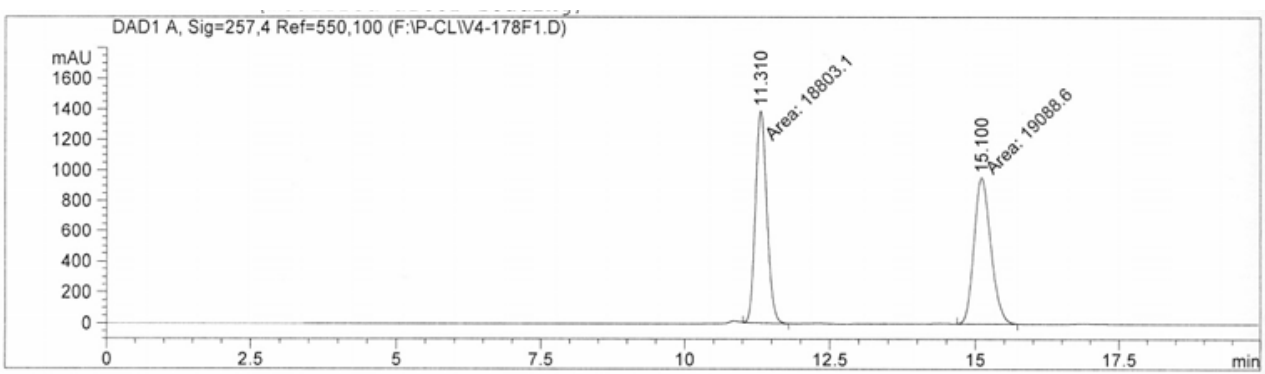

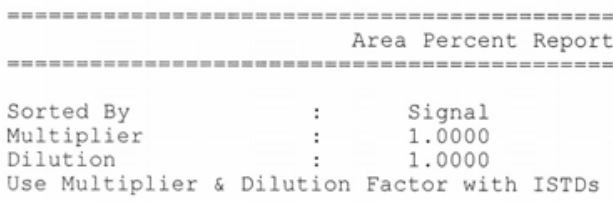

Signal 1: DAD1 A, Sig=257, 4 Ref $=550,100$

\begin{tabular}{|c|c|c|c|c|c|c|}
\hline$\underset{\#}{\text { Peak }}$ & $\begin{array}{c}\text { RetTime } \\
\text { [min] }\end{array}$ & Type & $\begin{array}{l}\text { Width } \\
\text { [min] }\end{array}$ & $\begin{array}{c}\text { Area } \\
{\left[\mathrm{mAU}^{*} \mathrm{~s}\right]}\end{array}$ & $\begin{array}{l}\text { Height } \\
\text { [mAU] }\end{array}$ & $\begin{array}{c}\text { Area } \\
8\end{array}$ \\
\hline $\begin{array}{l}1 \\
2\end{array}$ & $\begin{array}{l}11.310 \\
15.100\end{array}$ & MM & $\begin{array}{l}0.2261 \\
0.3339\end{array}$ & $\begin{array}{l}1.88031 \mathrm{e} 4 \\
1.90886 \mathrm{e} 4\end{array}$ & $\begin{array}{r}1385.95349 \\
952.75128\end{array}$ & $\begin{array}{l}49.6233 \\
50.3767\end{array}$ \\
\hline Total & 1s : & & & $3.78917 \mathrm{e} 4$ & 2338.70477 & \\
\hline
\end{tabular}

Results obtained with enhanced integrator!

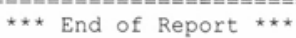

\section{(R)-2c, for Table 1 , entry 3}
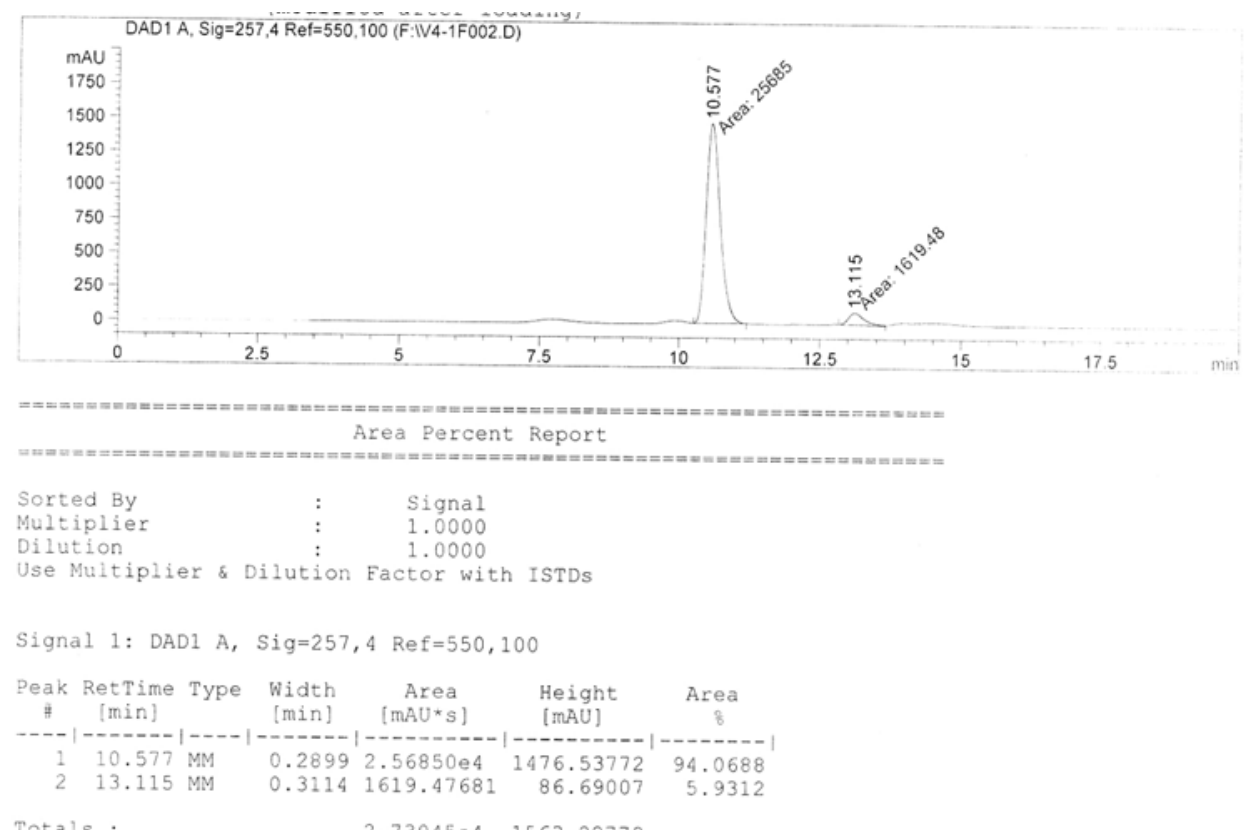

Totals : $\quad 2.73045 \mathrm{e} 4 \quad 1563.22779$

Results obtained with enhanced integrator!

$\star \star \star$ End of Report $* * *$ 
2d (Chiralcel OD column $0.46 \mathrm{~cm}$ x $25 \mathrm{~cm}, 1 \%$ IPA in hexane, $0.4 \mathrm{~mL} / \mathrm{min}$ )

\section{Racemic}
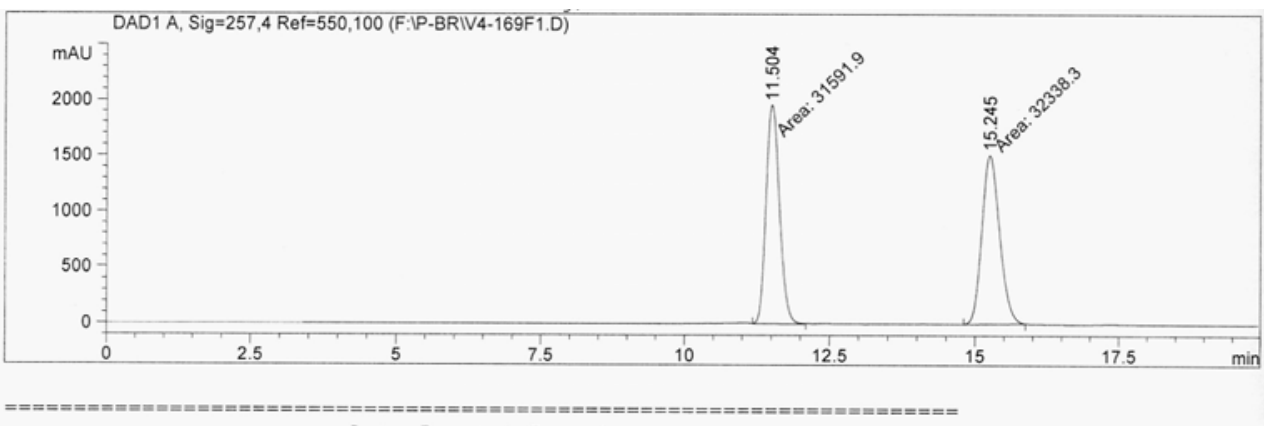

Area Percent Report

$\begin{array}{lcc} & & \\ \text { Sorted By } & \vdots & \text { Signal } \\ \text { Multiplier } & \vdots & 1.0000 \\ \text { Dilution } & \vdots & 1.0000 \\ \text { Use Multiplier \& Dilution Factor with } & \text { ISTDS }\end{array}$

Signal 1: DAD1 A, Sig=257, 4 Ref $=550,100$

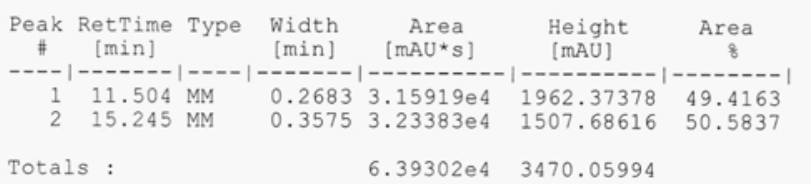

Totals :

$6.39302 \mathrm{e} 4 \quad 3470.05994$

Results obtained with enhanced integrator!

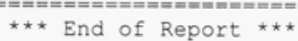

(R)-2d, for Table 1, entry 4

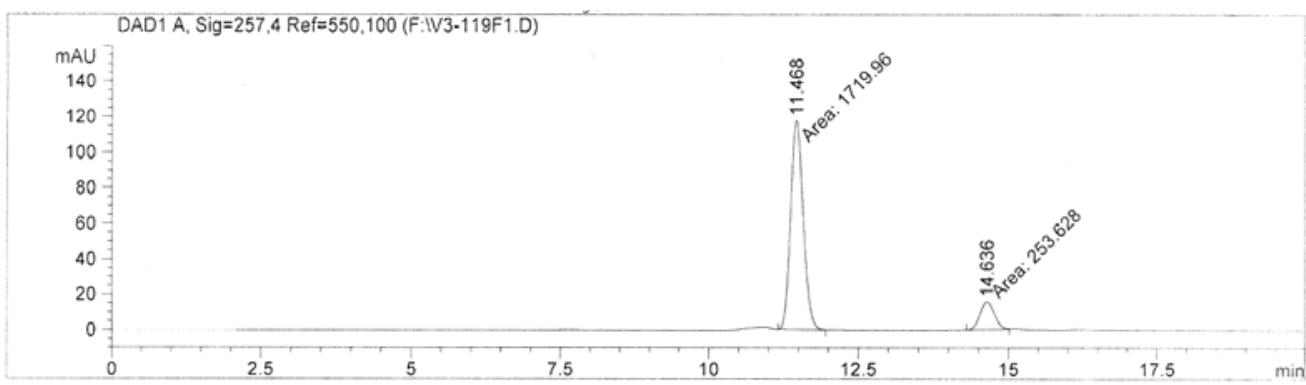

Area Percent Report

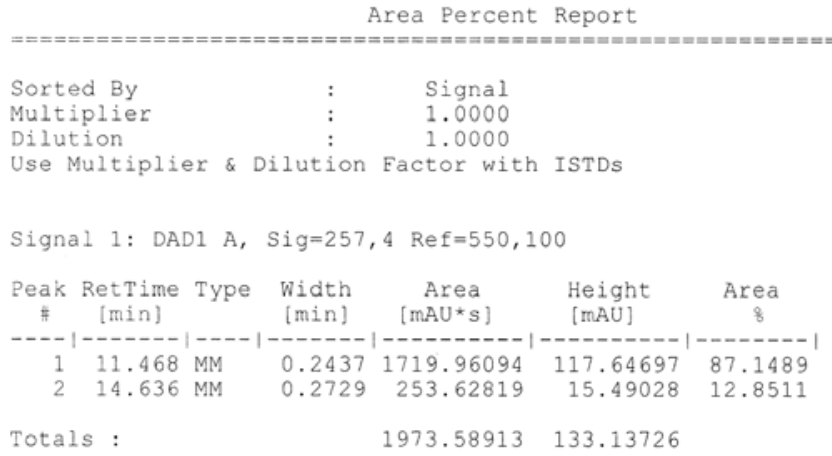

Results obtained with enhanced integrator

$\star * *$ End of Report *** 
2e (Chiralcel OD column $0.46 \mathrm{~cm}$ x $25 \mathrm{~cm}, 1 \%$ IPA in hexane, $0.4 \mathrm{~mL} / \mathrm{min}$ )

\section{Racemic}
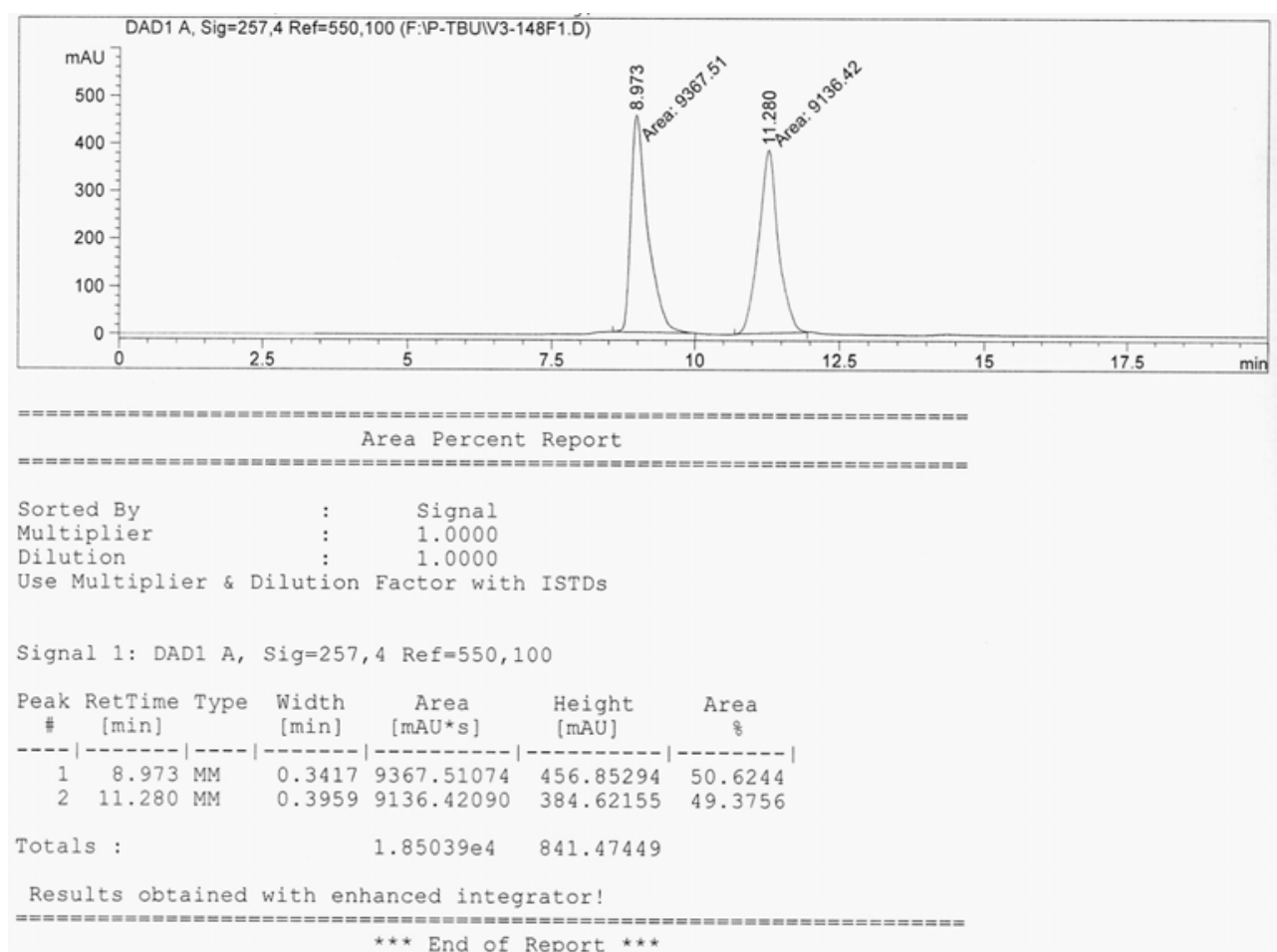

$(R)-2 e$, for Table 1 , entry 5

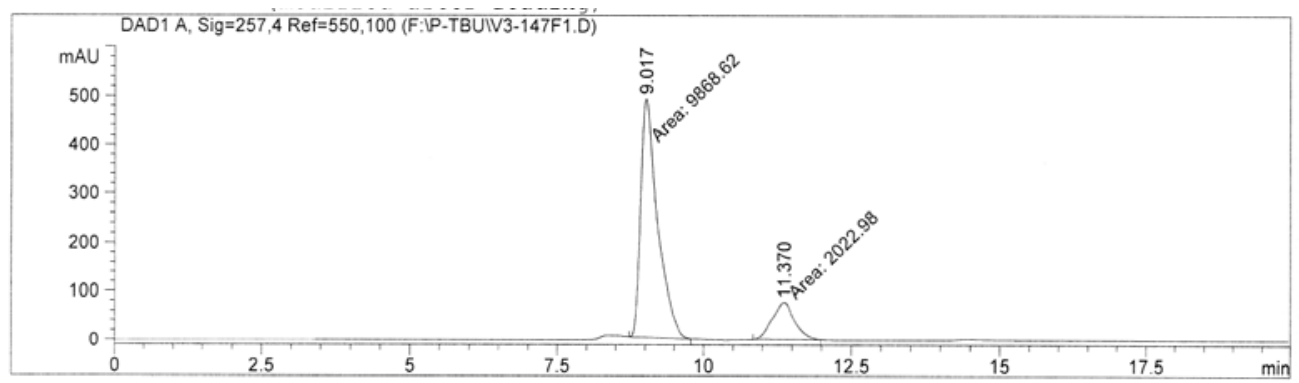

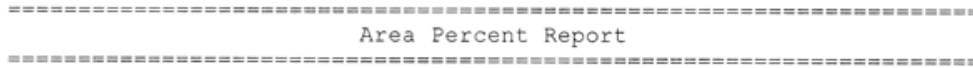

$\begin{array}{lll}\text { Sorted By } & : & \text { Signal } \\ \text { Multiplier } & : & 1.0000\end{array}$

$\begin{array}{lll}\text { Multiplier } & : & 1.0000 \\ \text { Dilution } & : & 1.0000\end{array}$

Use Multiplier \& Dilution Factor with ISTDs

Signal 1: DAD1 A, Sig=257, 4 Ref $=550,100$

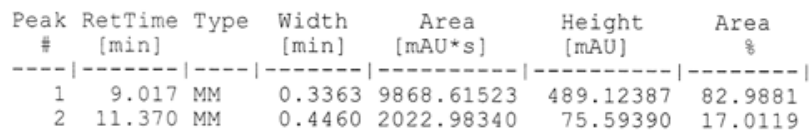

Totals: $\quad 1.18916 \mathrm{e} 4 \quad 564.71777$

Results obtained with enhanced integrator!

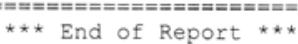




\section{2f (Chiralcel OD column $0.46 \mathrm{~cm} \times 25 \mathrm{~cm}, 1 \%$ IPA in hexane, $0.4 \mathrm{~mL} / \mathrm{min}$ )}

\section{Racemic}
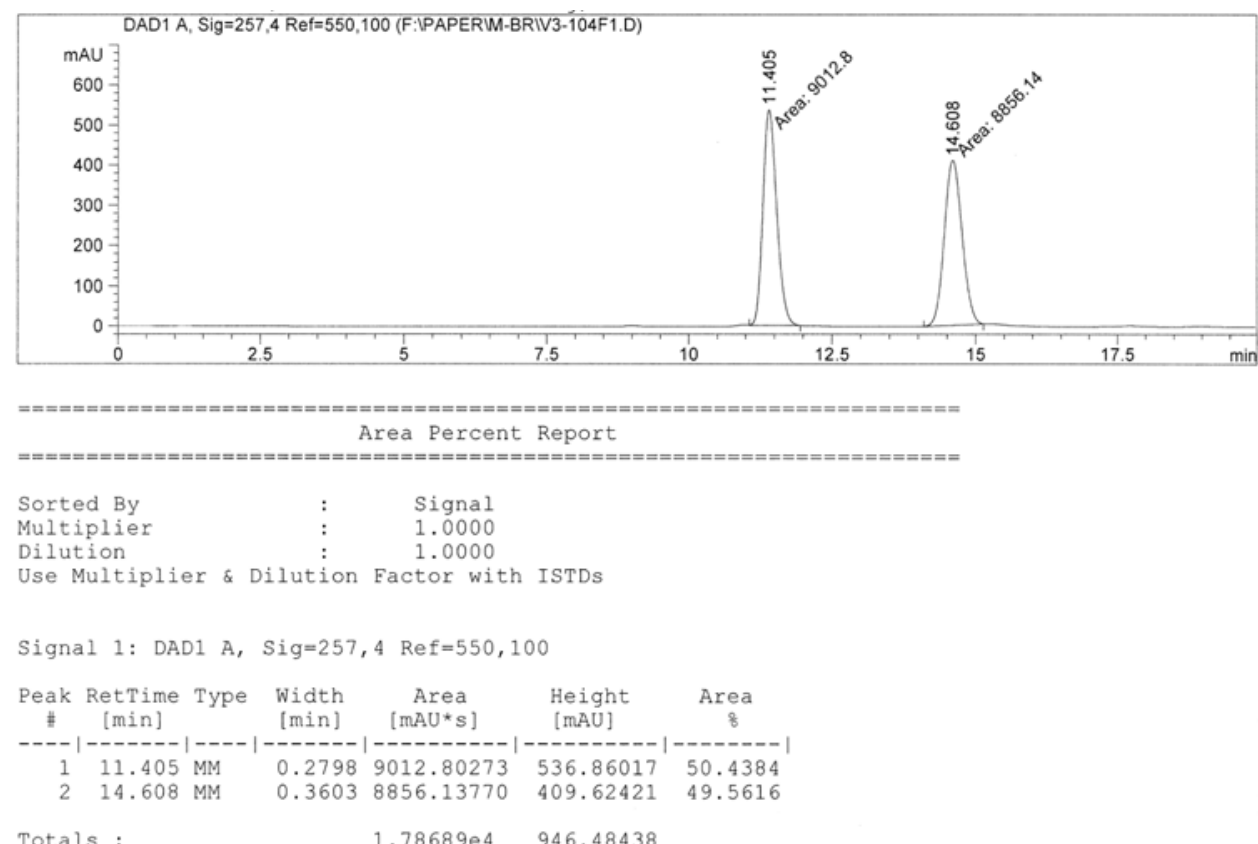

Totals :

$1.78689 \mathrm{e} 4 \quad 946.48438$

Results obtained with enhanced integrator!

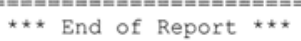

\section{$(R)-2 f$, for Table 1 , entry 6}
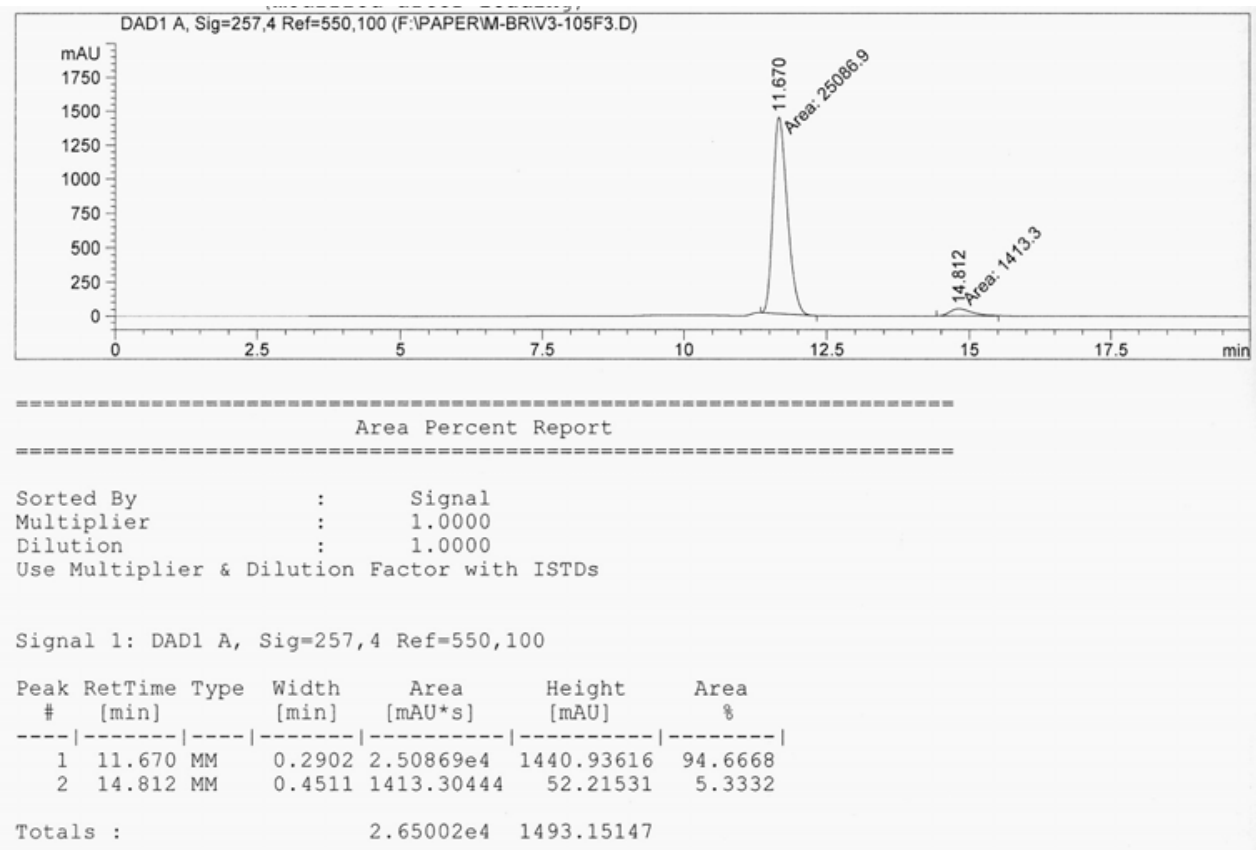

Results obtained with enhanced integrator!

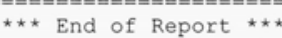




\section{$2 \mathbf{g}$ (Chiralcel OD column $0.46 \mathrm{~cm} \times 25 \mathrm{~cm}, 1 \%$ IPA in hexane, $1 \mathrm{~mL} / \mathrm{min}$ )}

\section{Racemic}

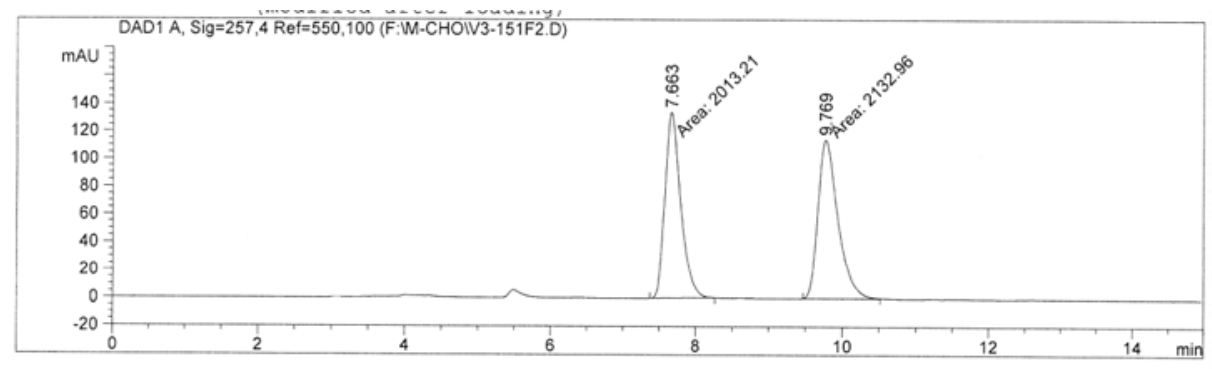

Area Percent Report

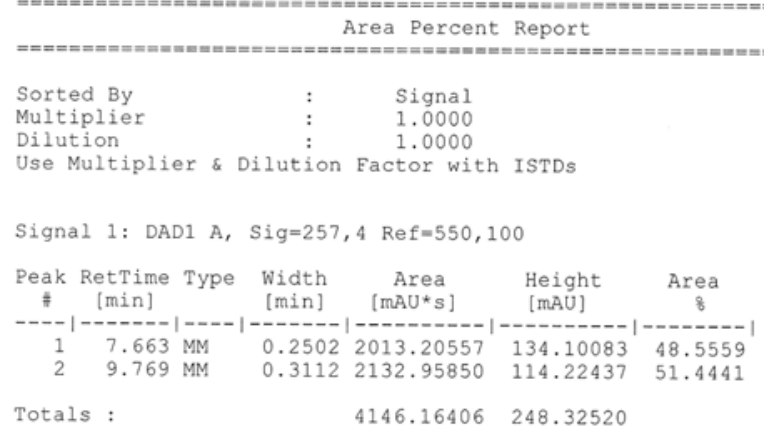

Results obtained with enhanced integrator!

$\star \star \star$ End of Report $\star \star \star$

$(R)-2 g$, for Table 1 , entry 7

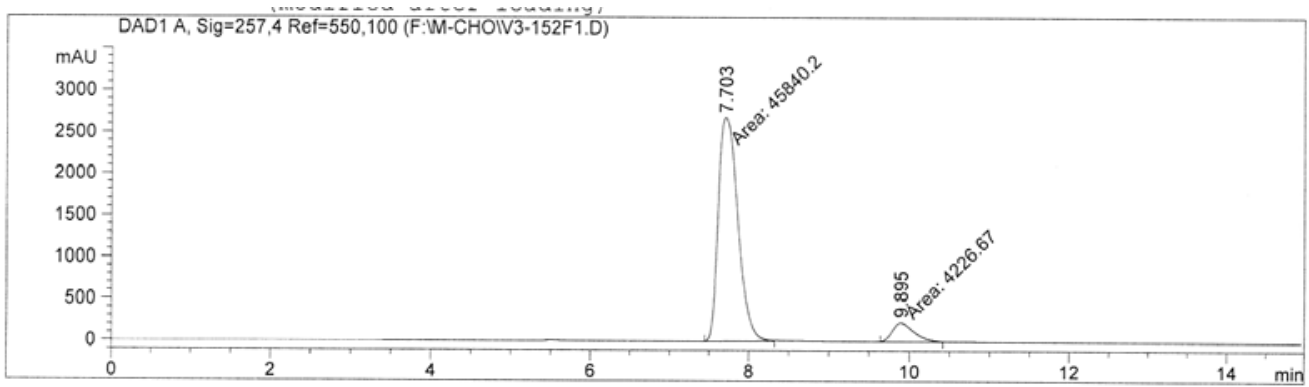

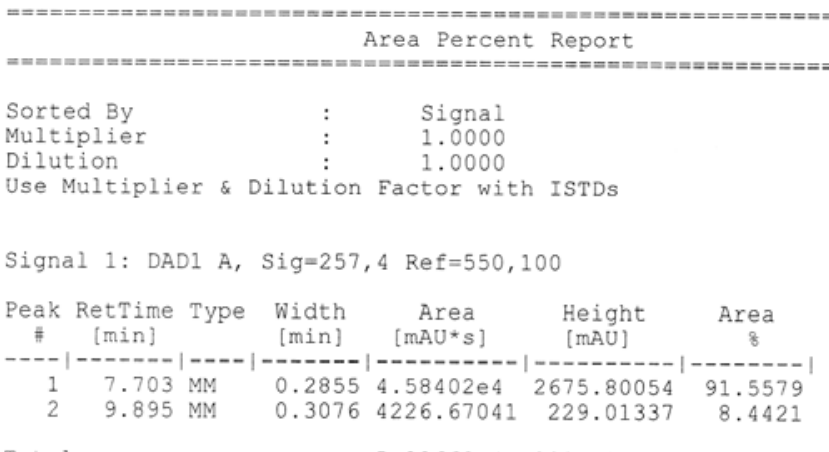

Totals:

$5.00669 e 4 \quad 2904.81390$

Results obtained with enhanced integrator!

$\star * \star$ End of Report $* * *$ 
(R)-2b, for Table 1, entry 8

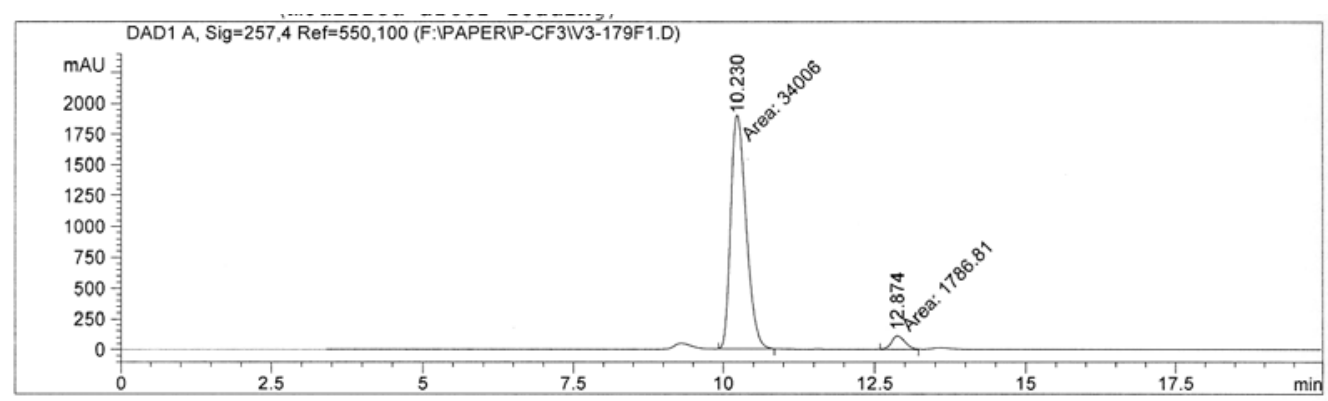

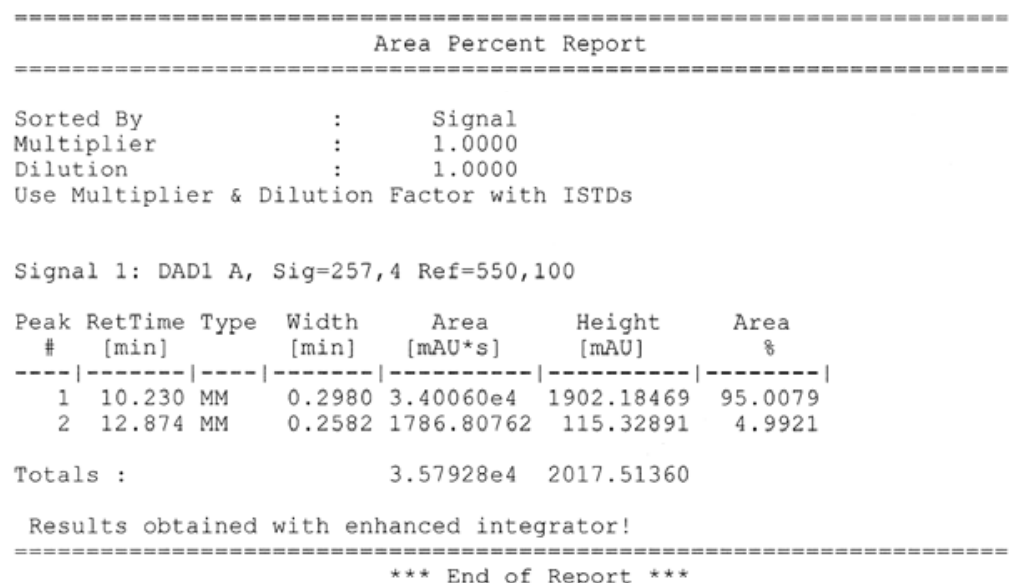




\section{$2 \mathbf{i}$ (Chiralcel OD column $0.46 \mathrm{~cm}$ x $25 \mathrm{~cm}, 1 \%$ IPA in hexane, $0.2 \mathrm{~mL} / \mathrm{min}$ )}

\section{Racemic}

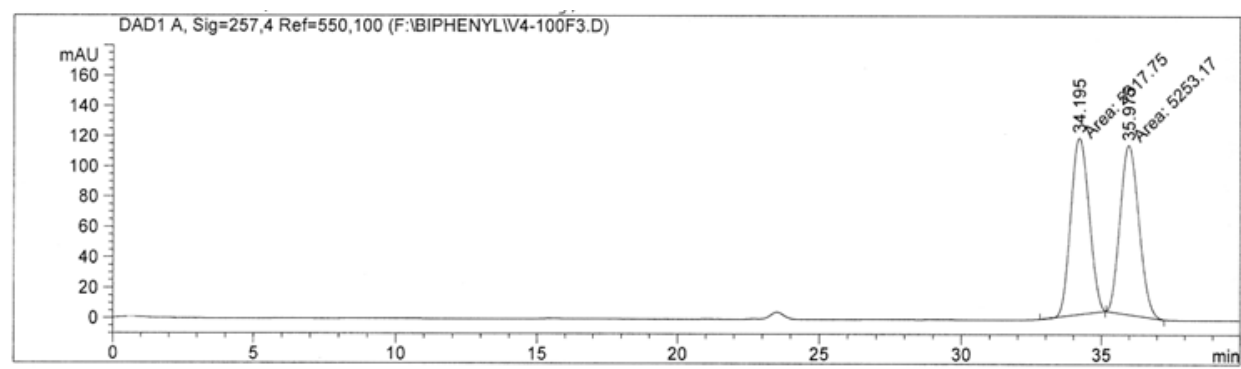

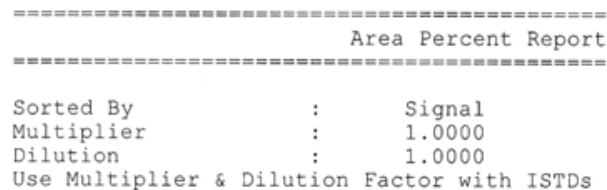

Signal 1: DAD1 A, Sig=257, 4 Ref $=550,100$

\begin{tabular}{|c|c|c|c|c|c|c|}
\hline $\begin{array}{c}\text { Peak } \\
\#\end{array}$ & $\begin{array}{l}\text { RetTime } \\
\text { [min] }\end{array}$ & Type & $\begin{array}{l}\text { Width } \\
\text { [min] }\end{array}$ & $\begin{array}{c}\text { Area } \\
{\left[\mathrm{mAU}^{\star} \mathrm{s}\right]}\end{array}$ & $\begin{array}{l}\text { Height } \\
\text { [mAU] }\end{array}$ & $\begin{array}{c}\text { Area } \\
8\end{array}$ \\
\hline $\begin{array}{l}1 \\
2\end{array}$ & $\begin{array}{l}34.195 \\
35.975\end{array}$ & MM & $\begin{array}{l}0.7619 \\
0.7860\end{array}$ & $\begin{array}{l}5317.74561 \\
5253.16650\end{array}$ & $\begin{array}{l}116.32757 \\
111.38700\end{array}$ & $\begin{array}{l}50.3055 \\
49.6945\end{array}$ \\
\hline
\end{tabular}

Results obtained with enhanced integrator

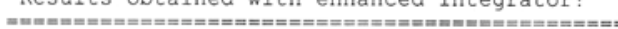

$\star \star \star$ End of Report $\star \star \star$

\section{(R)-2i, for Table 1 , entry 9}

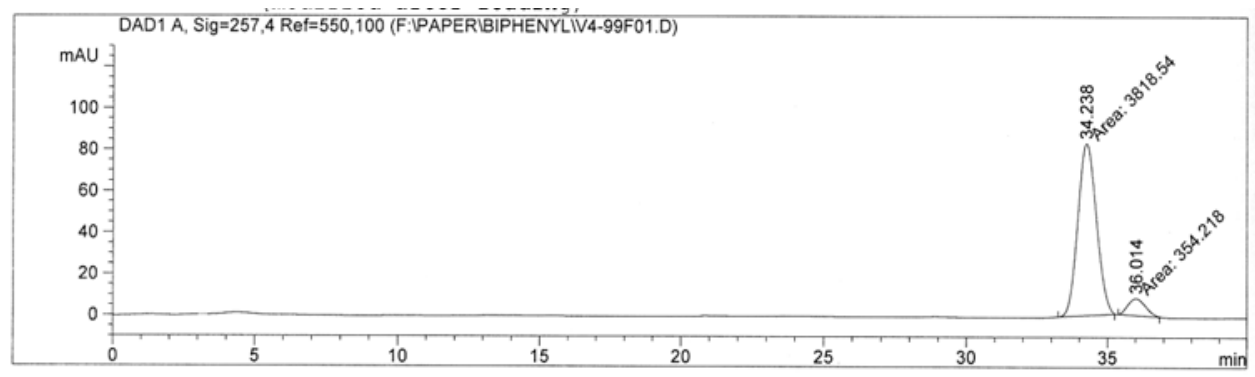

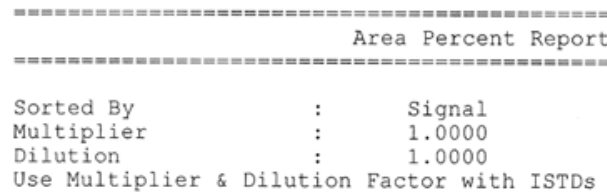

Signal 1: DAD1 A, Sig=257, 4 Ref $=550,100$

\begin{tabular}{|c|c|c|c|c|c|c|}
\hline $\begin{array}{c}\text { Peak } \\
\#\end{array}$ & $\begin{array}{l}\text { RetTime } \\
\text { [min] }\end{array}$ & Type & $\begin{array}{l}\text { Width } \\
\text { [min] }\end{array}$ & $\begin{array}{c}\text { Area } \\
{\left[m A U^{*} s\right]}\end{array}$ & $\begin{array}{l}\text { Height } \\
\text { [mAU] }\end{array}$ & $\begin{array}{c}\text { Area } \\
8\end{array}$ \\
\hline $\begin{array}{l}1 \\
2\end{array}$ & $\begin{array}{l}34.238 \\
36.014\end{array}$ & $\begin{array}{l}\text { MM } \\
\text { MM }\end{array}$ & $\begin{array}{l}0.7683 \\
0.7203\end{array}$ & $\begin{array}{r}3818.53540 \\
354.21762\end{array}$ & $\begin{array}{r}82.83286 \\
8.19604\end{array}$ & $\begin{array}{r}91.5112 \\
8.4888\end{array}$ \\
\hline Total & : & & & 4172.75302 & 91.02889 & \\
\hline
\end{tabular}

Results obtained with enhanced integrator! 


\section{$2 \mathbf{j}$ (Chiralcel OD column $0.46 \mathrm{~cm}$ x $25 \mathrm{~cm}, 100 \%$ hexane, $0.3 \mathrm{~mL} / \mathrm{min}$ )}

\section{Racemic}

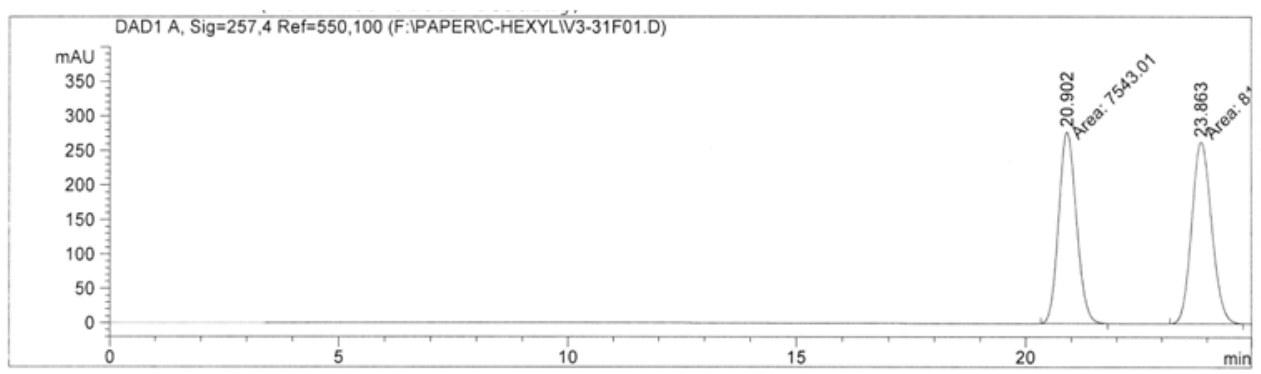

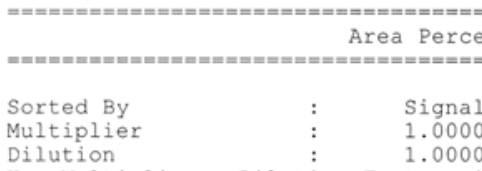

Use Multiplier \& Dilution Factor with ISTDs

Signal 1: DAD1 A, Sig=257, 4 Ref $=550,100$

\begin{tabular}{|c|c|c|c|c|c|c|}
\hline $\begin{array}{c}\text { Peak } \\
\#\end{array}$ & $\begin{array}{l}\text { RetTime } \\
\text { [min] }\end{array}$ & Type & $\begin{array}{l}\text { Width } \\
\text { [min] }\end{array}$ & $\begin{array}{c}\text { Area } \\
{\left[\mathrm{mAU}{ }^{\star} \mathrm{S}\right]}\end{array}$ & $\begin{array}{l}\text { Height } \\
\text { [mAU] }\end{array}$ & $\begin{array}{c}\text { Area } \\
8\end{array}$ \\
\hline $\begin{array}{l}1 \\
2\end{array}$ & $\begin{array}{l}20.902 \\
23.863\end{array}$ & $\begin{array}{l}\text { MM } \\
\text { MM }\end{array}$ & $\begin{array}{l}0.4529 \\
0.5135\end{array}$ & $\begin{array}{l}7543.00537 \\
8117.41650\end{array}$ & $\begin{array}{l}277.55197 \\
263.46011\end{array}$ & $\begin{array}{l}48.1660 \\
51.8340\end{array}$ \\
\hline
\end{tabular}

Totals : $\quad 1.56604 \mathrm{e} 4 \quad 541.01208$

Results obtained with enhanced integrator!

$\star \star \star$
End of Report $\star \star \star$

\section{$(R)-\mathbf{2 j}$, for Table 1 , entry 10}

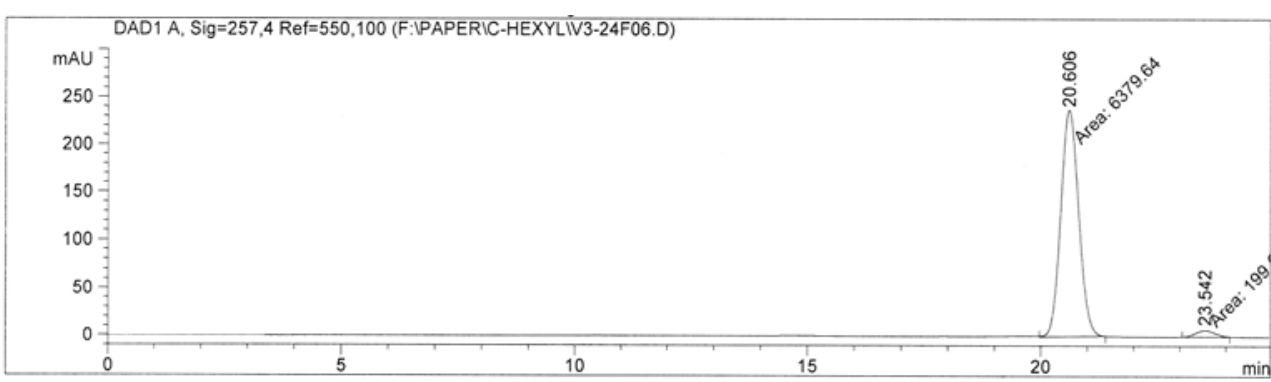

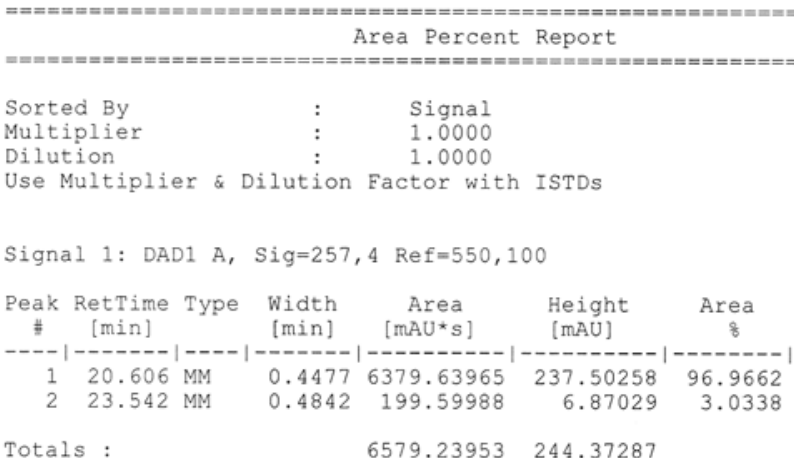

Results obtained with enhanced integrator!

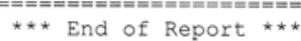


2k (Chiralcel OD column $0.46 \mathrm{~cm} \mathrm{x} 25 \mathrm{~cm}, 1 \%$ IPA in hexane, $0.3 \mathrm{~mL} / \mathrm{min}$ )

\section{Racemic}
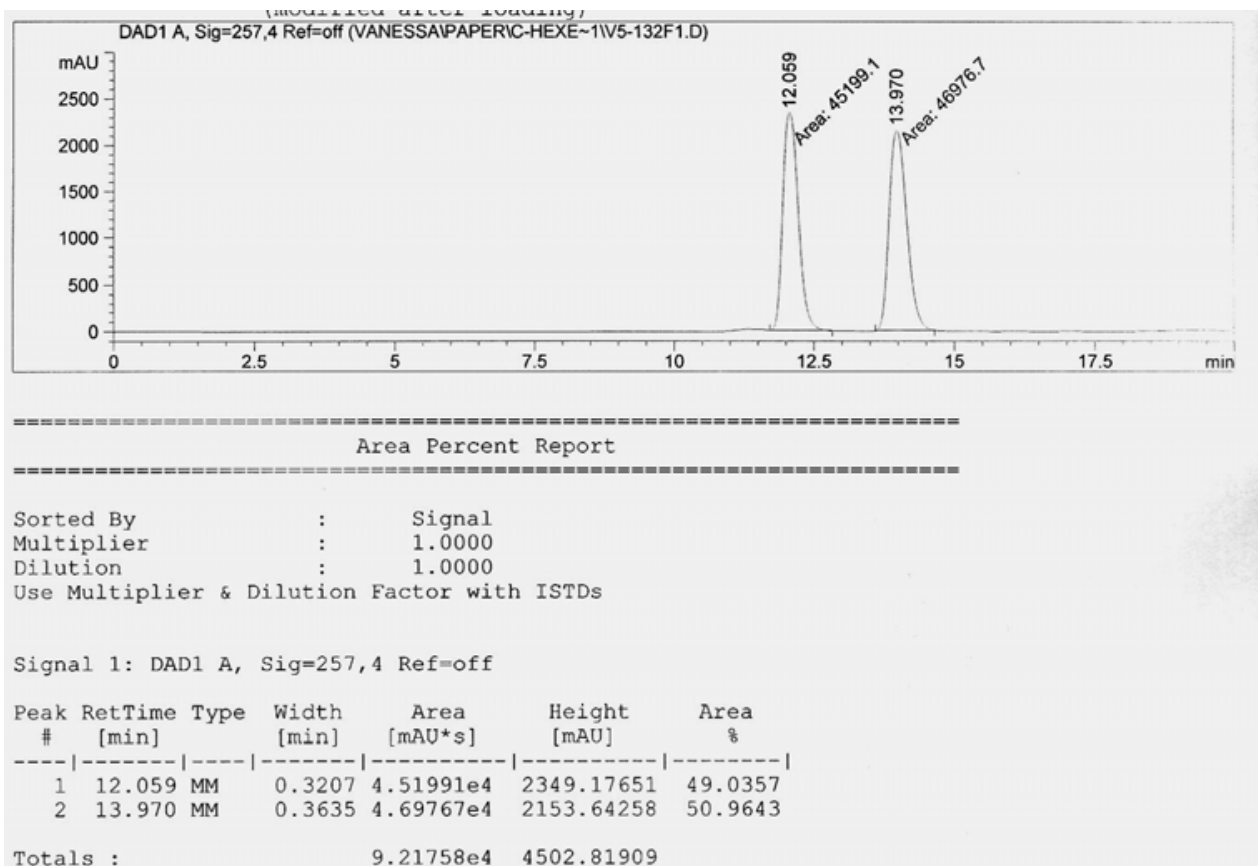

Totals : $\quad 9.21758 \mathrm{e} 4 \quad 4502.81909$

Results obtained with enhanced integrator!

\section{$(R)-\mathbf{2 k}$, for Table 1 , entry 11}

$$
\star \star \star \text { End of Report } \star \star \star *
$$
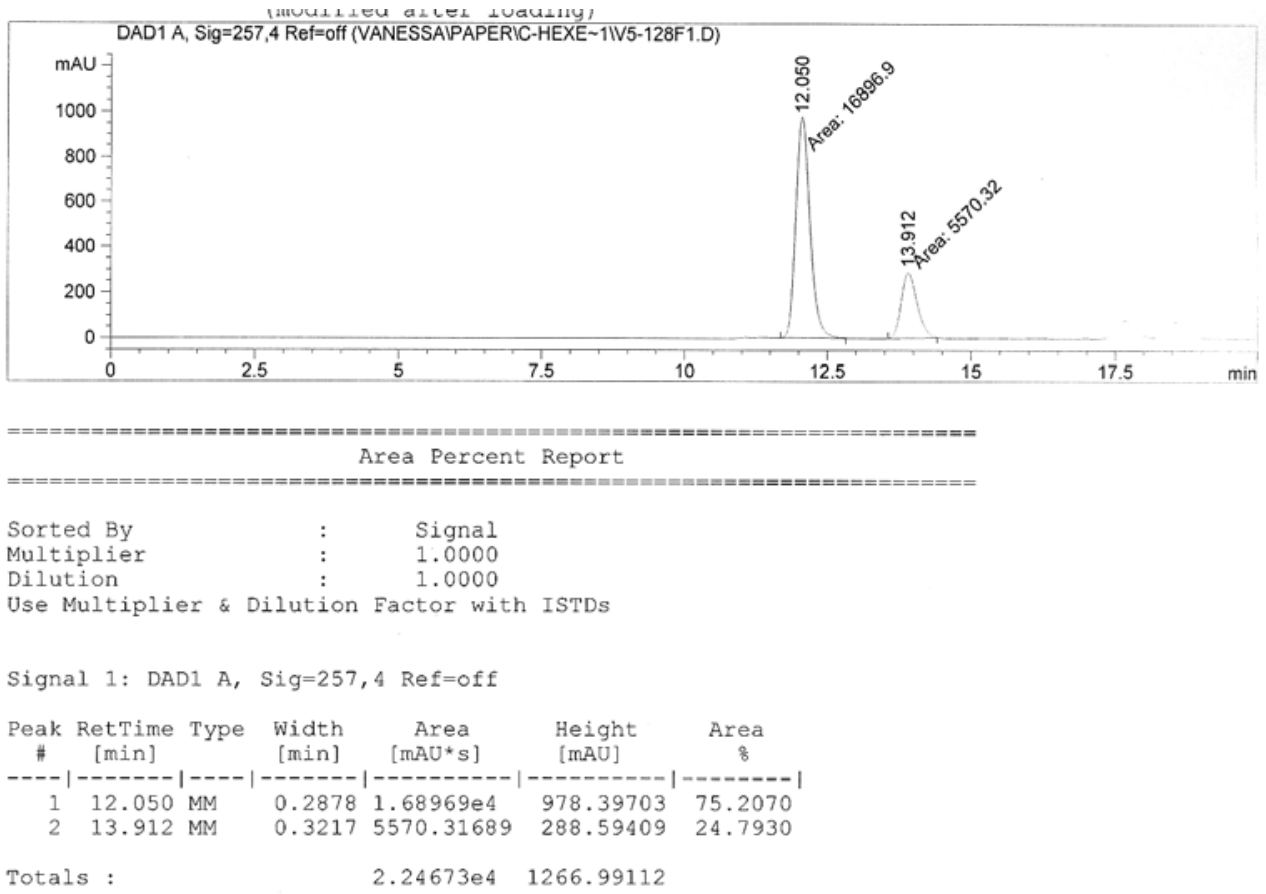

Results obtained with enhanced integrator!

$\star * *$ End of Report $* * *$ 


\section{2l (Chiralcel OD column $0.46 \mathrm{~cm}$ x $25 \mathrm{~cm}, 1 \%$ IPA in hexane, $0.5 \mathrm{~mL} / \mathrm{min}$ )}

\section{Racemic}
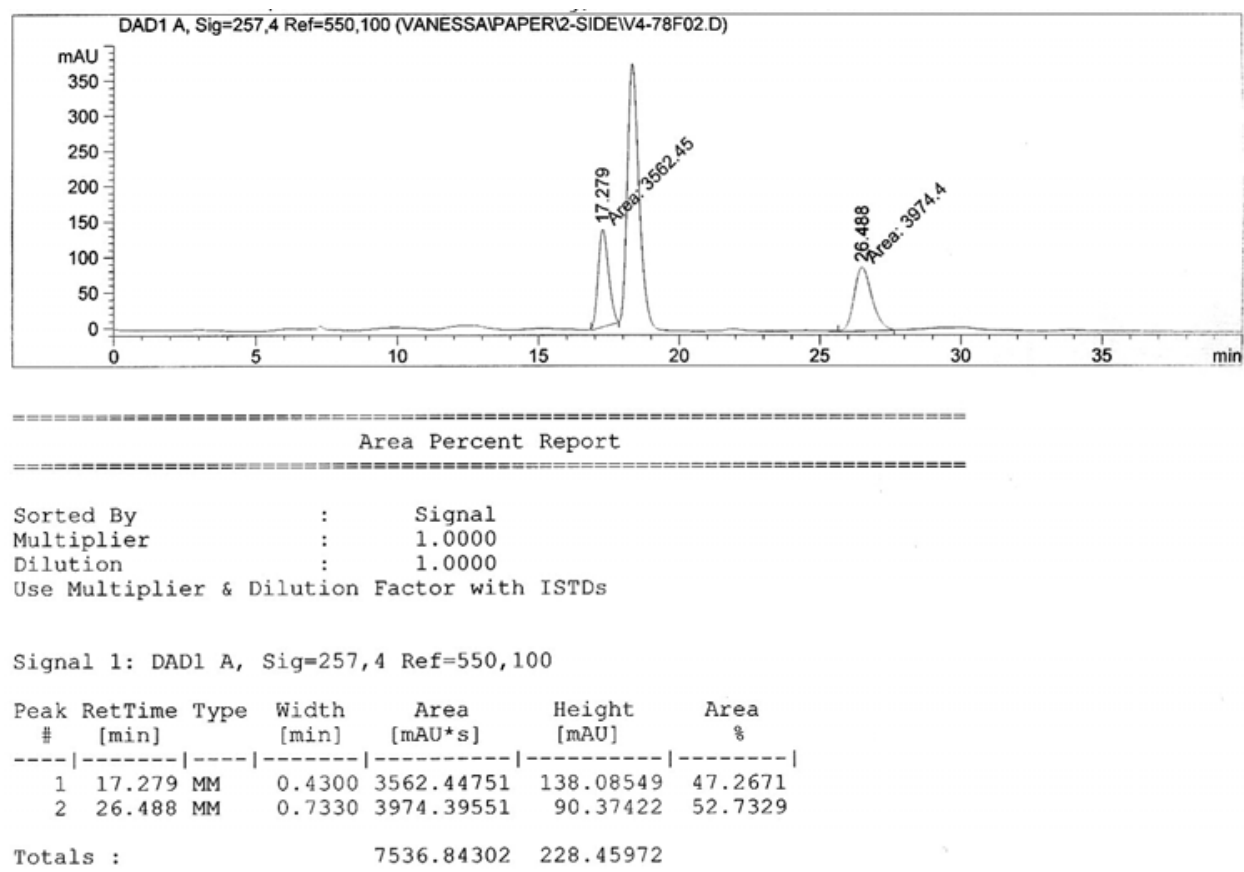

Results obtained with enhanced integrator!

$\star \star *$ End of Report $\star \star \star *$

\section{$(R, R)-2 \mathbf{l}$, for Table 1 , entry 12}

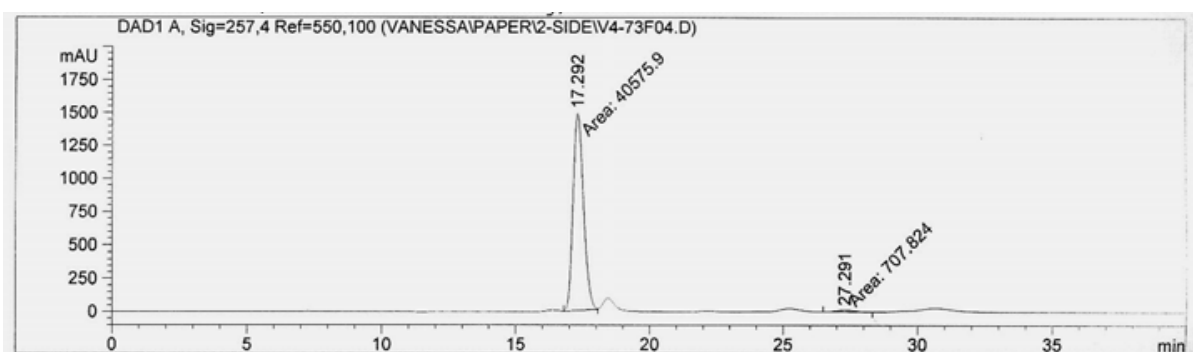

Area Percent Report

$\begin{array}{lll}\text { Sorted By } & : & \text { Signal } \\ \text { Multiplier } & : & 1.0000 \\ \text { Dilution } & : & 1.0000\end{array}$

Use Multiplier \& Dilution Factor with ISTDs

Signal 1: DAD1 A, Sig=257, 4 Ref $=550,100$

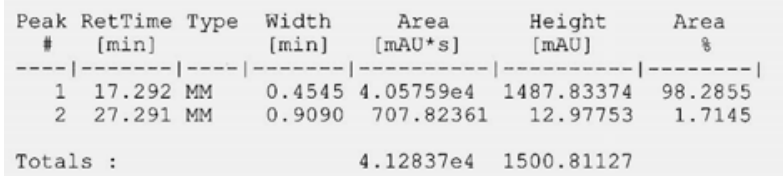

Totals :

$4.12837 \mathrm{e} 4 \quad 1500.81127$

Results obtained with enhanced integrator!

$\star \star \star$ End of Report $\star \star \star$ 
(S)-2a', for Table 1, entry 13

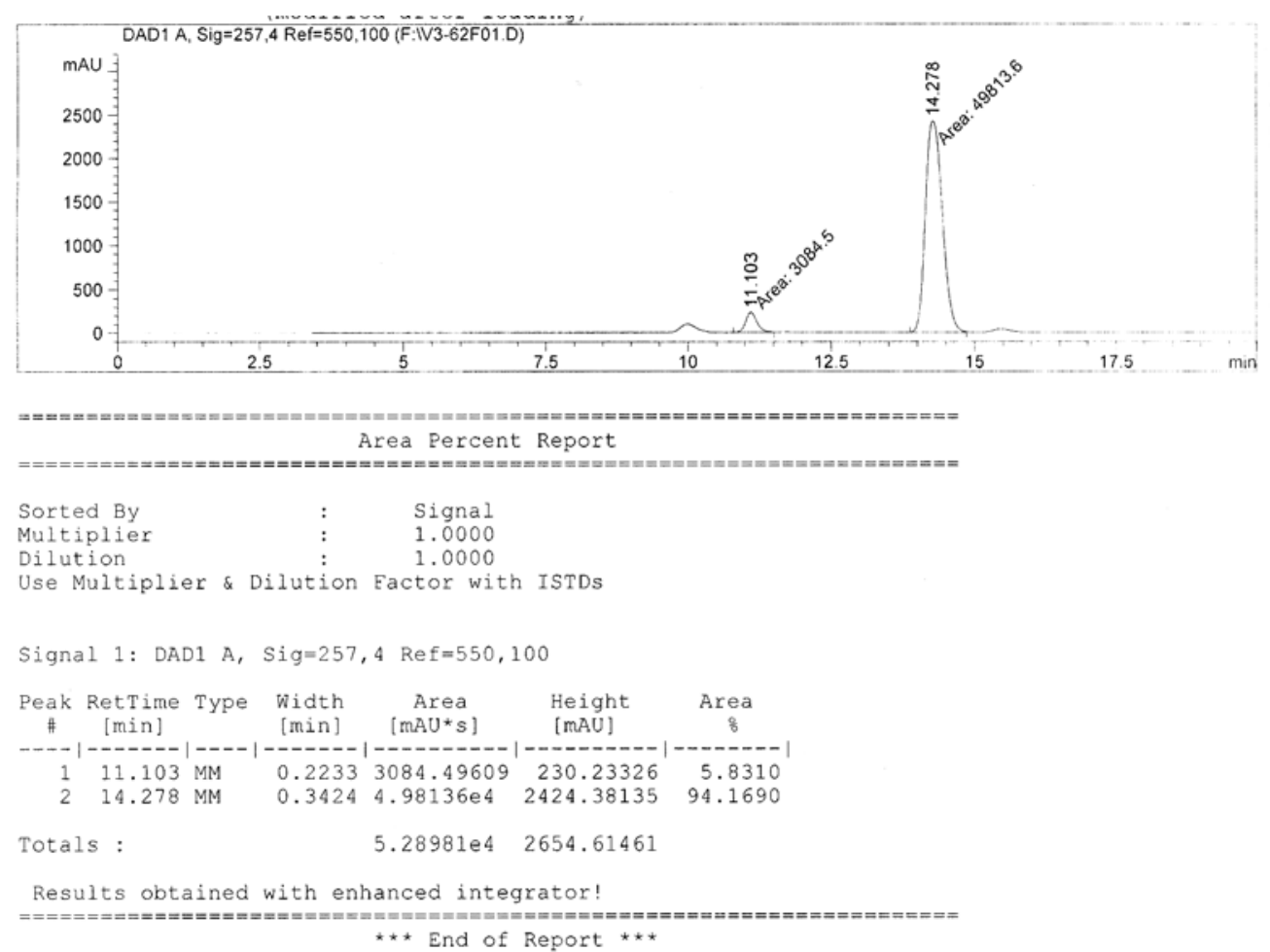

(R)-2a, for Table 1, entry 14

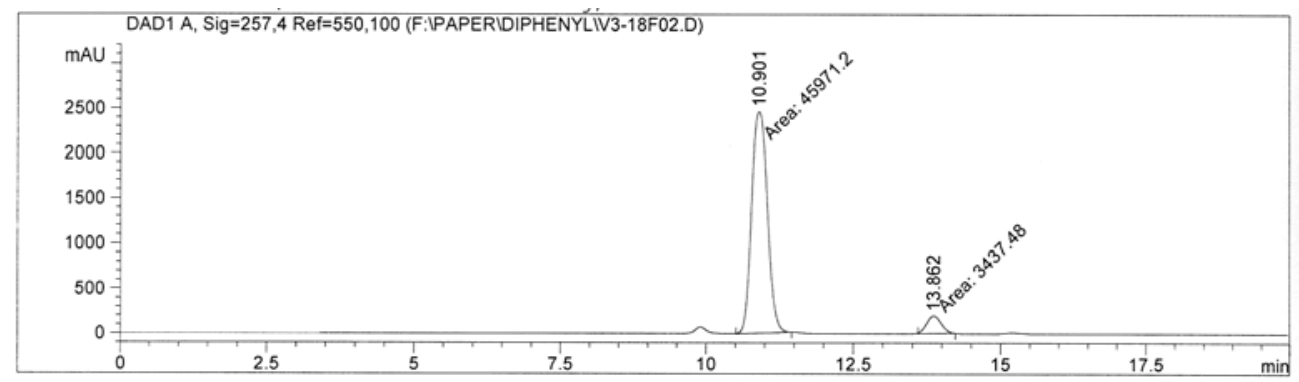

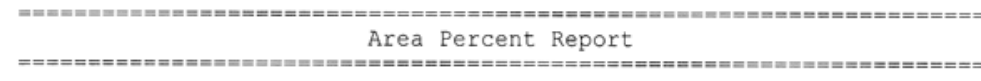

$\begin{array}{lll}\text { Sorted By } & : & \text { Signal } \\ \text { Multiplier } & : & 1.0000\end{array}$

$\begin{array}{lll}\text { Multiplier } & : & 1.0000 \\ \text { Dilution } & : 0000\end{array}$

Use Multiplier \& Dilution Factor with ISTDs

Signal 1: DAD1 A, Sig=257, 4 Ref $=550,100$

\begin{tabular}{|c|c|c|c|c|c|c|}
\hline $\begin{array}{c}\text { Peak } \\
\#\end{array}$ & $\begin{array}{c}\text { RetTime } \\
\text { [min] }\end{array}$ & Type & $\begin{array}{l}\text { Width } \\
\text { [min] }\end{array}$ & $\begin{array}{c}\text { Area } \\
{\left[\mathrm{mAU}^{\star} \mathrm{s}\right]}\end{array}$ & $\begin{array}{l}\text { Height } \\
\text { [MAU] }\end{array}$ & $\begin{array}{c}\text { Area } \\
8\end{array}$ \\
\hline $\begin{array}{l}1 \\
2\end{array}$ & $\begin{array}{l}10.901 \\
13.862\end{array}$ & $\begin{array}{l}\text { MM } \\
\text { MM }\end{array}$ & $\begin{array}{l}0.3113 \\
0.2884\end{array}$ & $\begin{array}{l}4.59712 \mathrm{e} 4 \\
3437.48096\end{array}$ & $\begin{array}{r}2460.99170 \\
198.66257\end{array}$ & $\begin{array}{r}93.0428 \\
6.9572\end{array}$ \\
\hline Tota & : & & & $4.94087 \mathrm{e} 4$ & 2659.65427 & \\
\hline
\end{tabular}

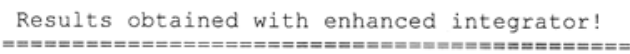

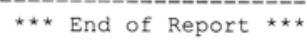




\section{(R)-2a, for Table S1, entry 2}

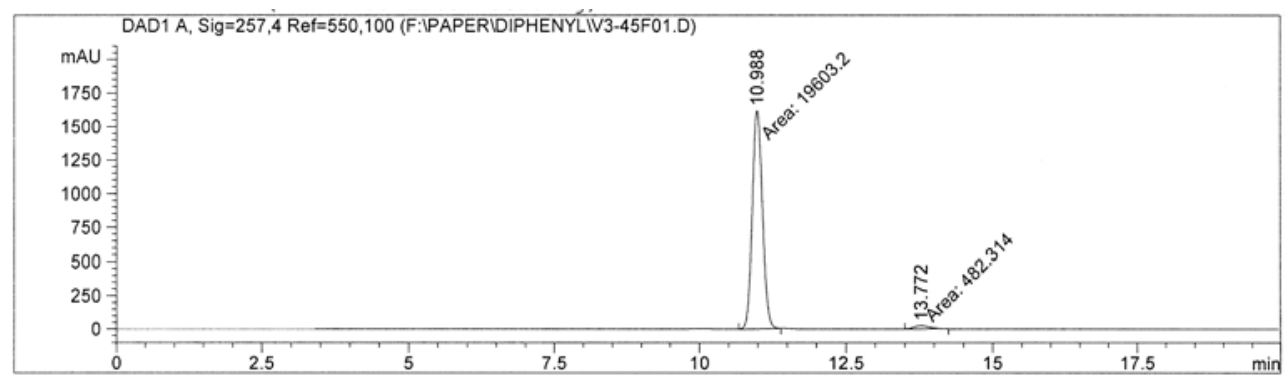

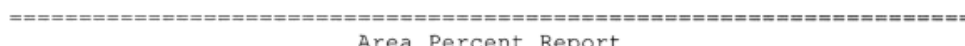

Area Percent Report

$\begin{array}{lll}\text { Sorted By } & : & \text { Signal } \\ \text { Multiplier } & : & 1.0000 \\ \text { Dilution } & : & 1.0000\end{array}$

Dilution 1.0000

Use Multiplier \& Dilution Factor with ISTDs

Signal 1: DAD1 A, Sig=257, 4 Ref $=550,100$

\begin{tabular}{|c|c|c|c|c|c|c|}
\hline $\begin{array}{c}\text { Peak } \\
\#\end{array}$ & $\begin{array}{l}\text { RetTime } \\
\text { [min] }\end{array}$ & Type & $\begin{array}{l}\text { Width } \\
\text { [min] }\end{array}$ & $\begin{array}{c}\text { Area } \\
{\left[\mathrm{mAU}{ }^{\star} \mathrm{s}\right]}\end{array}$ & $\begin{array}{l}\text { Height } \\
\text { [mAU] }\end{array}$ & $\begin{array}{c}\text { Area } \\
\quad 8\end{array}$ \\
\hline $\begin{array}{l}1 \\
2\end{array}$ & $\begin{array}{l}10.988 \\
13.772\end{array}$ & $\begin{array}{l}\text { MM } \\
\text { MM }\end{array}$ & $\begin{array}{l}0.2017 \\
0.3165\end{array}$ & $\begin{array}{c}1.96032 \mathrm{e} 4 \\
482.31448\end{array}$ & $\begin{array}{r}1619.79358 \\
25.39960\end{array}$ & $\begin{array}{r}97.5987 \\
2.4013\end{array}$ \\
\hline Tota & : & & & $2.00855 e 4$ & 1645.19318 & \\
\hline
\end{tabular}

Results obtained with enhanced integrator!

$* * *$ End of Report $* * *$

\section{(R)-2a, for Table S1, entry 3}

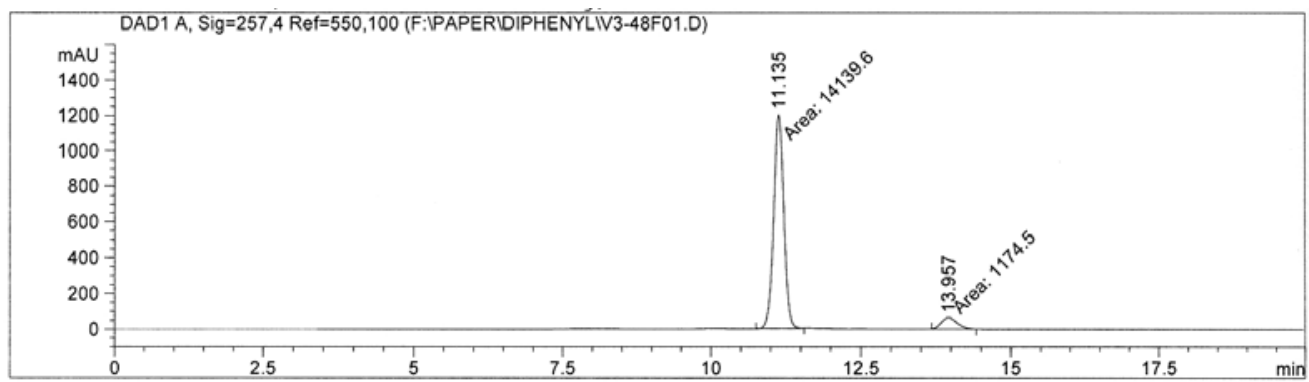

\begin{tabular}{|c|c|c|}
\hline Sorted By & : & Signal \\
\hline Multiplier & : & 1.0000 \\
\hline Dilution & : & 1.0000 \\
\hline
\end{tabular}

Use Multiplier \& Dilution Factor with ISTDS

Signal 1: DAD1 A, Sig=257, 4 Ref $=550,100$

\begin{tabular}{|c|c|c|c|c|c|c|}
\hline $\begin{array}{c}\text { Peak } \\
\#\end{array}$ & $\begin{array}{l}\text { RetTime } \\
\text { [min] }\end{array}$ & Type & $\begin{array}{l}\text { Width } \\
\text { [min] }\end{array}$ & $\begin{array}{c}\text { Area } \\
{\left[\mathrm{mAU}{ }^{\star} \mathrm{s}\right]}\end{array}$ & $\begin{array}{l}\text { Height } \\
{[\mathrm{mAU}]}\end{array}$ & $\begin{array}{c}\text { Area } \\
8\end{array}$ \\
\hline 1 & 11.135 & MM & 0.1961 & $1.41396 \mathrm{e} 4$ & 1201.82605 & 92.3306 \\
\hline 2 & 13.957 & MM & 0.3090 & 1174.50464 & 63.34413 & 7.6694 \\
\hline
\end{tabular}

Totals:

$1.53141 \mathrm{e} 4 \quad 1265.17018$

Results obtained with enhanced integrator!

$* \star *$ End of Report $* * *$ 


\section{(R)-2a, for Table S1, entry 4}

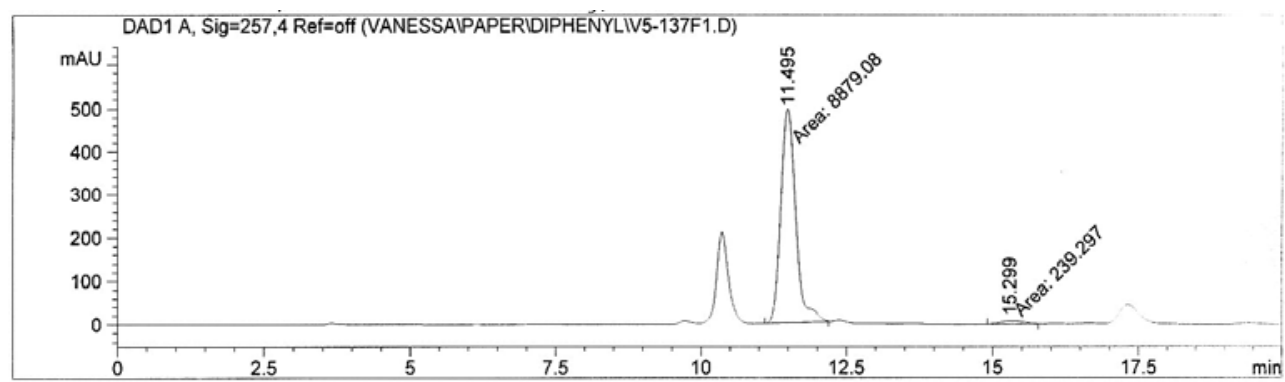

\begin{tabular}{|c|c|}
\hline Sorted By & Signal \\
\hline Multiplier & 1.0000 \\
\hline Dilution & 1.0000 \\
\hline
\end{tabular}

Signal 1: DAD1 A, Sig=257, 4 Ref=off

\begin{tabular}{|c|c|c|c|c|c|c|}
\hline $\begin{array}{c}\text { Peak } \\
\#\end{array}$ & $\begin{array}{l}\text { RetTime } \\
\text { [min] }\end{array}$ & Type & $\begin{array}{l}\text { Width } \\
\text { [min] }\end{array}$ & $\begin{array}{c}\text { Area } \\
{[\mathrm{mAU} * \mathrm{~s}]}\end{array}$ & $\begin{array}{l}\text { Height } \\
\text { [mAU] }\end{array}$ & $\begin{array}{c}\text { Area } \\
8\end{array}$ \\
\hline 1 & $\begin{array}{l}11.495 \\
15.299\end{array}$ & $\begin{array}{l}\mathrm{MM} \\
\mathrm{MM}\end{array}$ & $\begin{array}{l}0.2982 \\
0.5093\end{array}$ & $\begin{array}{r}8879.08398 \\
239.29669\end{array}$ & $\begin{array}{r}496.20871 \\
7.83071\end{array}$ & $\begin{array}{r}97.3757 \\
2.6243\end{array}$ \\
\hline Tota & : & & & 9118.38068 & 504.03942 & \\
\hline
\end{tabular}

Results obtained with enhanced integrator!

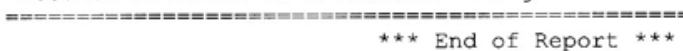

\section{(R)-2a, for Table S1, entry 5}

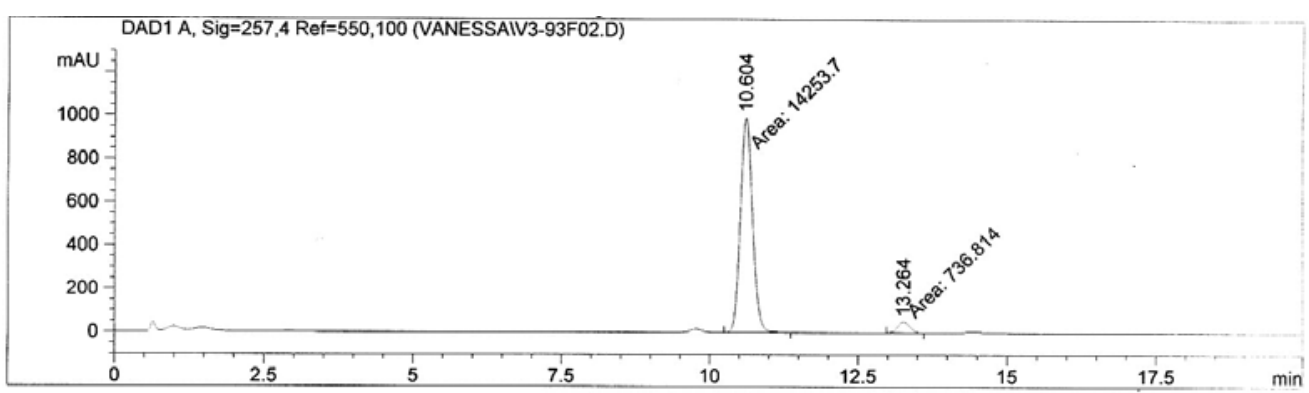

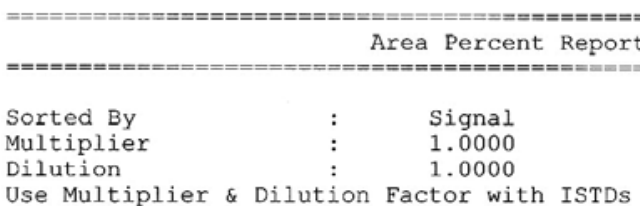

Signal 1: DAD1 A, Sig=257, 4 Ref $=550,100$

\begin{tabular}{|c|c|c|c|c|c|c|}
\hline $\begin{array}{c}\text { Peak } \\
\#\end{array}$ & $\begin{array}{l}\text { RetTime } \\
\text { [min] }\end{array}$ & Type & $\begin{array}{l}\text { Width } \\
\text { [min] }\end{array}$ & $\begin{array}{c}\text { Area } \\
{\left[\mathrm{mAU}^{\star} \mathrm{s}\right]}\end{array}$ & $\begin{array}{l}\text { Height } \\
\text { [mAU] }\end{array}$ & $\begin{array}{c}\text { Area } \\
\quad 8\end{array}$ \\
\hline $\begin{array}{l}1 \\
2\end{array}$ & 10.604 & MM & 0.2381 & $1.42537 \mathrm{e} 4$ & $\begin{array}{r}997.89264 \\
51.66946\end{array}$ & 95.0848 \\
\hline Tota & : & & & $1.49905 \mathrm{e} 4$ & 1049.56210 & \\
\hline
\end{tabular}

Results obtained with enhanced integrator! 


\section{(R)-2a, for Table S1, entry 6}
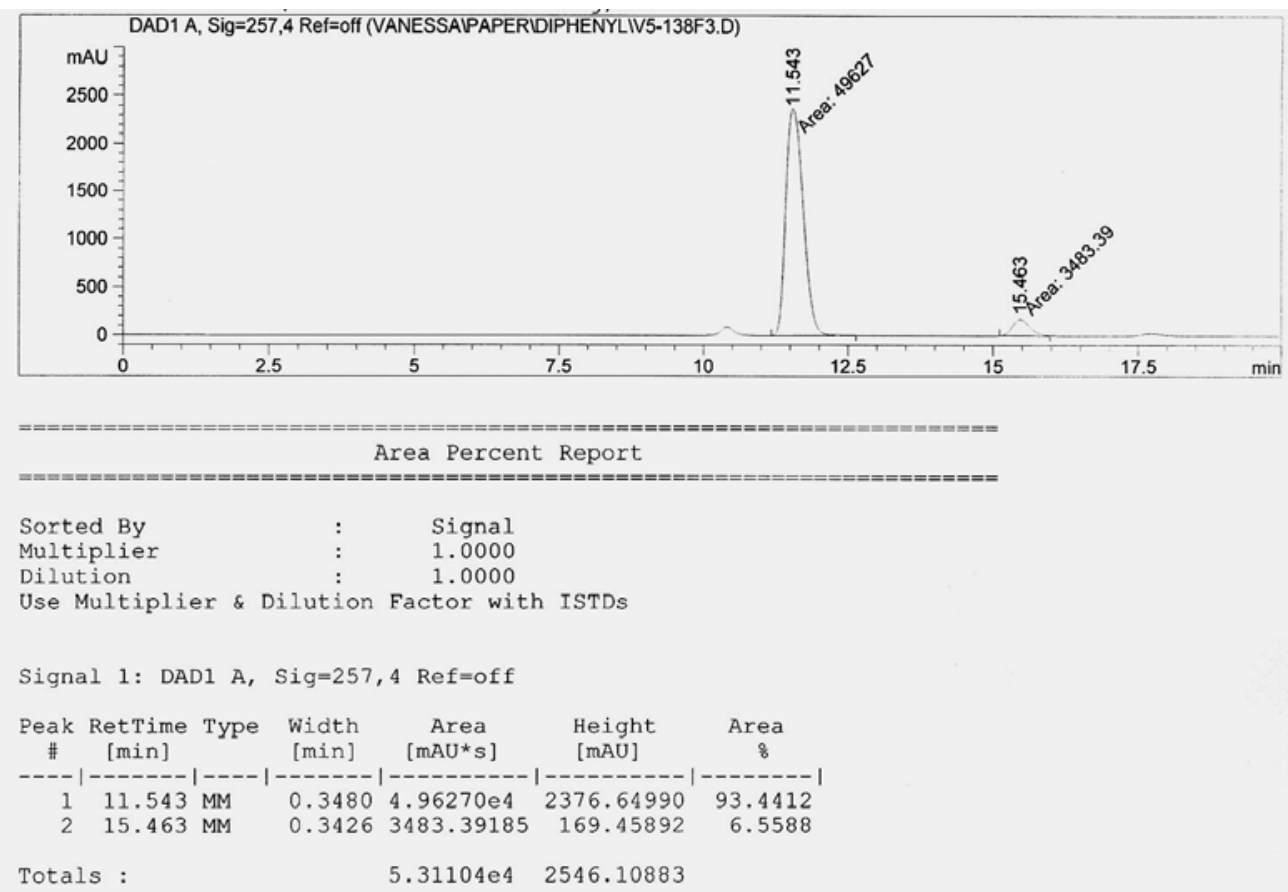

Results obtained with enhanced integrator!

\section{(R)-2a, for Table S1, entry 9}

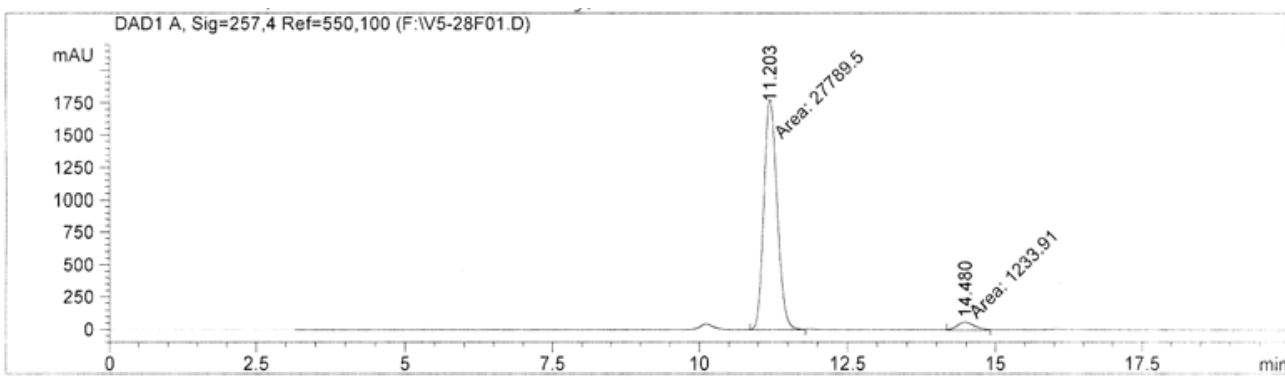

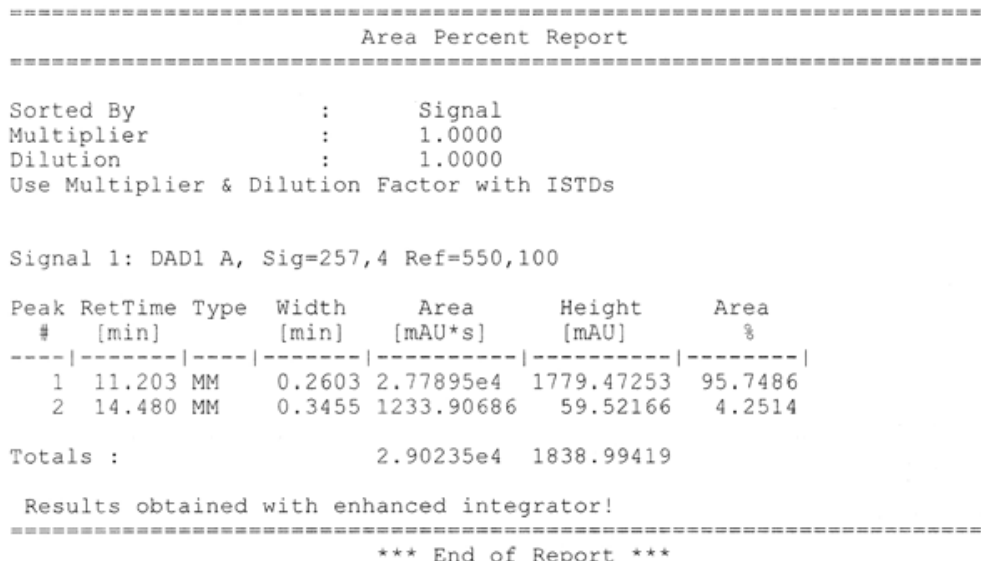




\section{${ }^{1} \mathrm{H}$ and ${ }^{13} \mathrm{C}$ NMR Spectra of $1 \mathrm{~b}-\mathrm{i}, 1 \mathrm{k}-\mathrm{l}$ and 10}

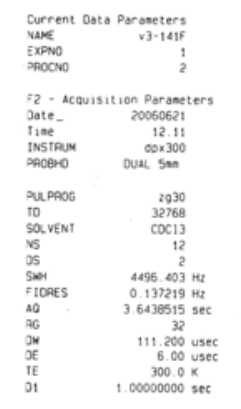

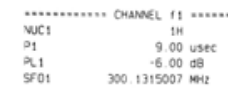

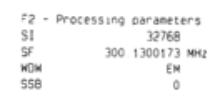

558
58
08
08$$
10 \text { nas olot seraseters } 1.00
$$

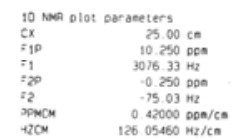

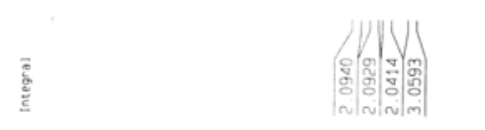

$n \pi$

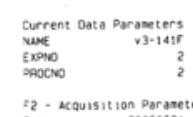

$z_{2}$ - Acquisition paraneters
Date 2005052 - 20

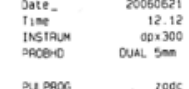

$\begin{array}{lr}\text { PUPAOC } & 2906 \\ \text { ID } & 32769 \\ \text { 5a VENT } & \text { COC13 } \\ \text { VS } & 68\end{array}$

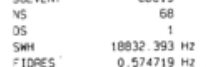

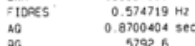

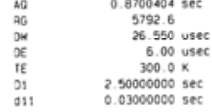

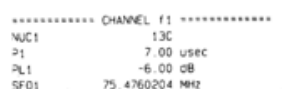

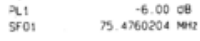

c............. crundel 12 ................

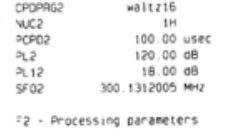

\&2. - Arocessiog paraneters

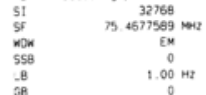

$\begin{array}{ll}-8 & 1.00 \mathrm{~Hz} \\ 3 \mathrm{~B} & 0 \\ x & 1.40\end{array}$

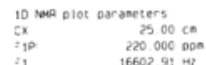

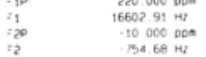

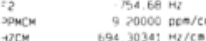
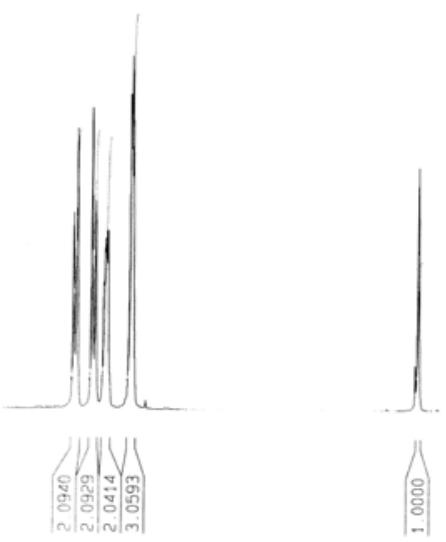

$1 b$
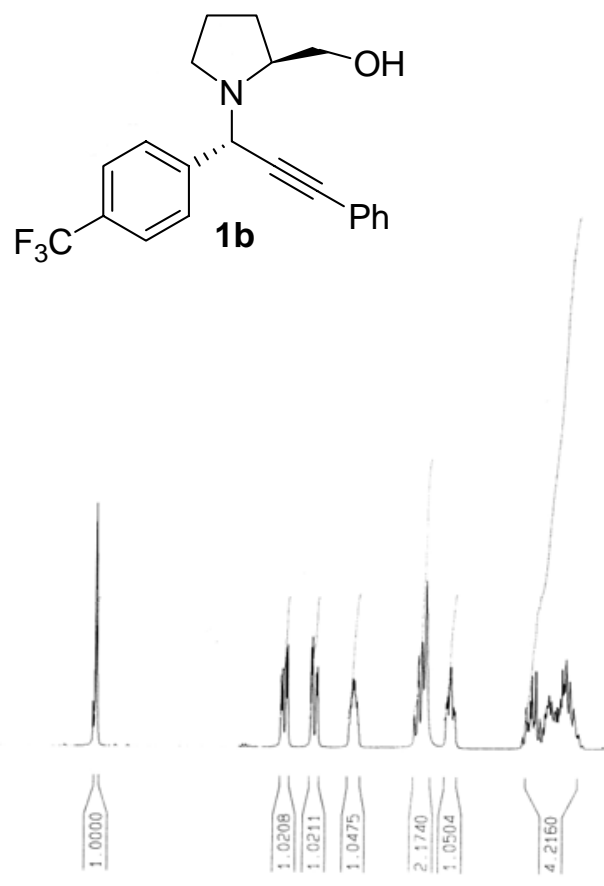


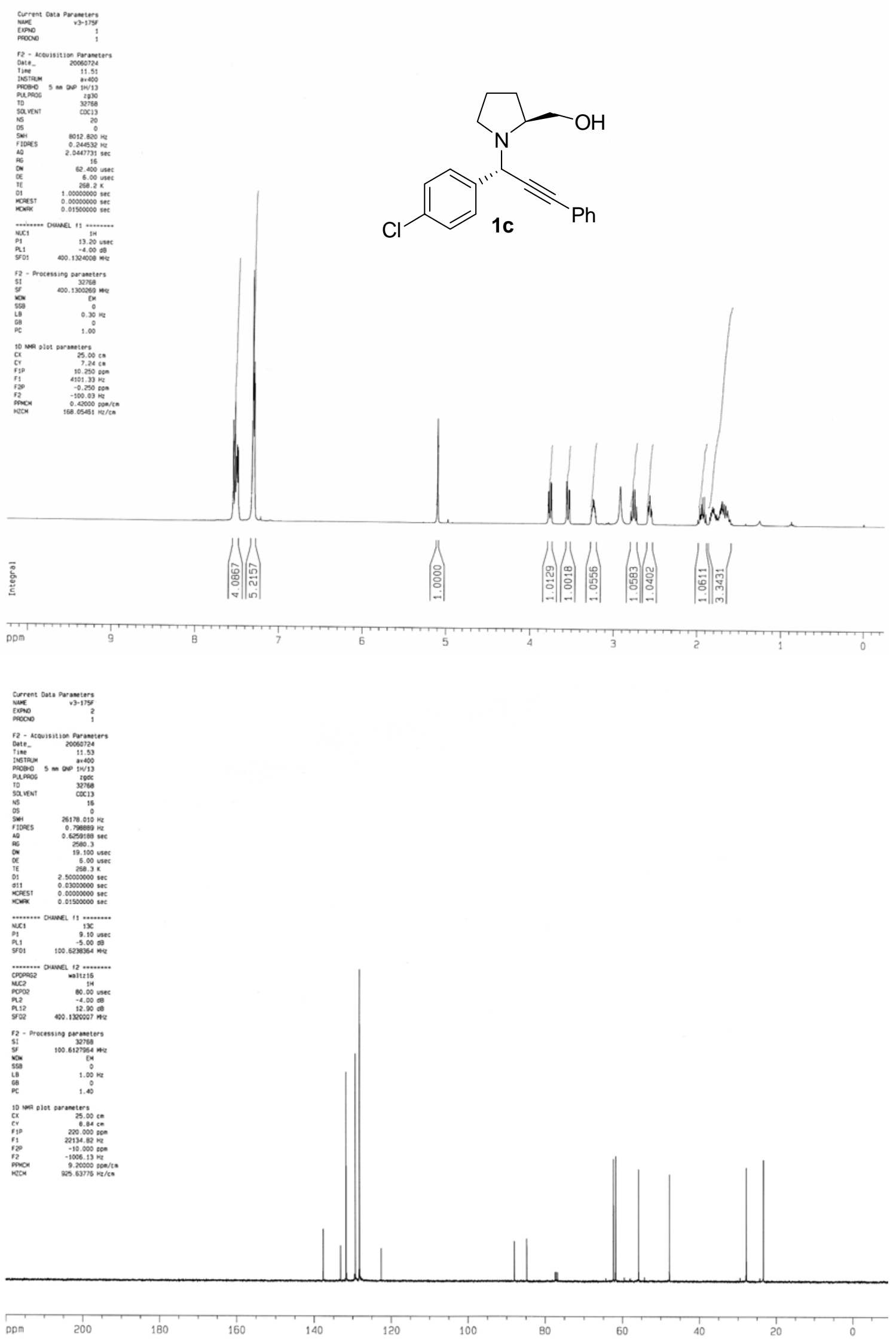



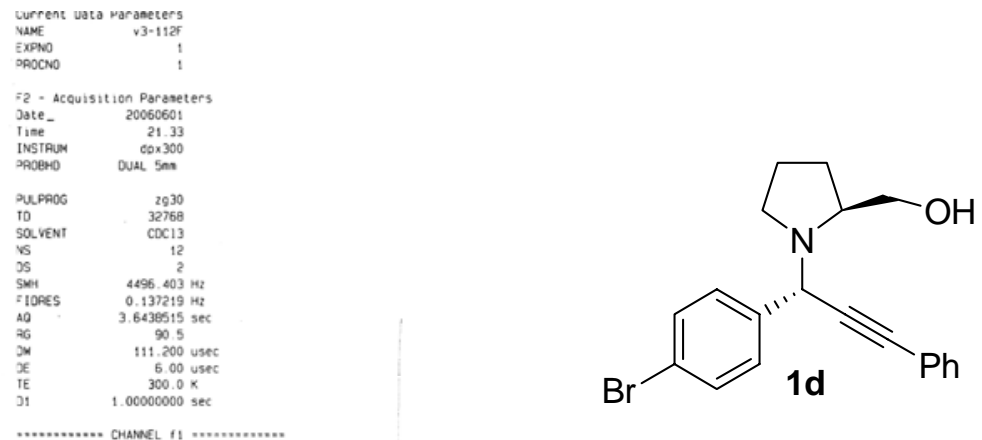

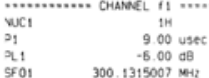

2 - Processing parameters

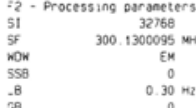

10 Nap olot porsneters

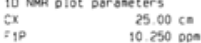

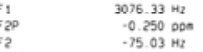

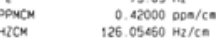
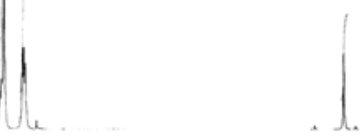

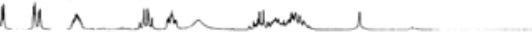

$\stackrel{\vec{\vdots}}{\stackrel{5}{\leftrightarrows}}$
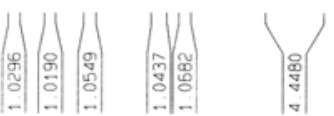

Current vata parameters
vaMe
v3-112

Expro

72. Acquisition Paraneters
Date_- 20060601
Tige
21.35

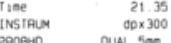

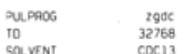

$\begin{array}{lr}\text { SOLVENT } & \text { COC13 } \\ \text { VS } & 87 \\ \text { OS } & 1 \\ \text { SW } & 18832.393 \mathrm{~Hz}\end{array}$

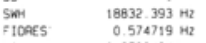

$\begin{array}{ll}40 & 0.8700404 \text { set } \\ 76 & 8192\end{array}$

$\begin{array}{ll}26.550 \text { usec } \\ \text { ON } & 6.00 \text { usec } \\ \text { of } & 3000.0 \%\end{array}$

$\begin{array}{ll}25 & 50000000 \mathrm{sec} \\ 01 & 0.0300000 \mathrm{gec}\end{array}$

.............. Chanevel 11 .................

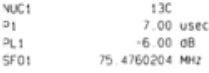

$\begin{array}{lc}\text { CPOPAG } & \text { waltz16 } \\ \text { WC2 } & \text { it } \\ \text { PCPOS } & 100.00 \text { uset }\end{array}$

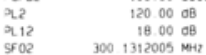

:2. Processing paraseter:

$51 \quad 759677520$ Not

$\begin{array}{lc}\text { now } & \text { EM } \\ 5 S \mathrm{BS} & 0 \\ -8 & 1.00 \mathrm{~Hz} \\ 68 & 1.00\end{array}$

1.40

10 nas plot paraneters
$=x$
$2500 \mathrm{cos}$

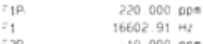

$\begin{array}{ll}20 & 10000 \\ 2 & 5000\end{array}$

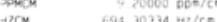

and

IEO

100

PC

$\frac{1}{40}$

20 

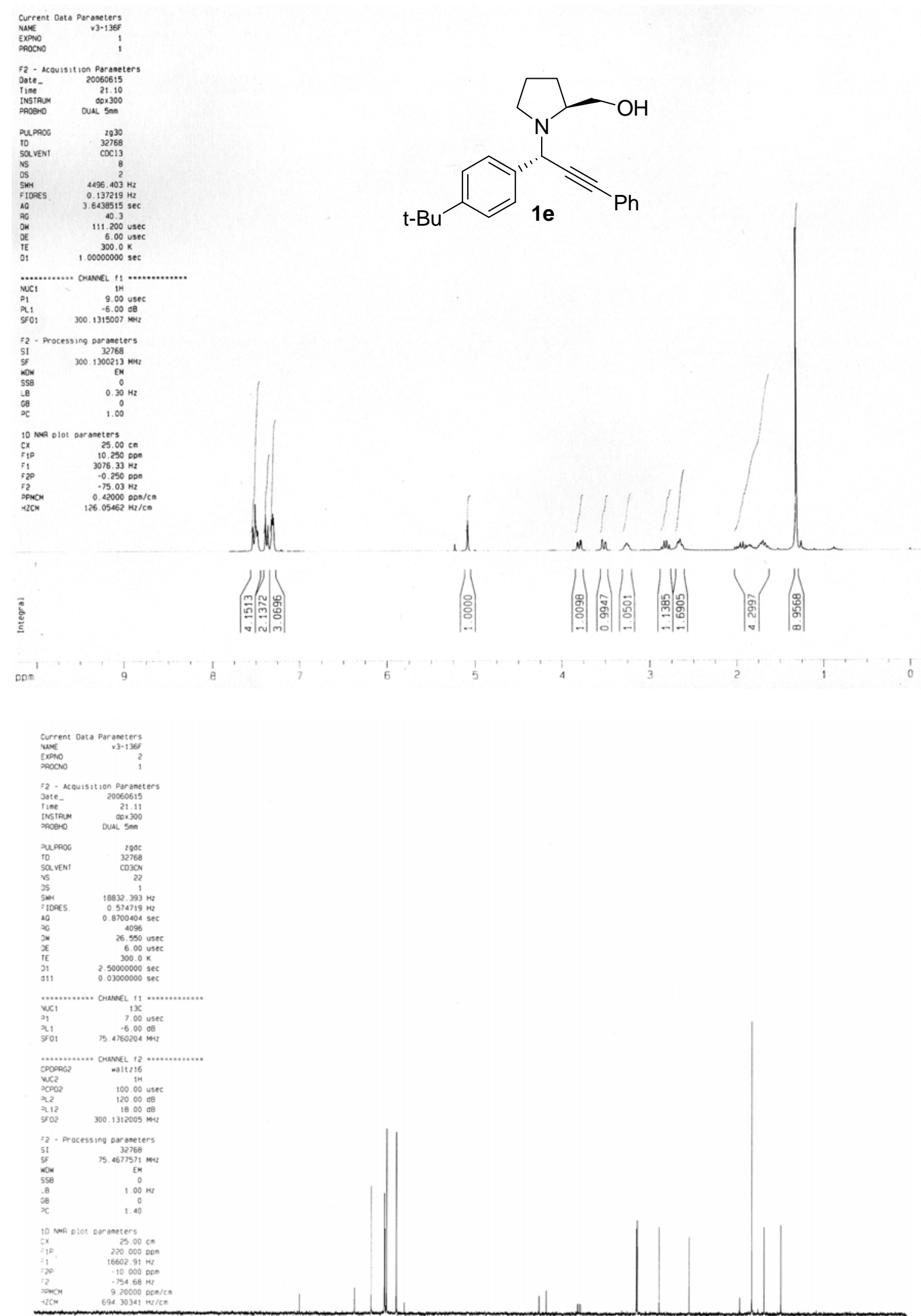


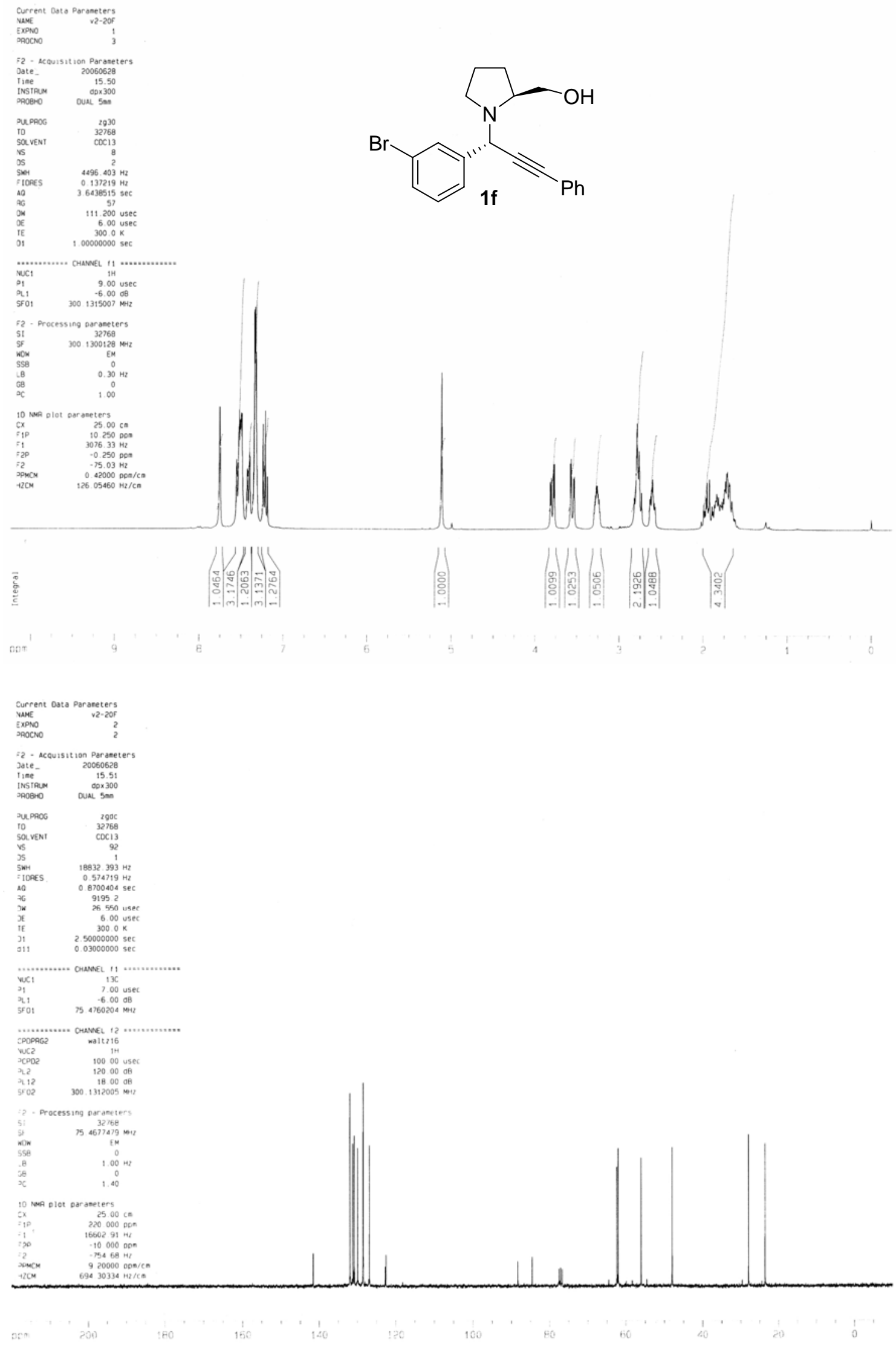




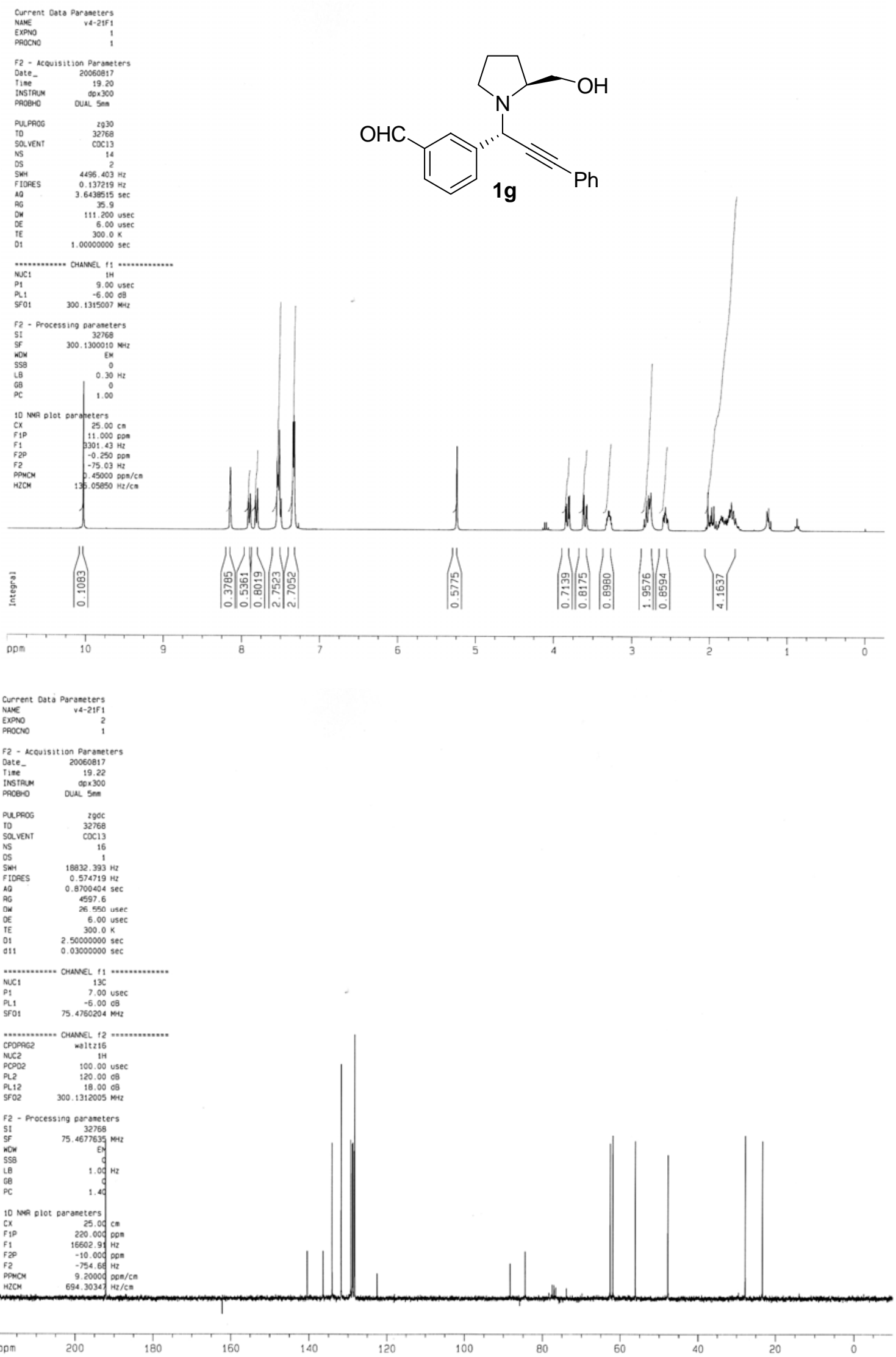




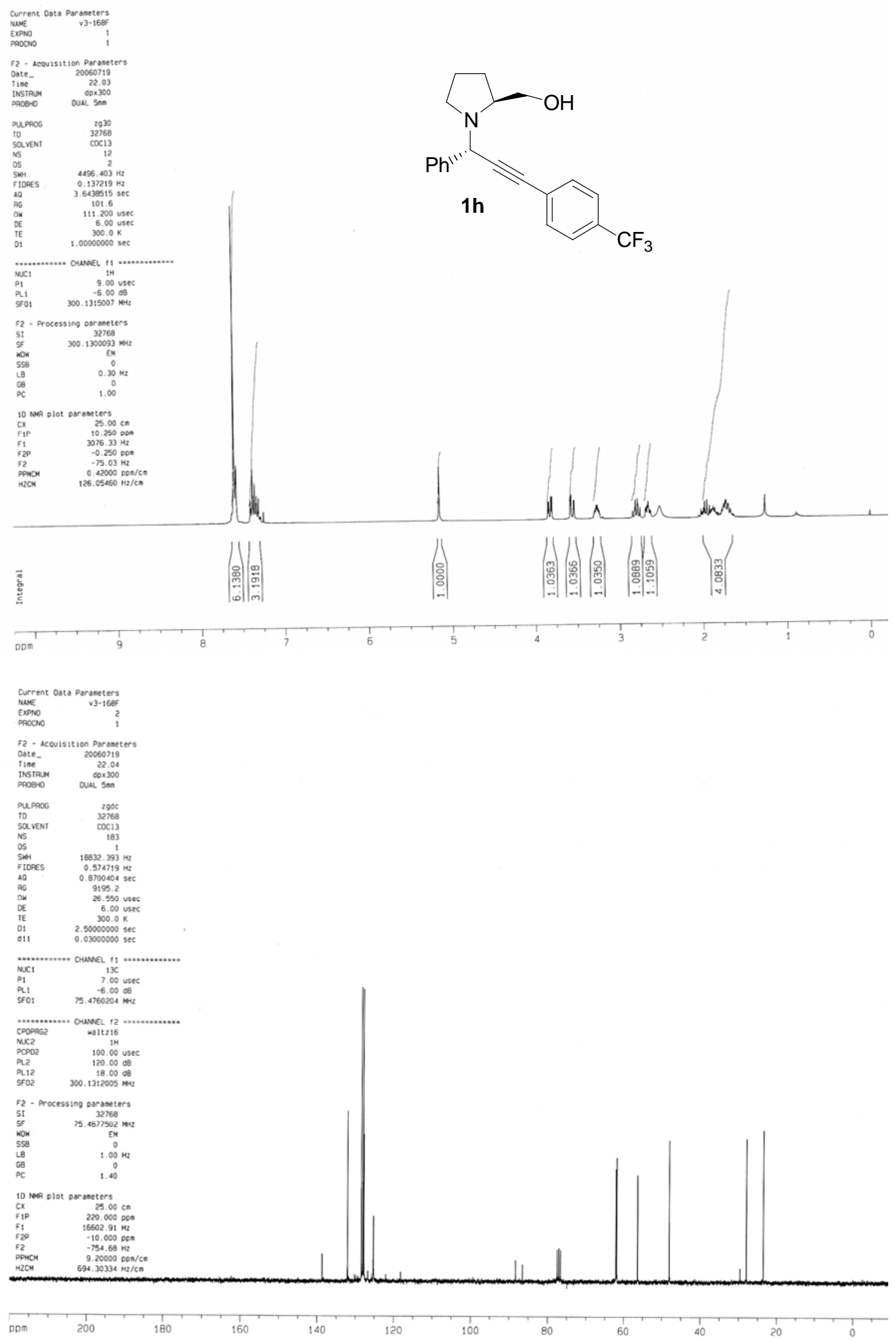



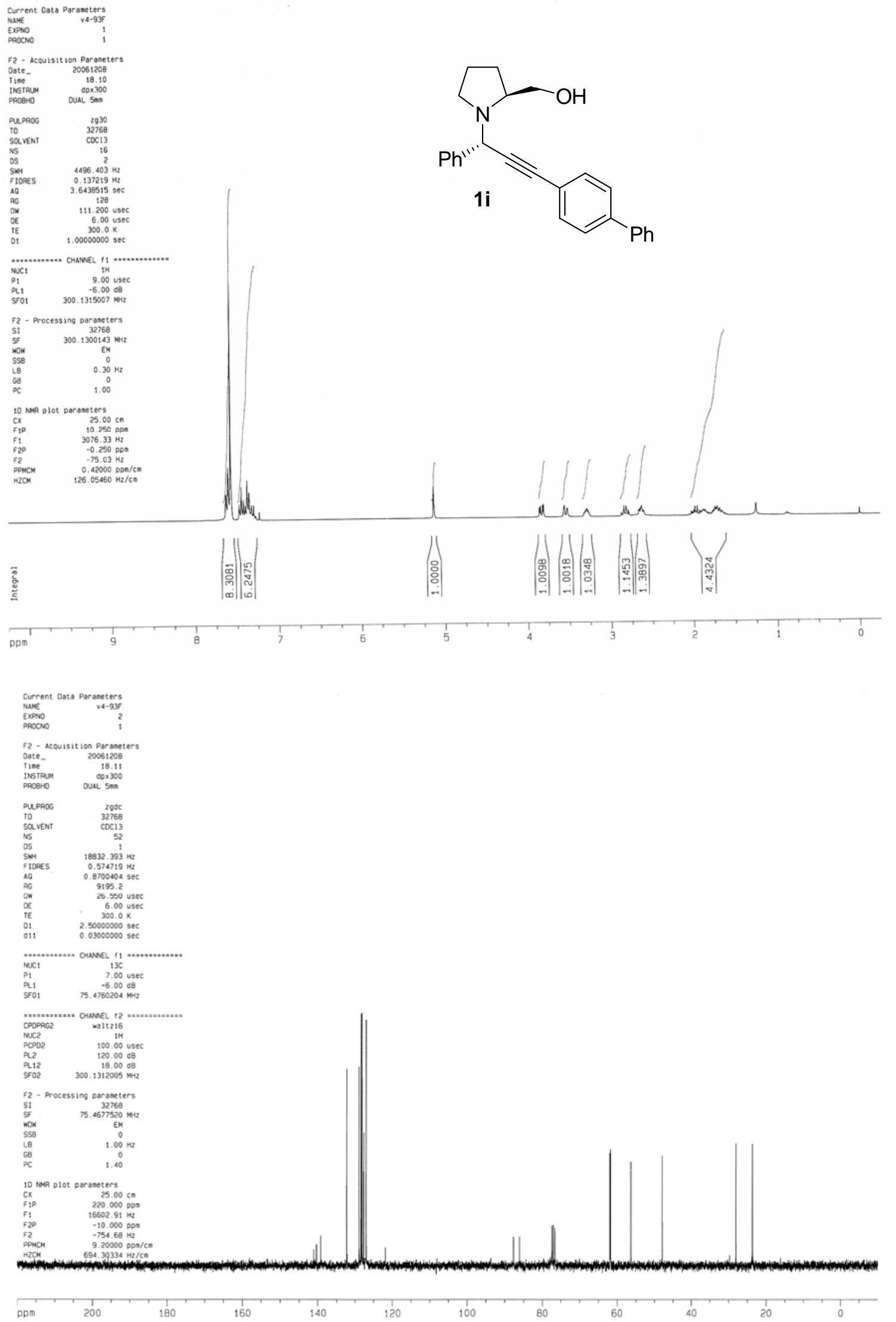

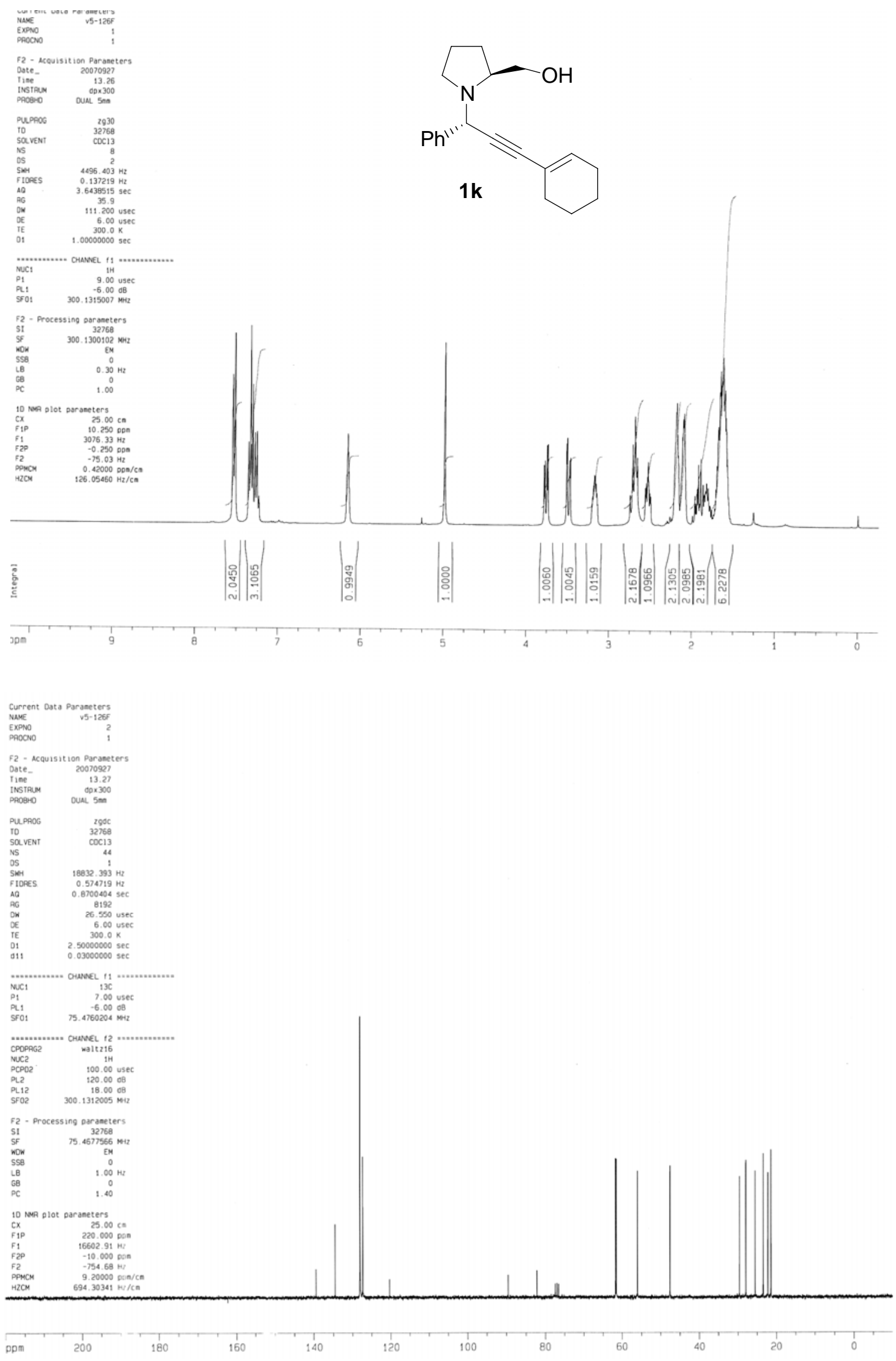

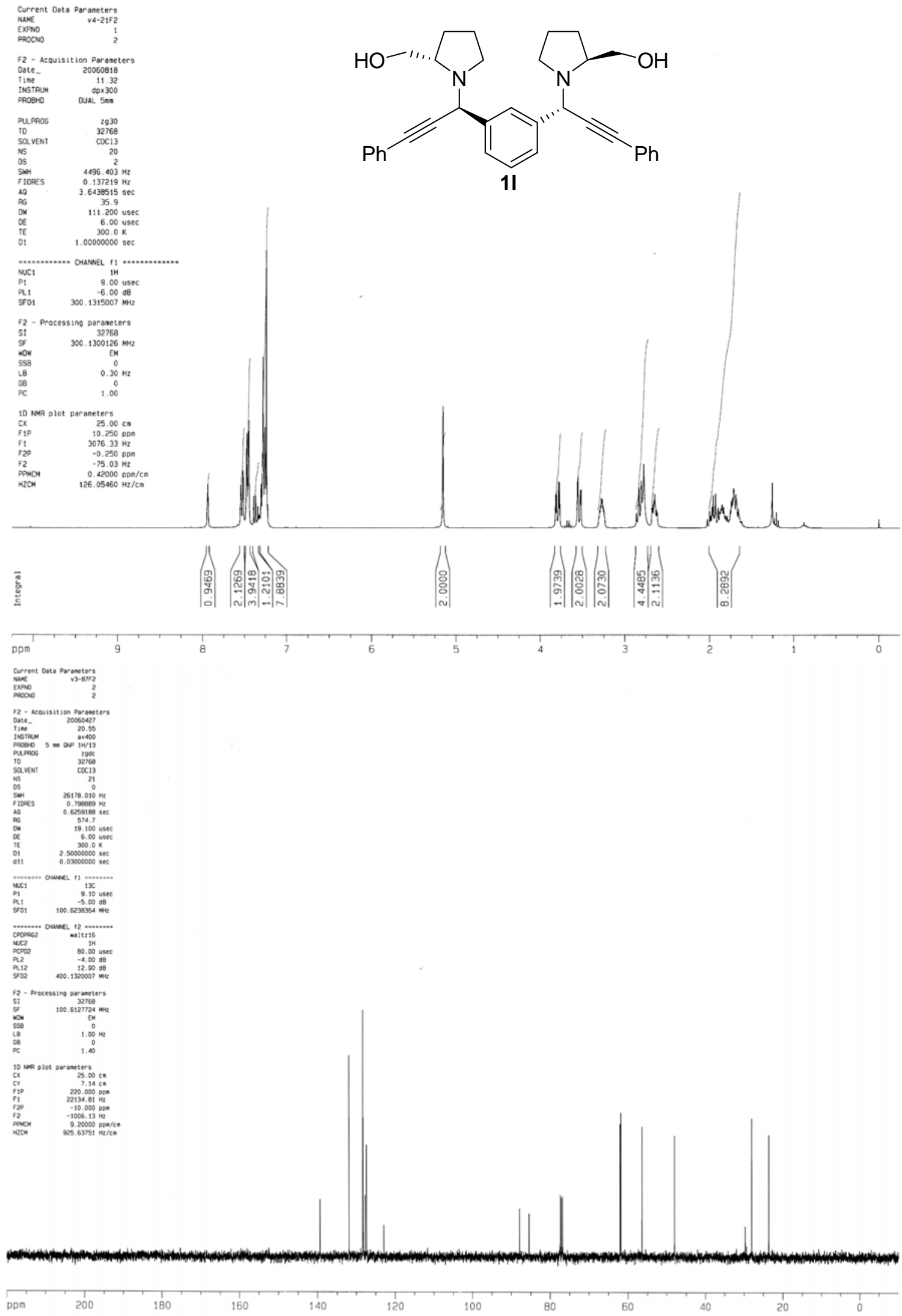


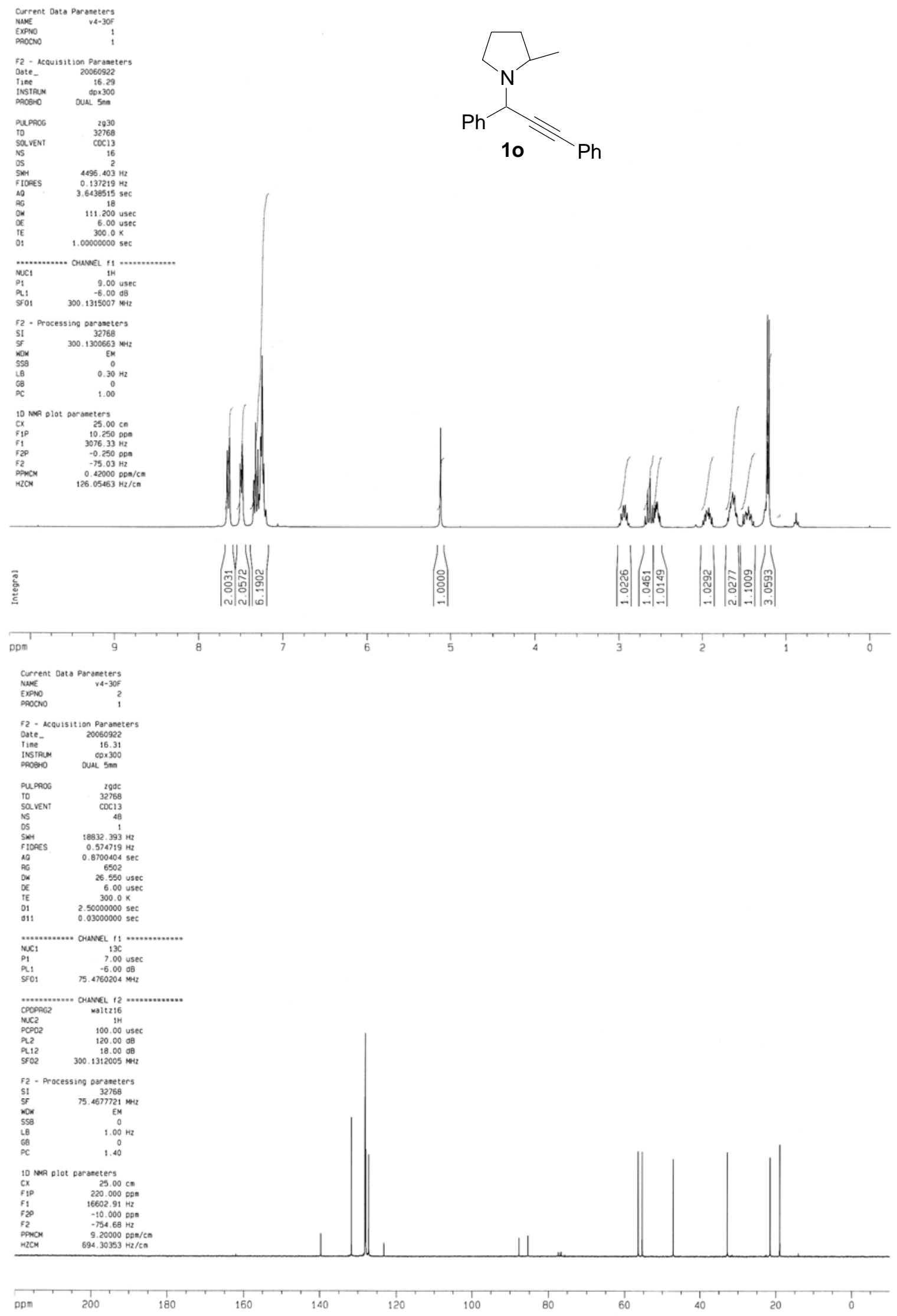



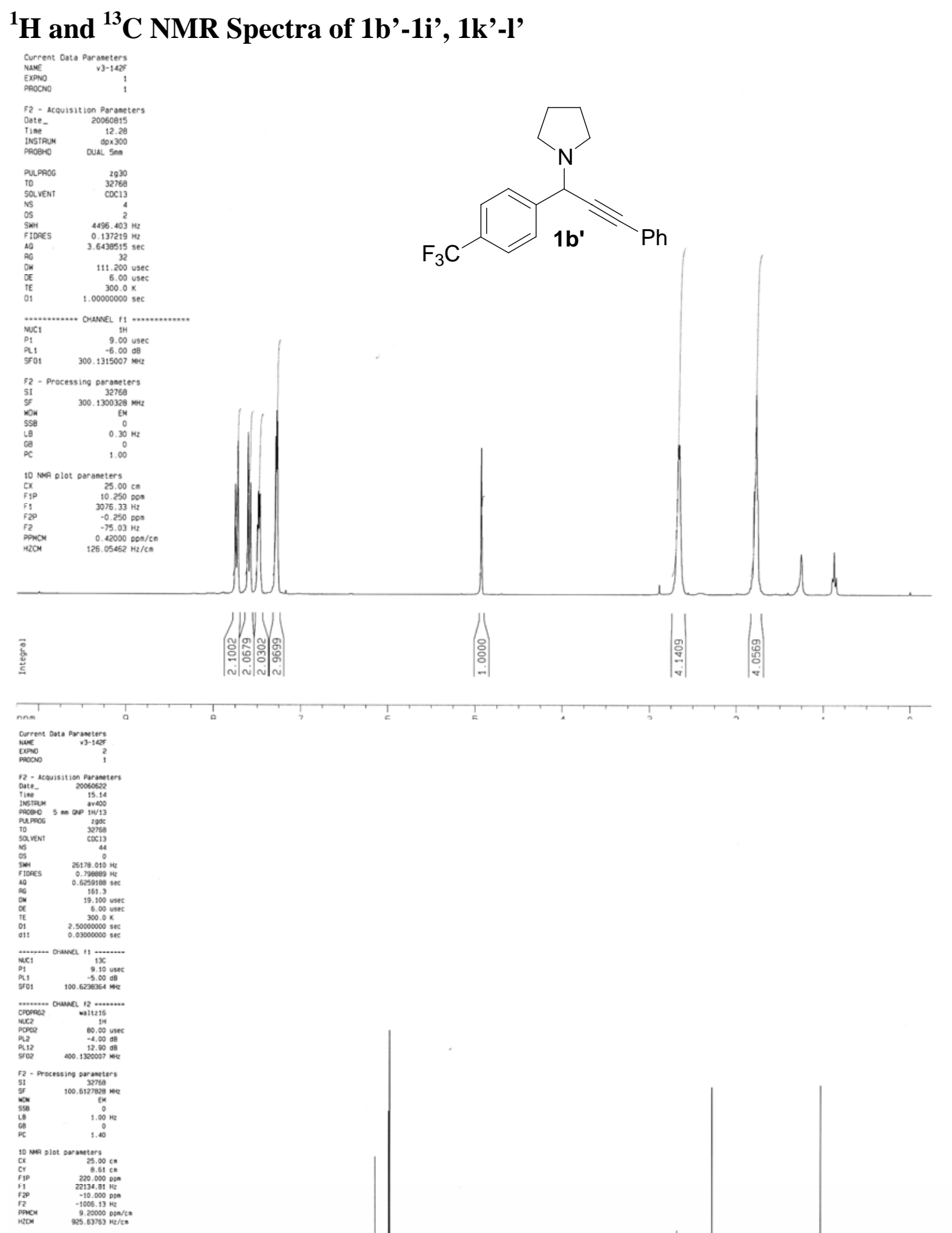


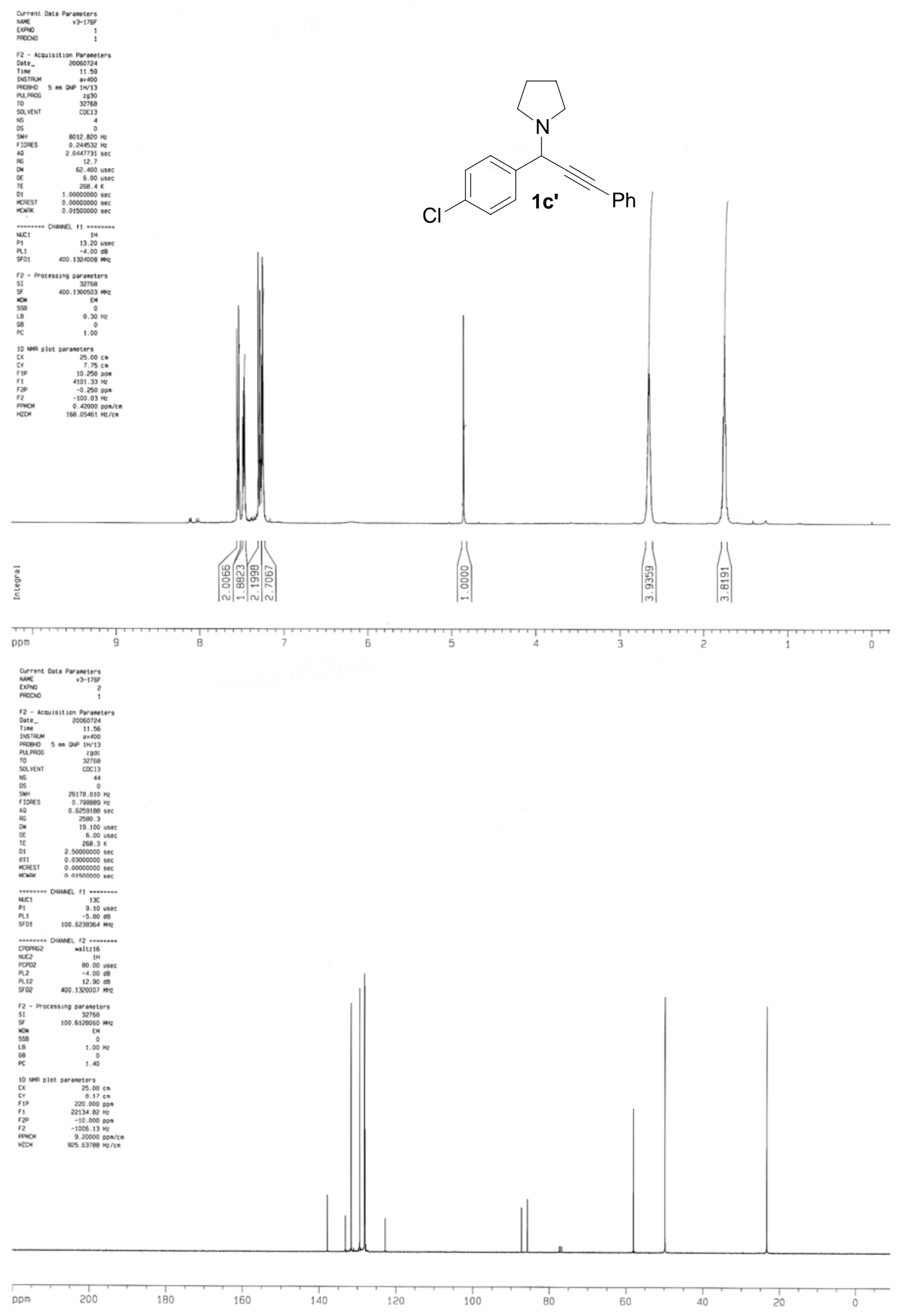




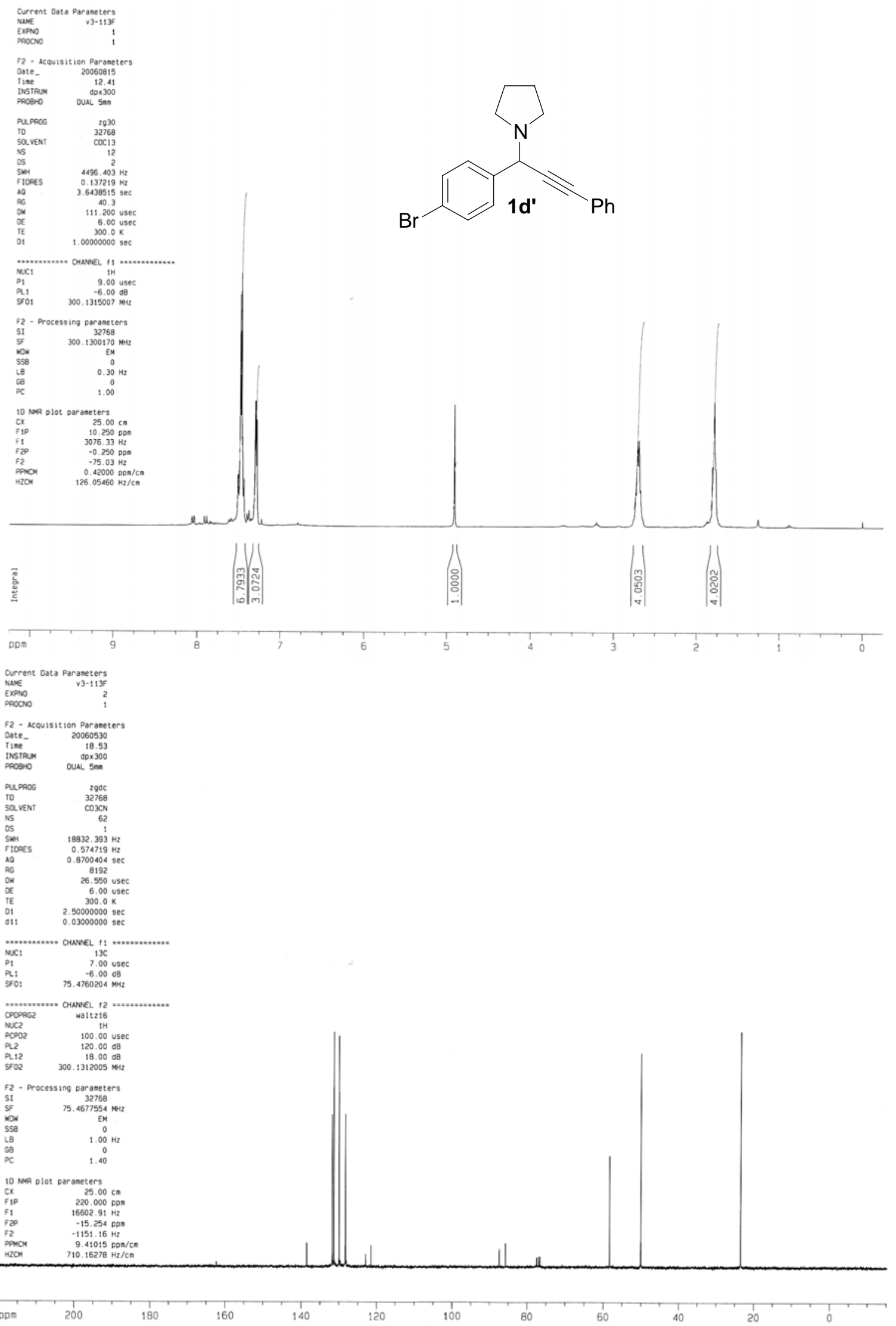




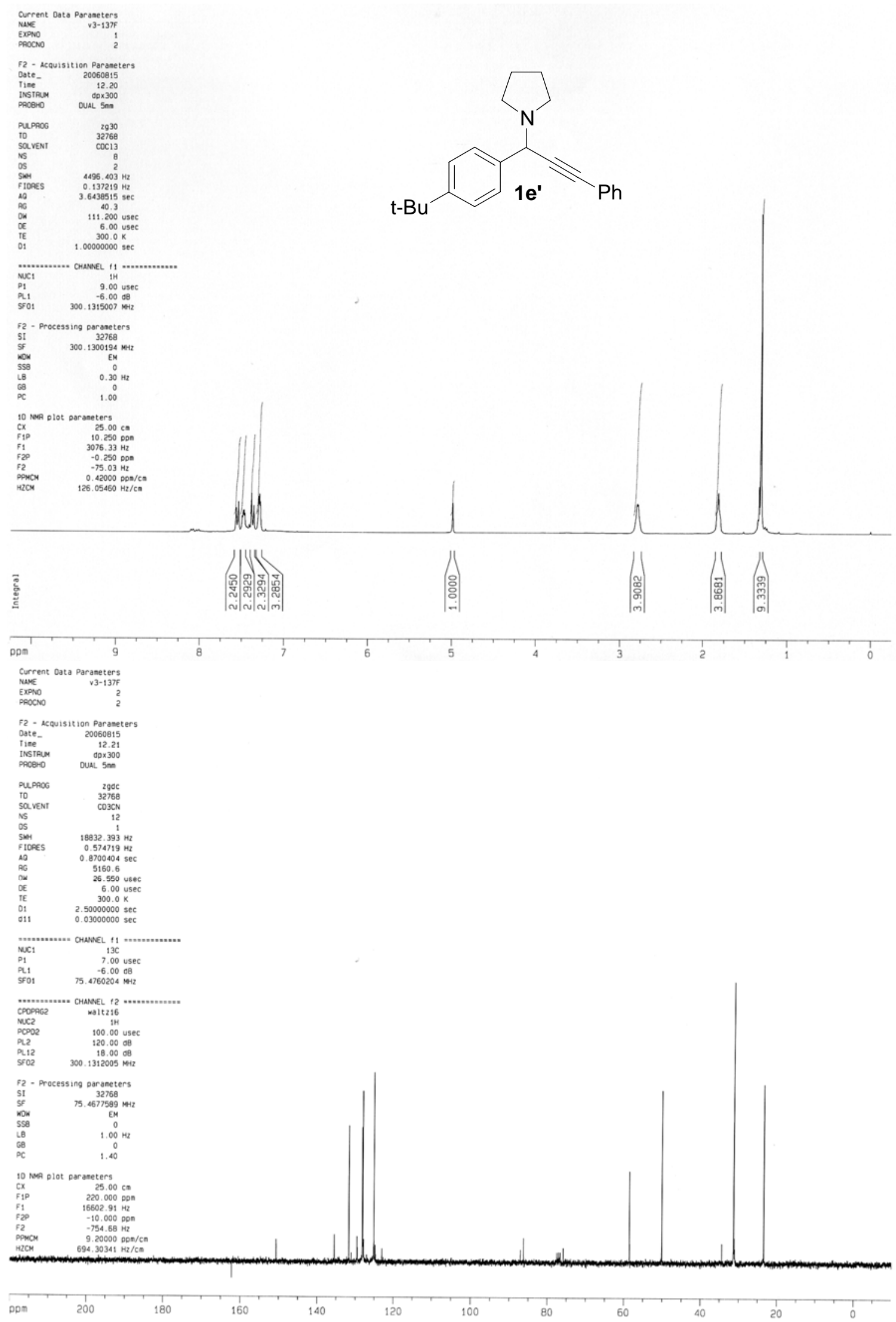




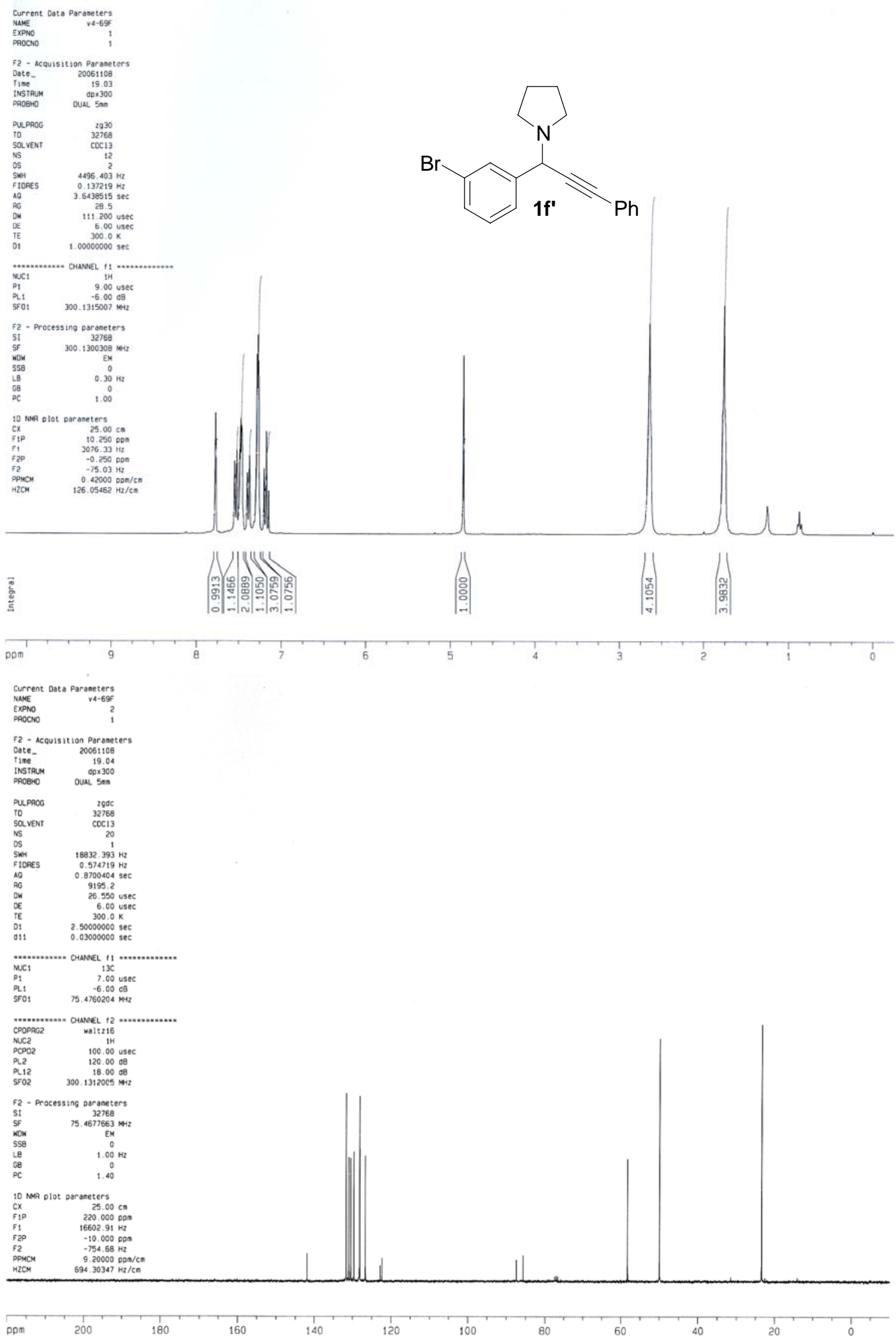



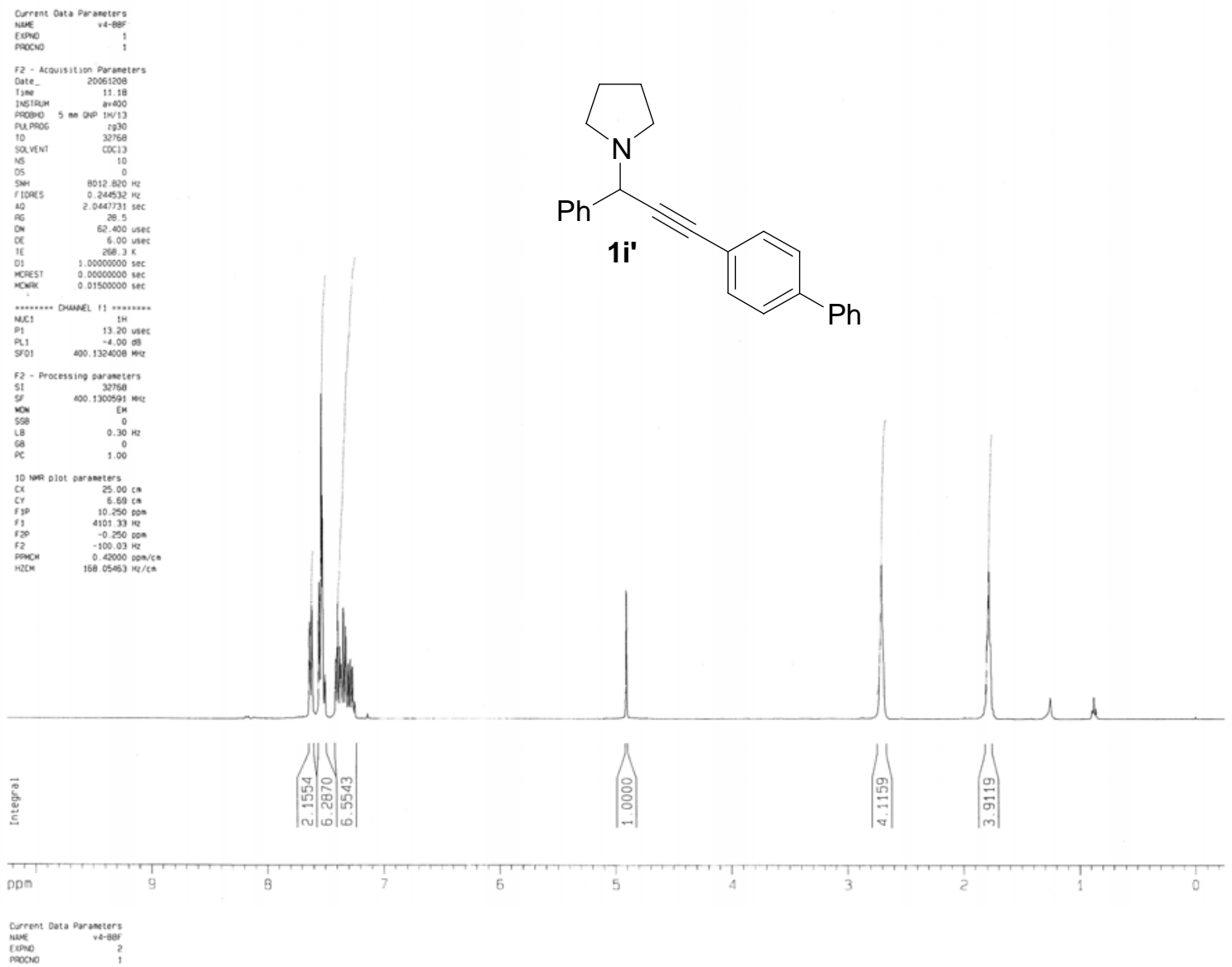

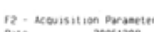

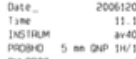

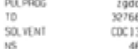

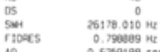

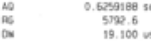

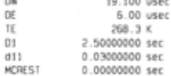

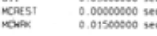

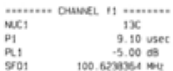

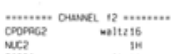

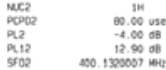

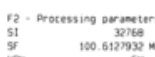

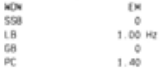

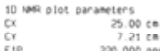

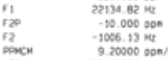

(1)

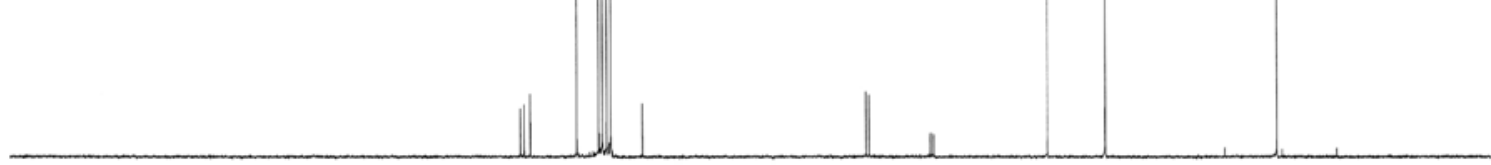

160

140

120

100

60 


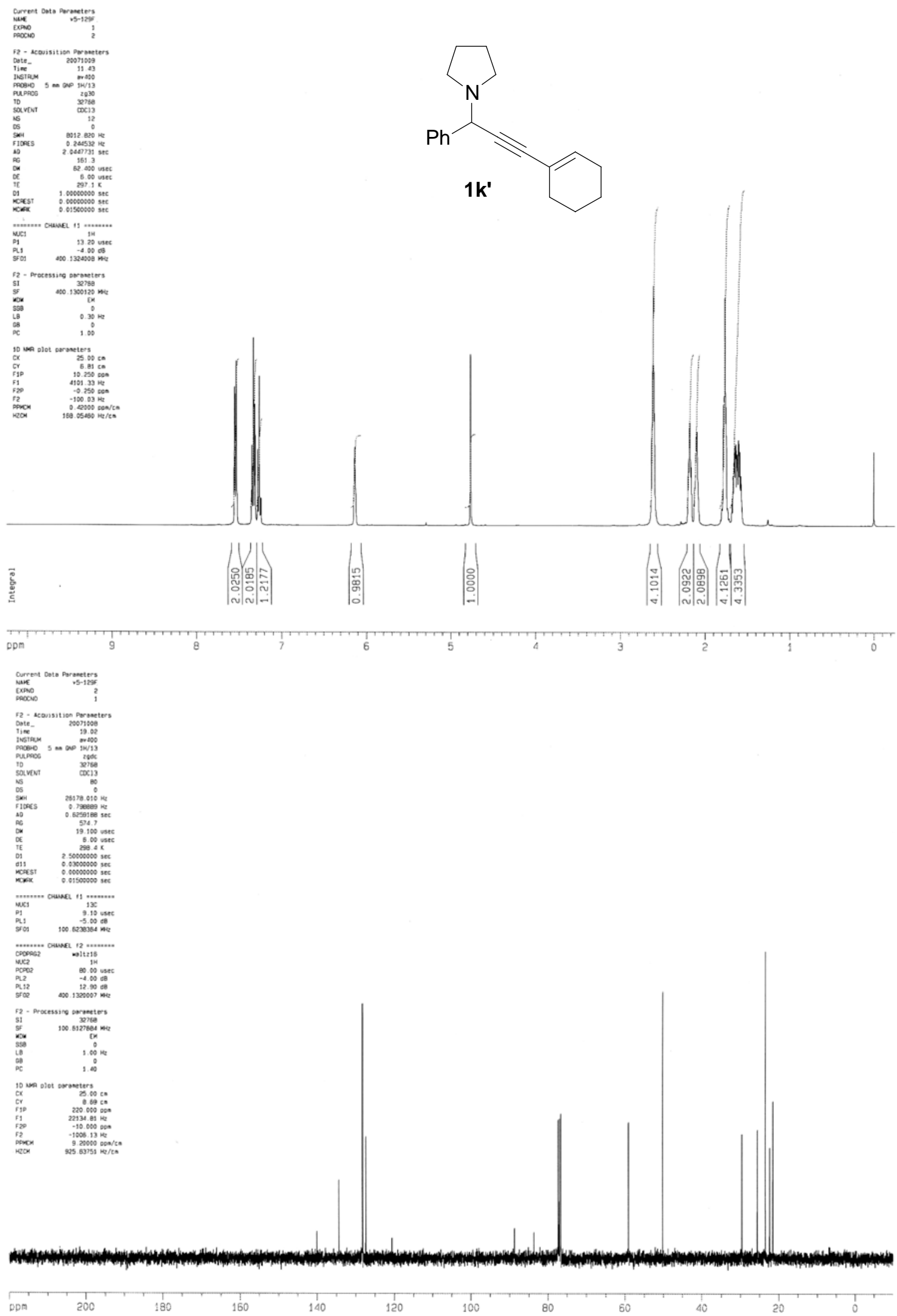




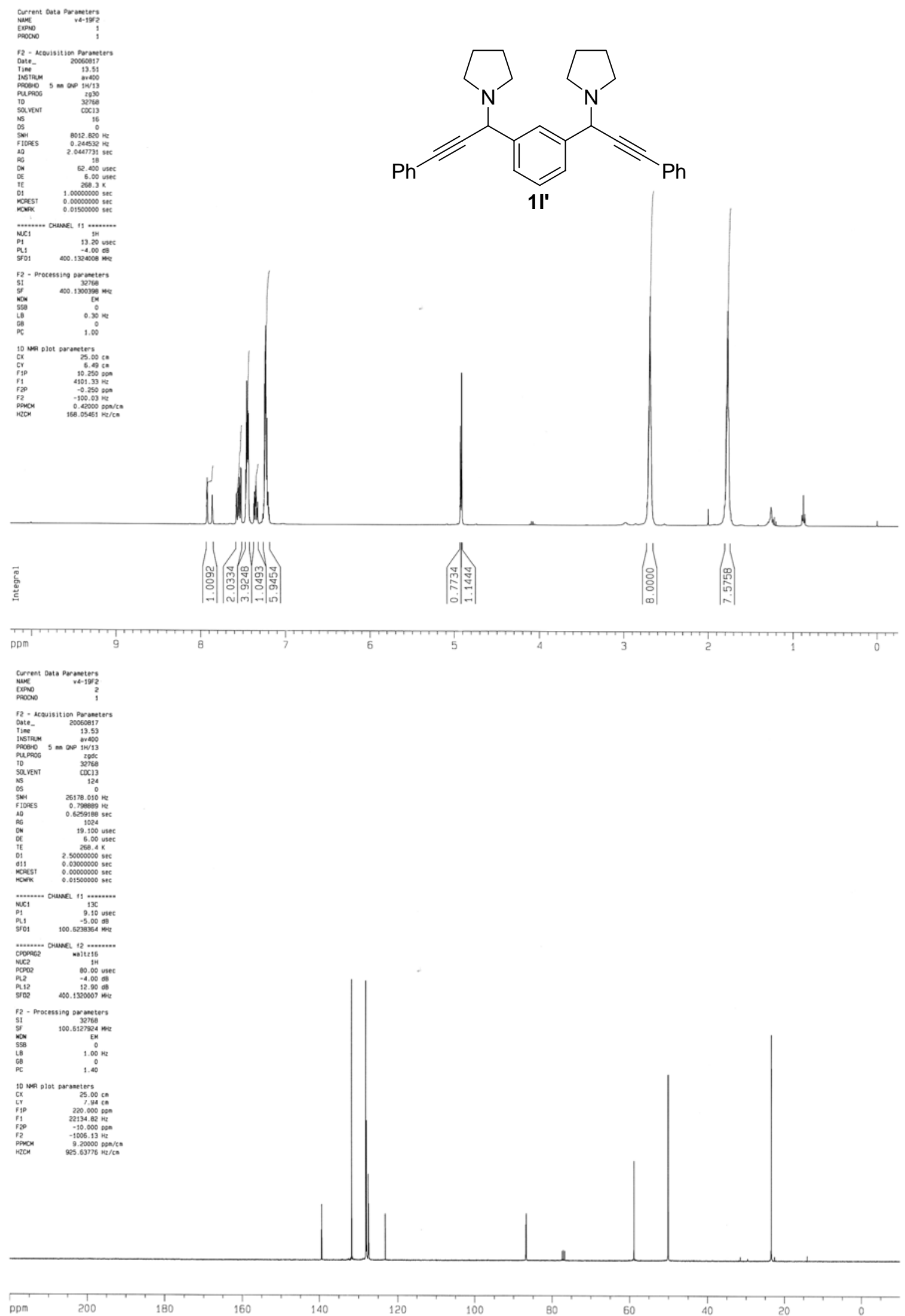




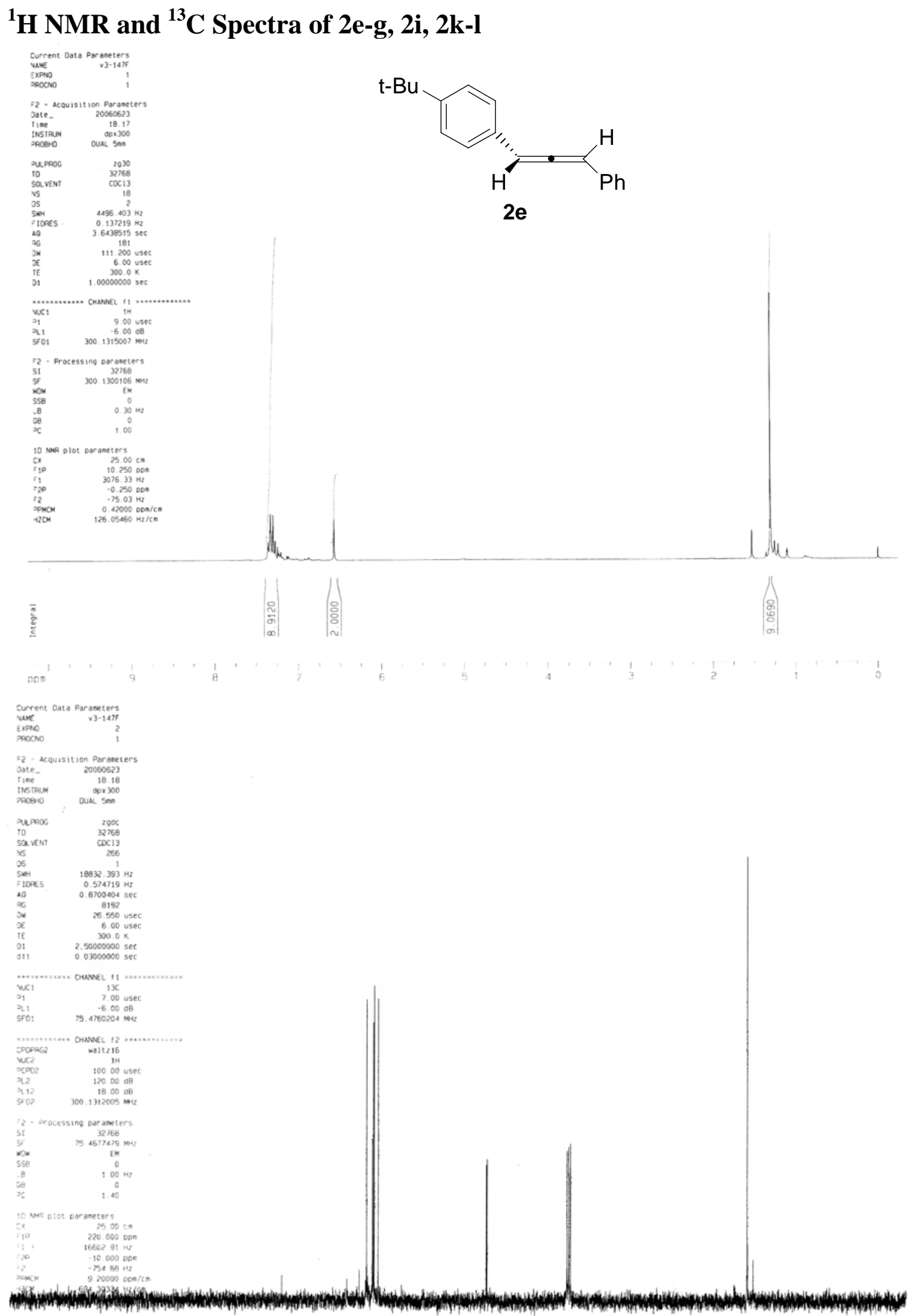




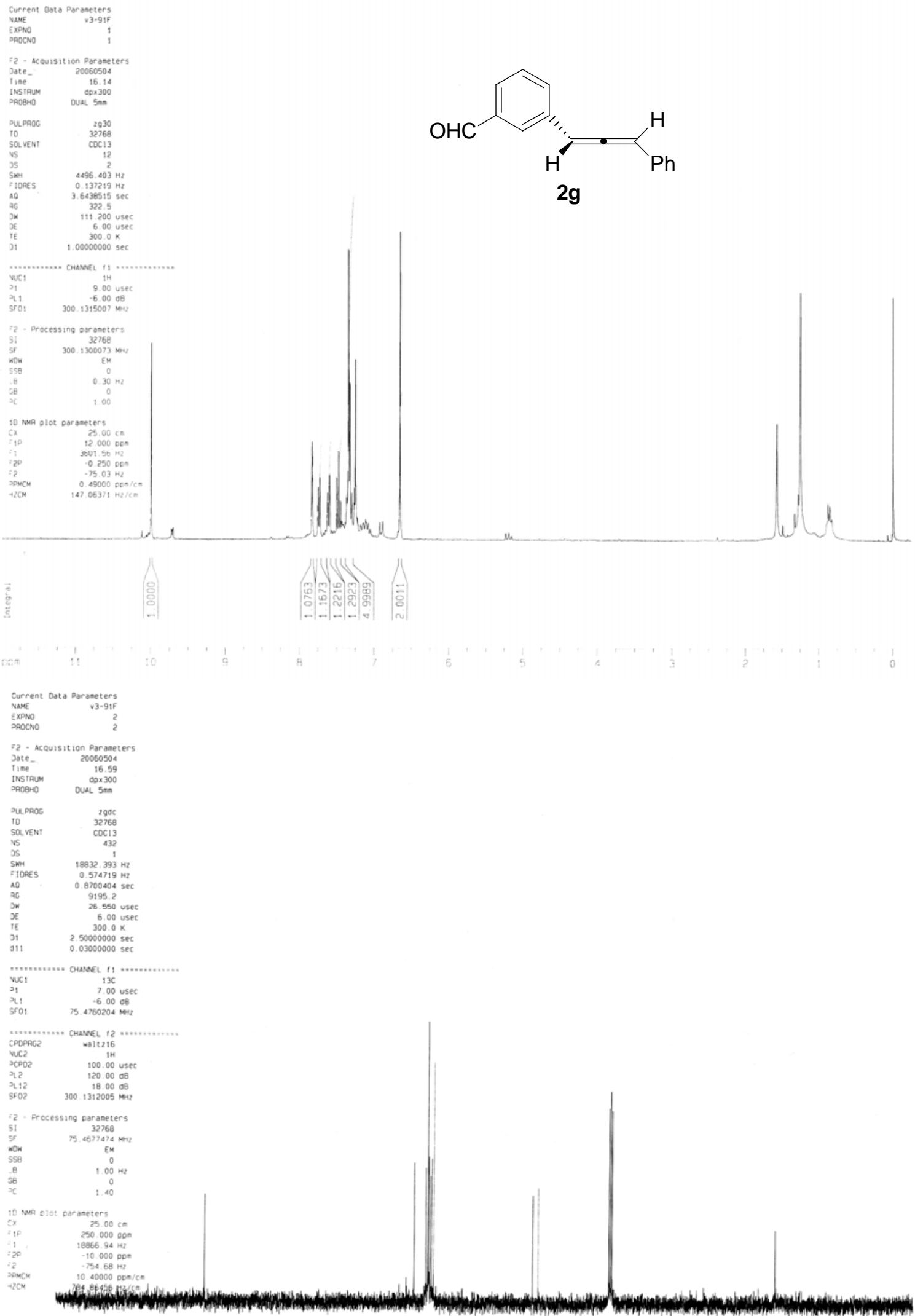
ann $22^{6}$ 


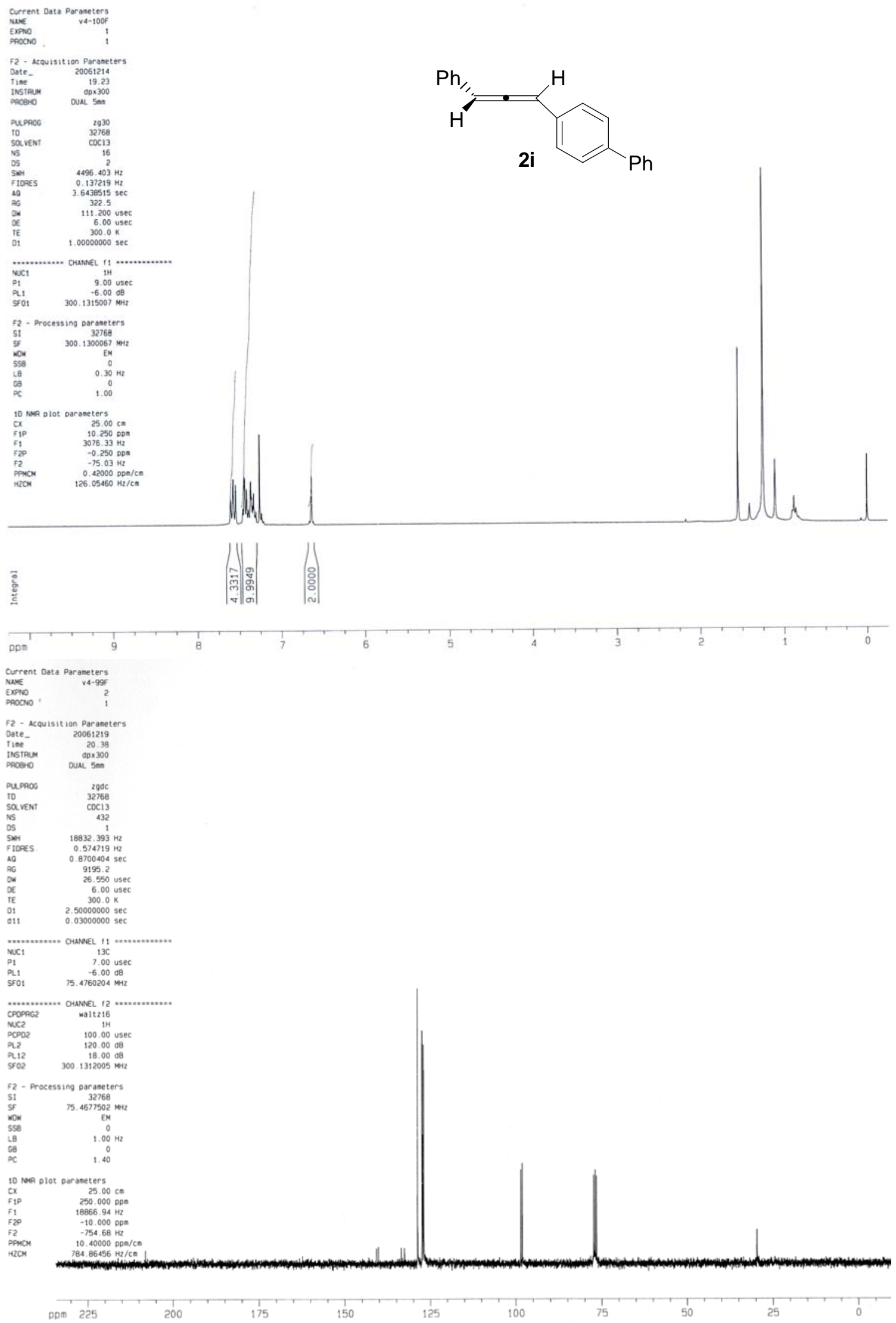



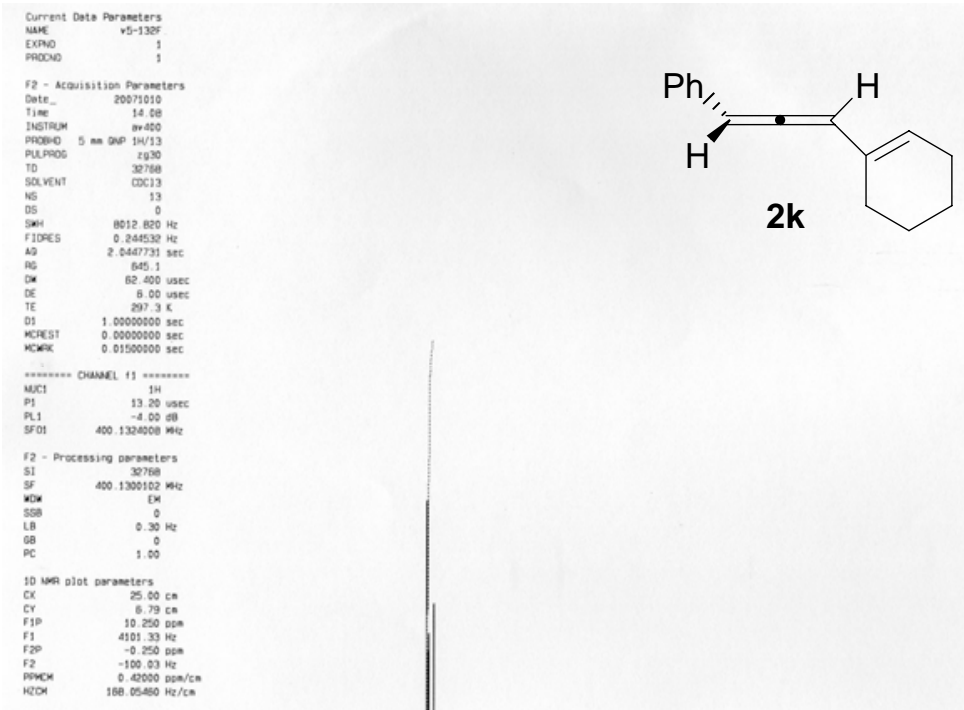

ฐัّ

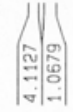

$\left|\begin{array}{c|c|}\mid & \mid \\ 0 \\ 0 \\ 0 \\ 0\end{array}\right| \begin{gathered}\mid \\ 0 \\ 0\end{gathered} \mid$

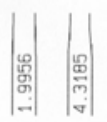
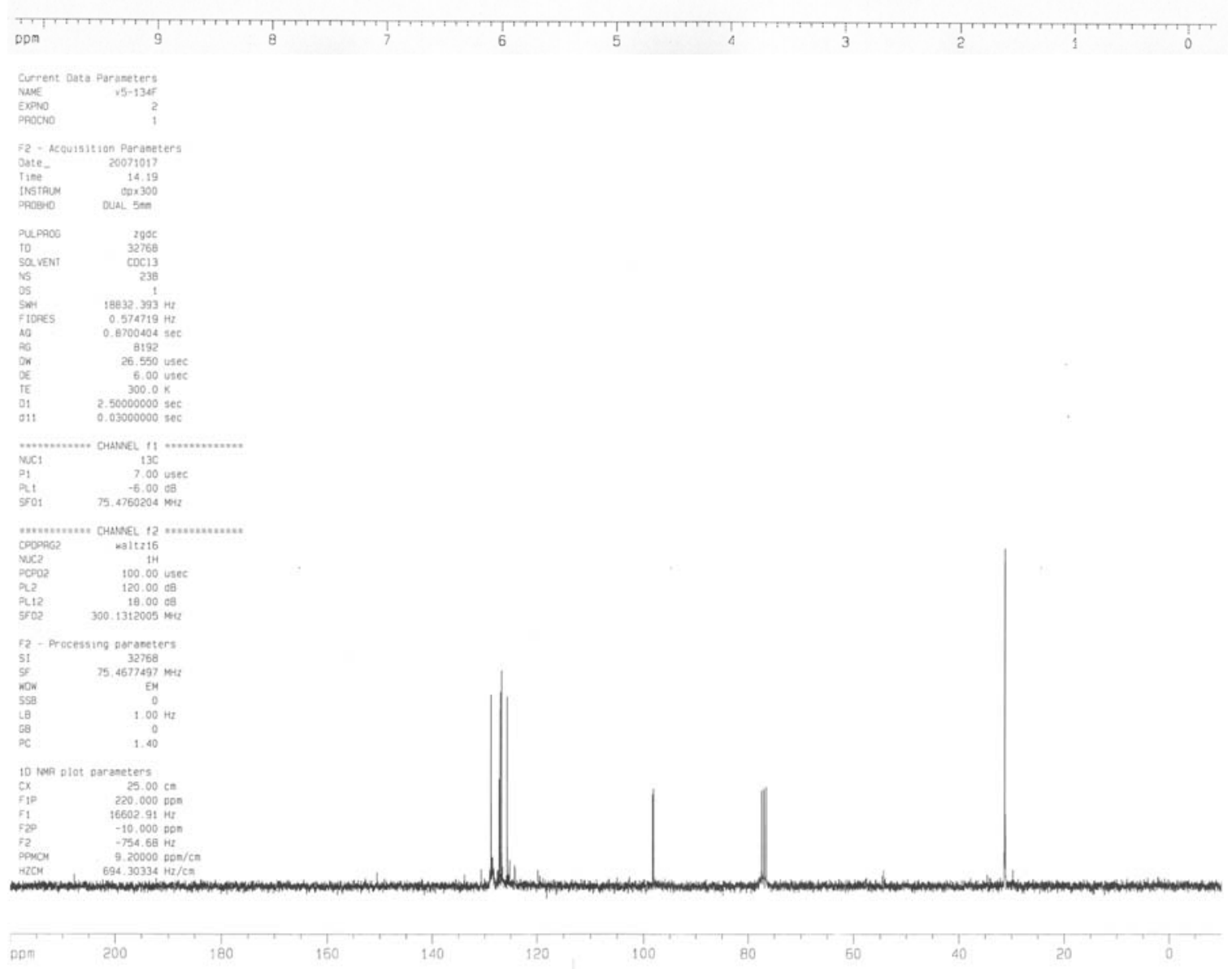

S70 

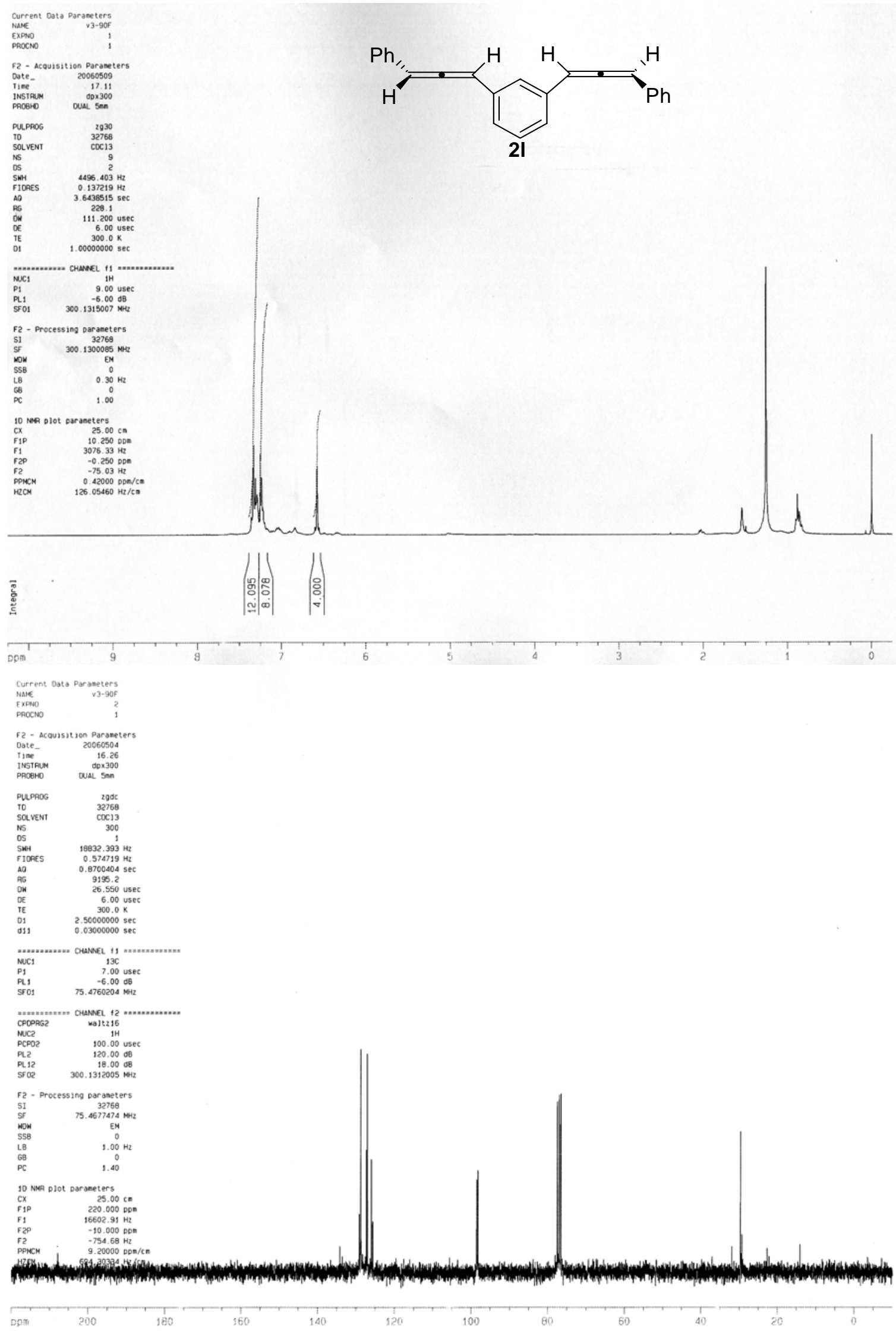


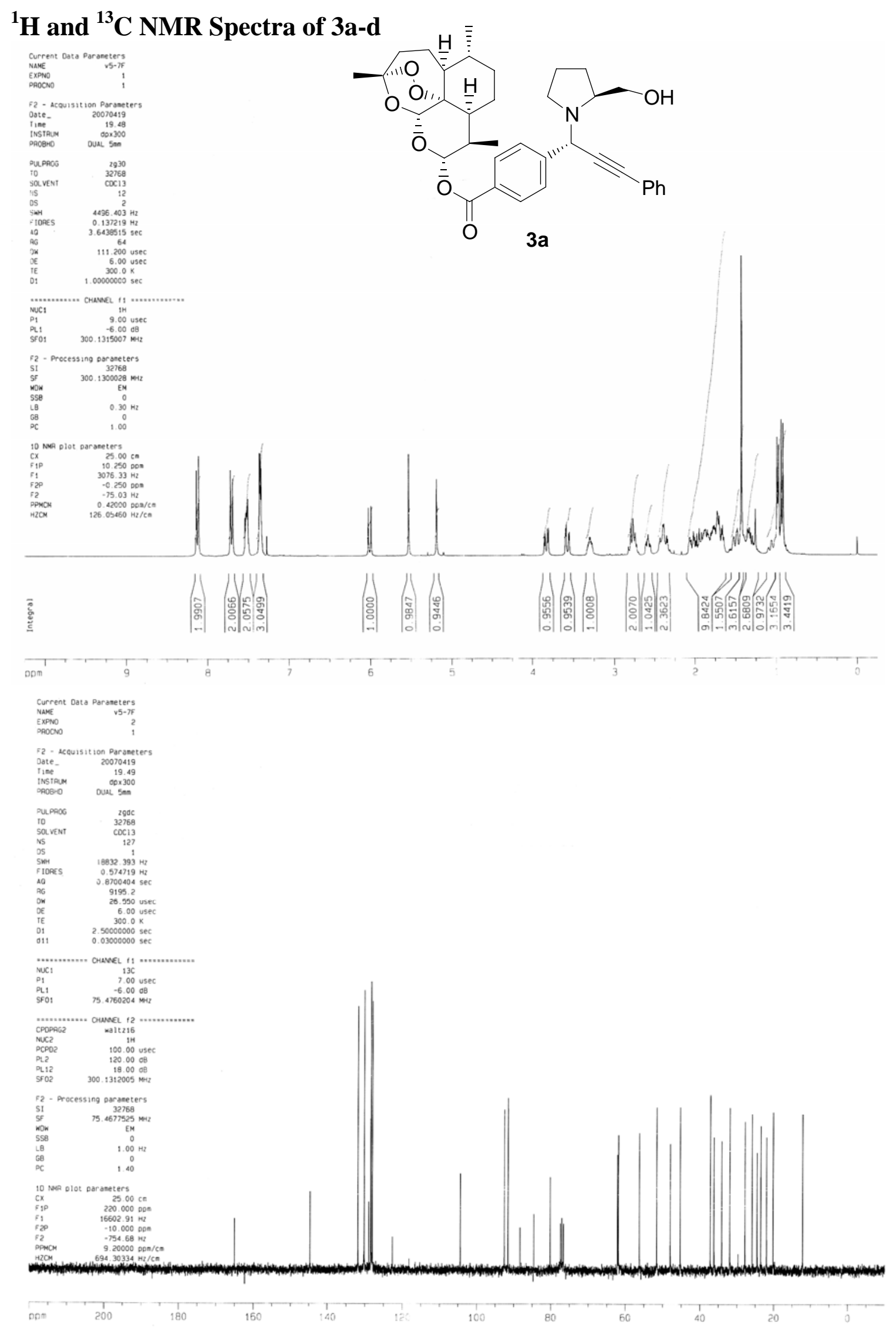




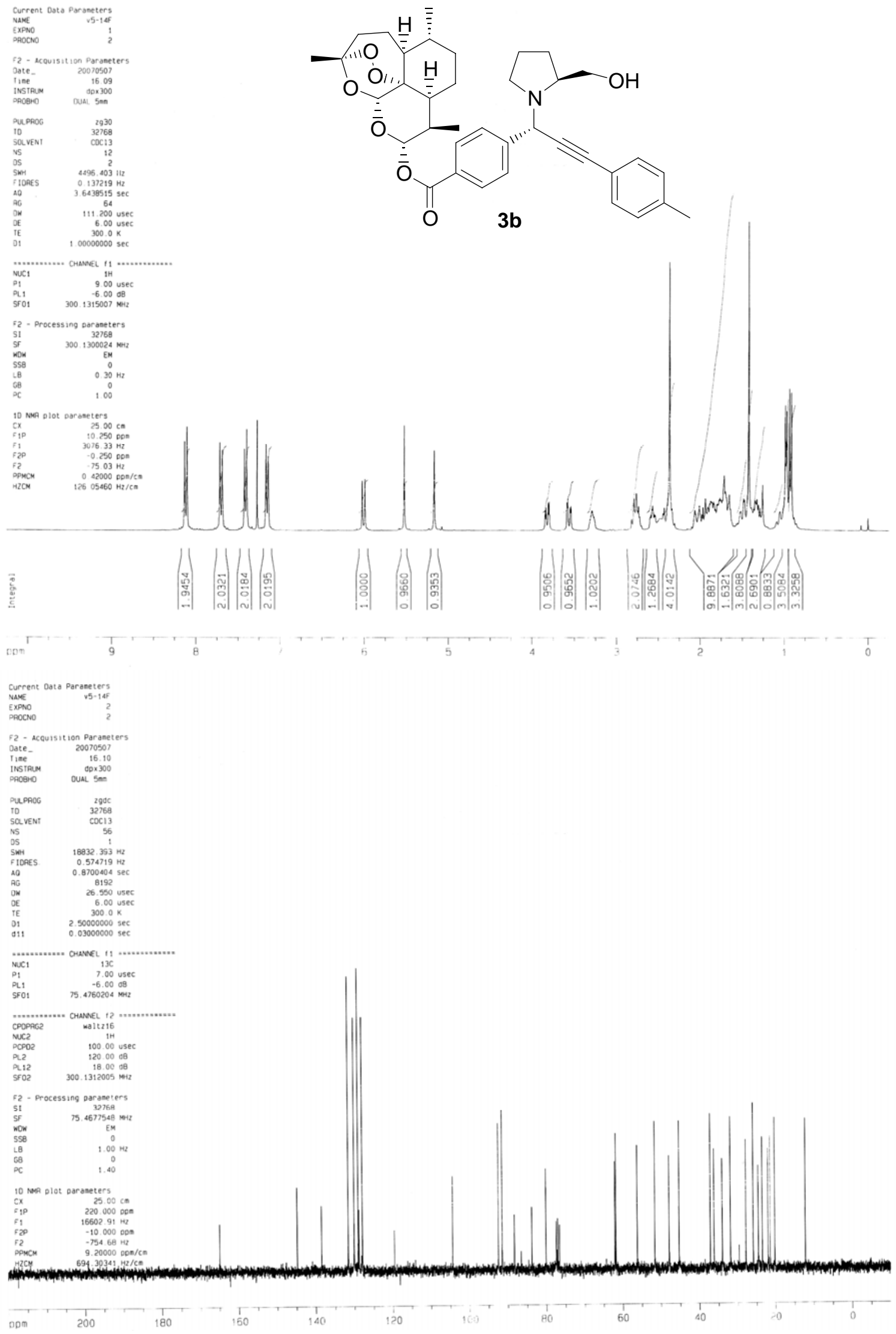

S73 

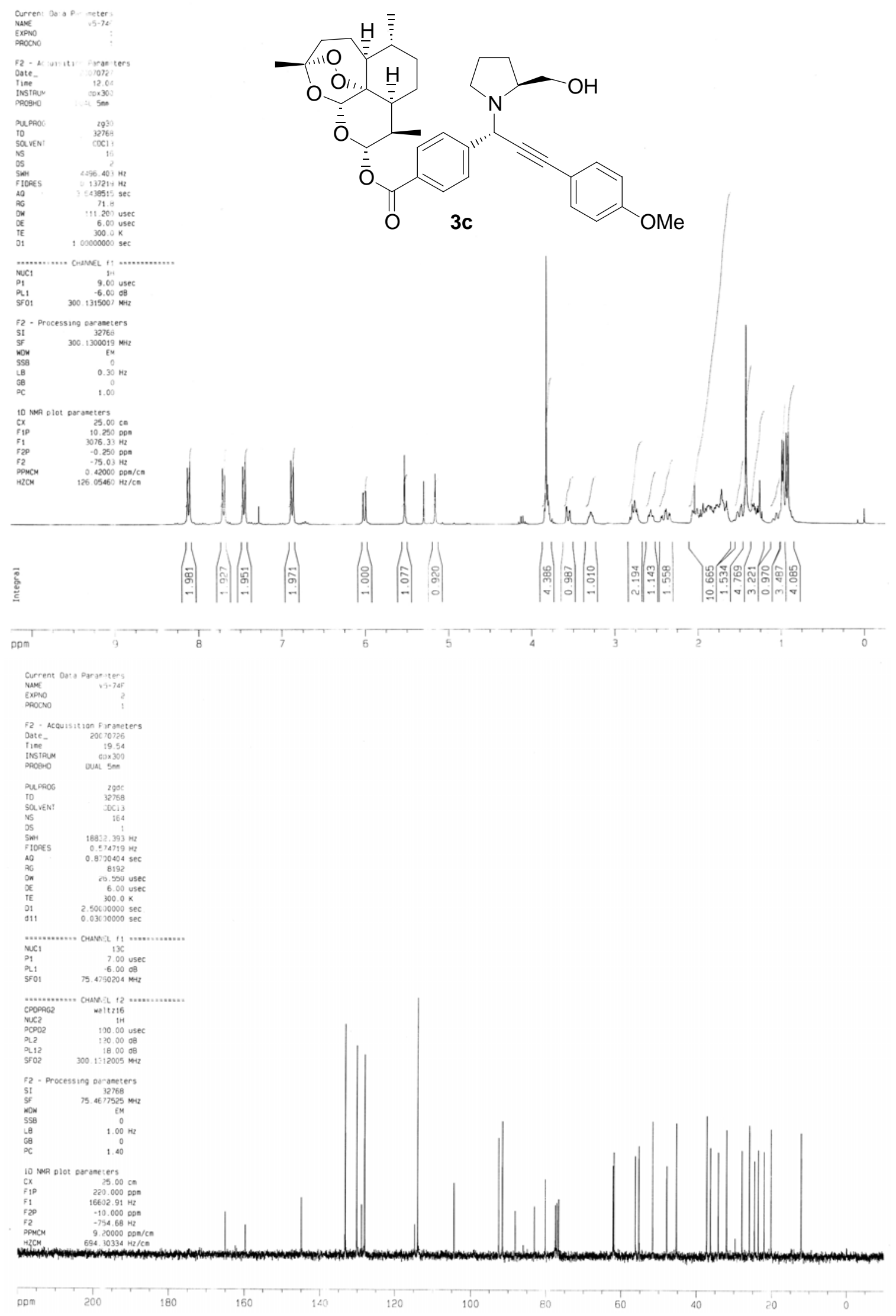

S74 


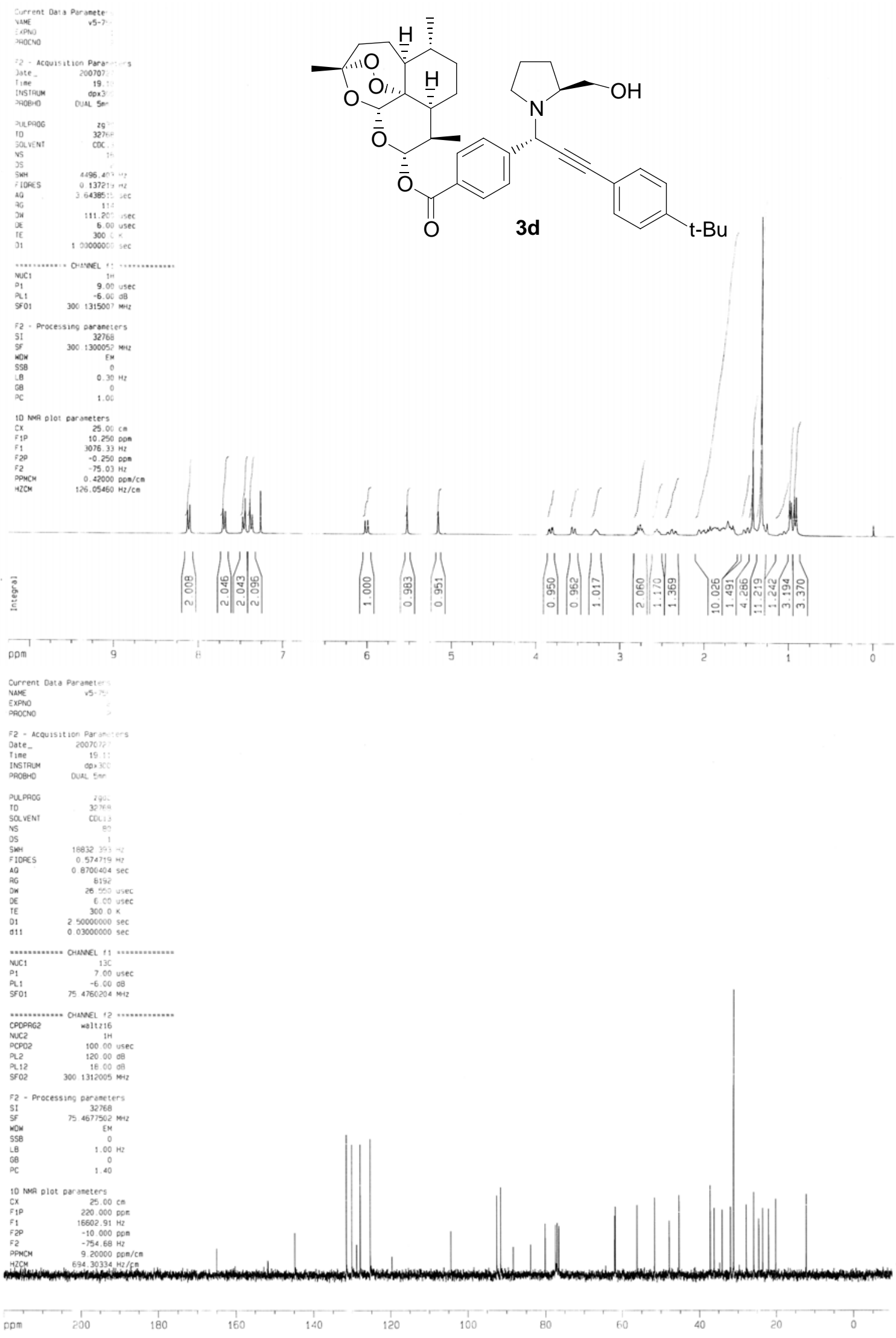




\section{${ }^{1} \mathrm{H}$ and ${ }^{13} \mathrm{C}$ NMR Spectra of 4a-d}
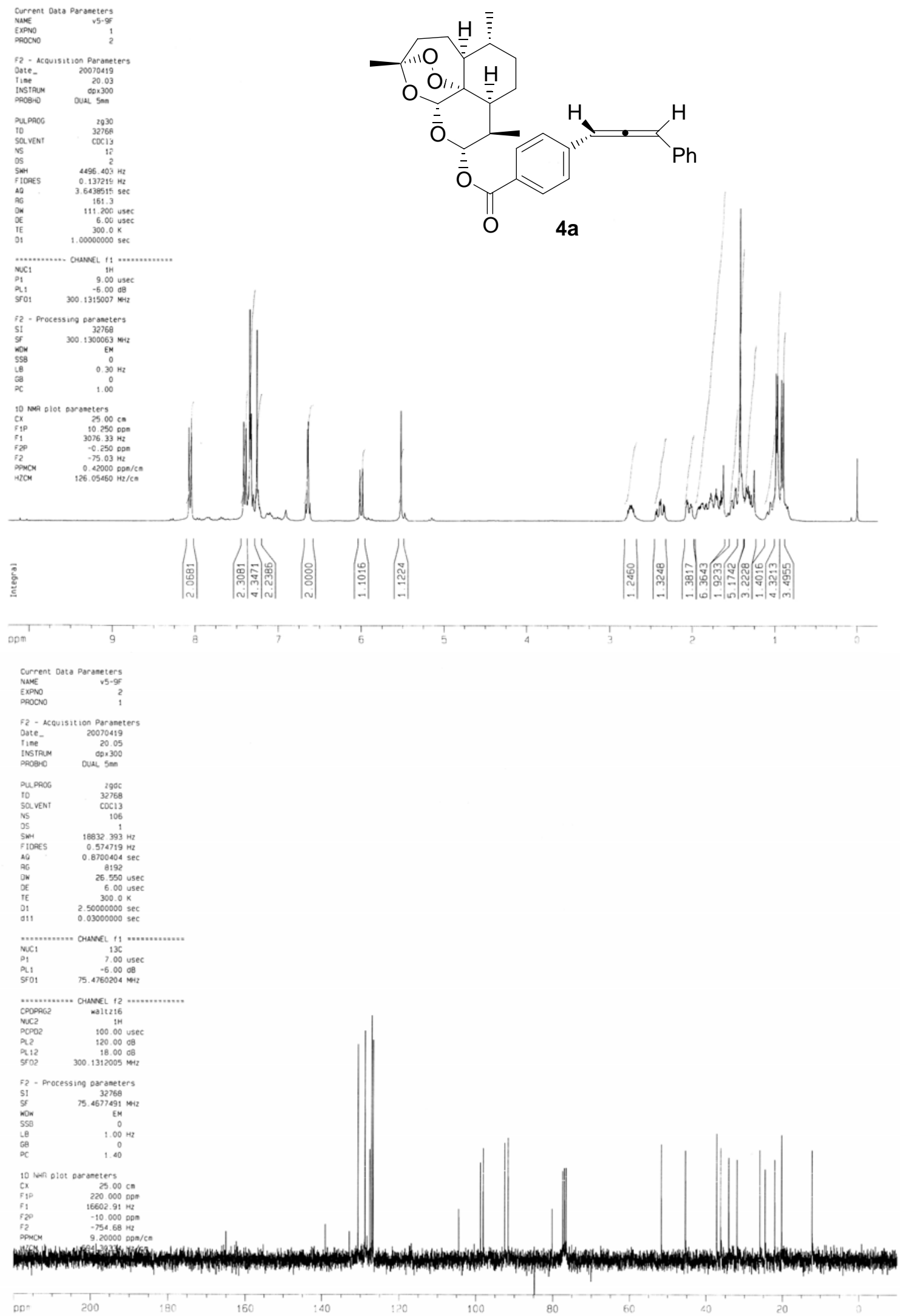

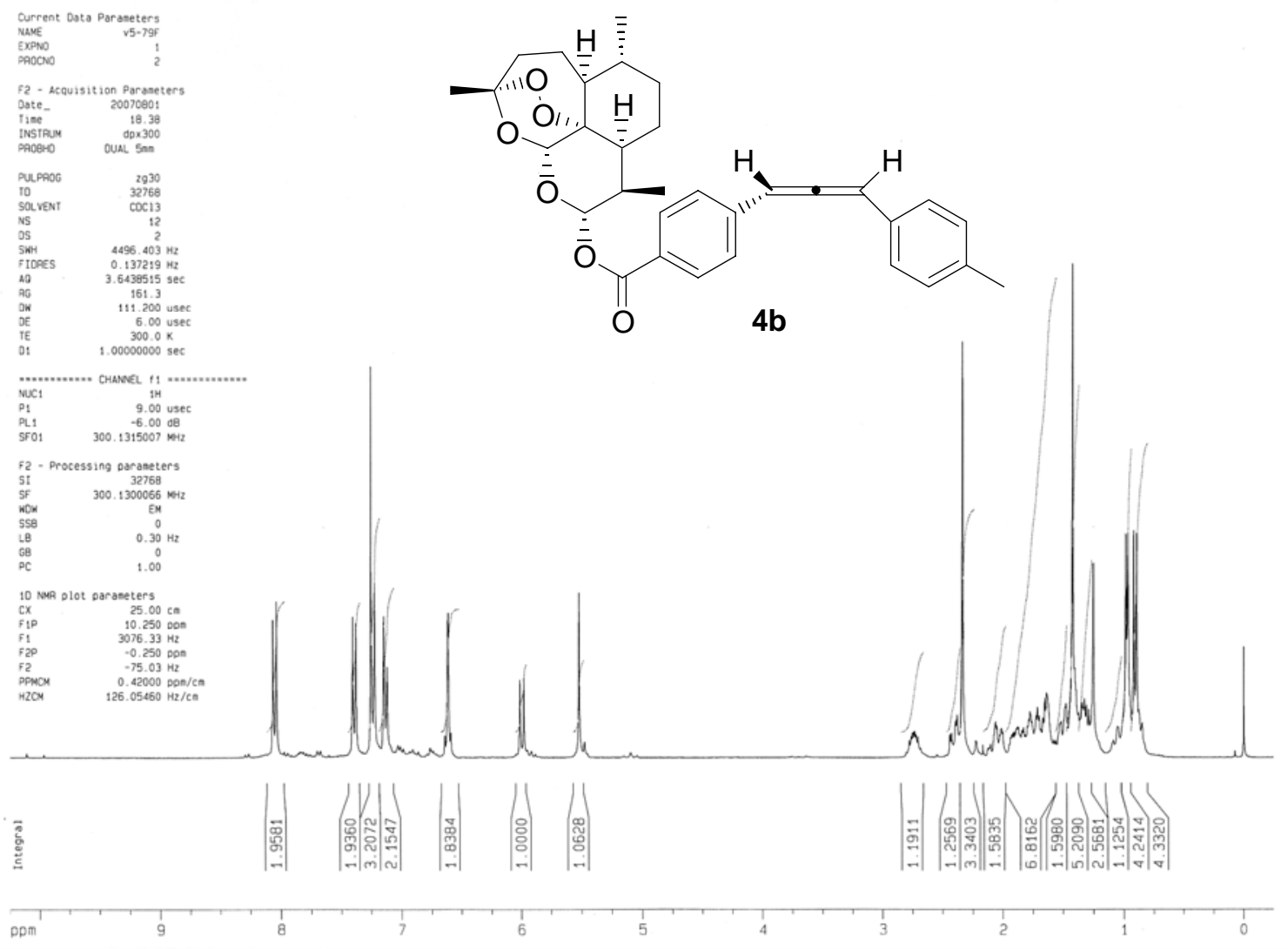

Current Data Paraneters
ruvE
EXPNO
PAOCNO

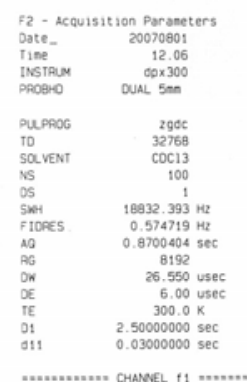

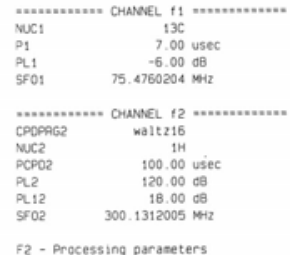

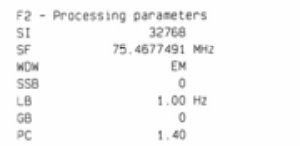

10 Naf olot paraneters

$\begin{array}{lr}C X & 25.00 \mathrm{~cm} \\ F 1 P & 220.000 \mathrm{pon} \\ F 1 & 16602.91 \mathrm{~Hz} \\ F 1 & -100000000\end{array}$

$\begin{array}{ll}F 2 P & -10.000 \mathrm{pDm} \\ F 2 & -754.68 \mathrm{~Hz} \\ \text { PPMOK } & 9.20000 \mathrm{pon}\end{array}$

Wiper.

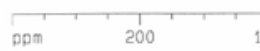

180

160

${ }_{140}^{1}$

${ }_{100}^{1}$

60 

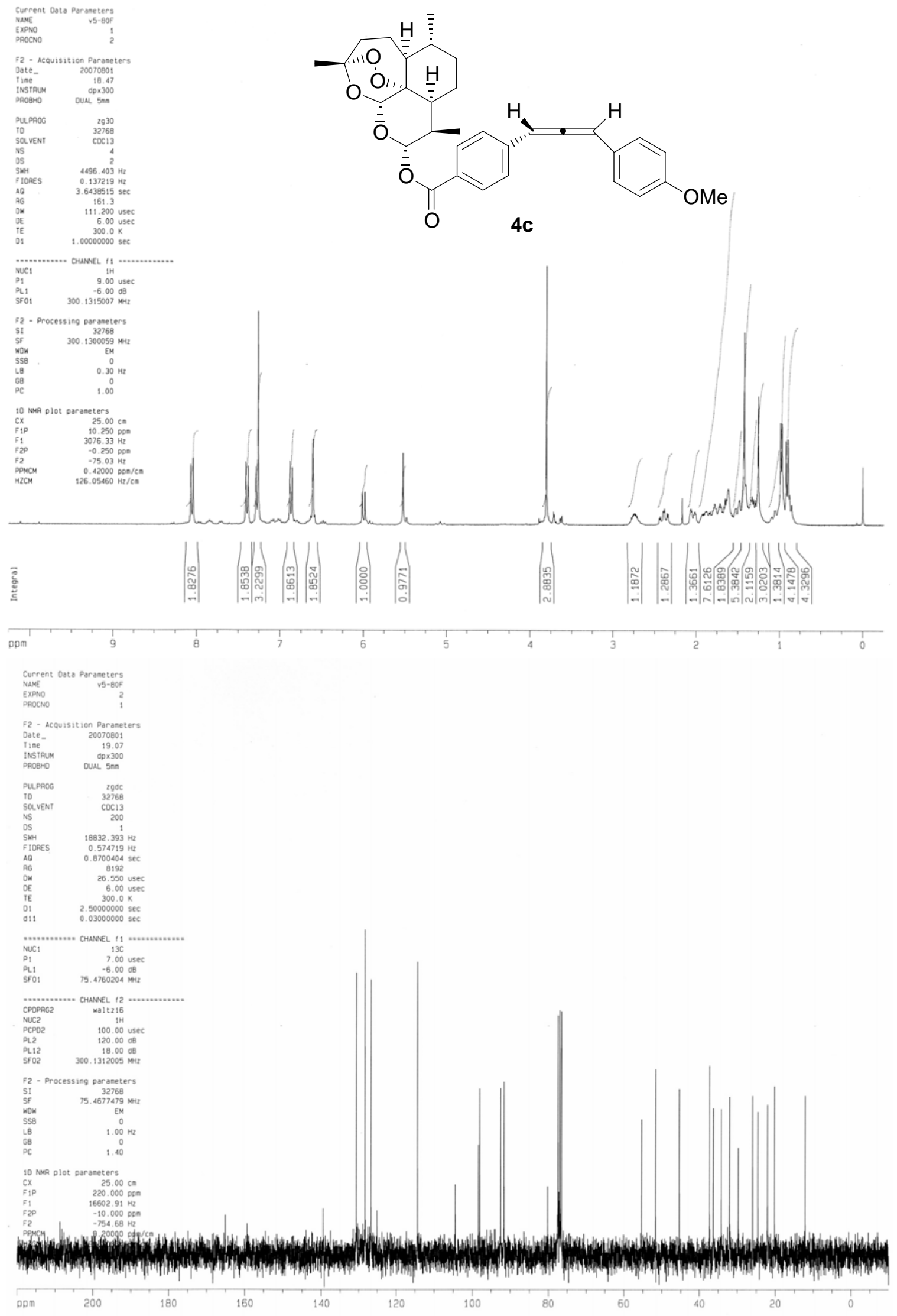

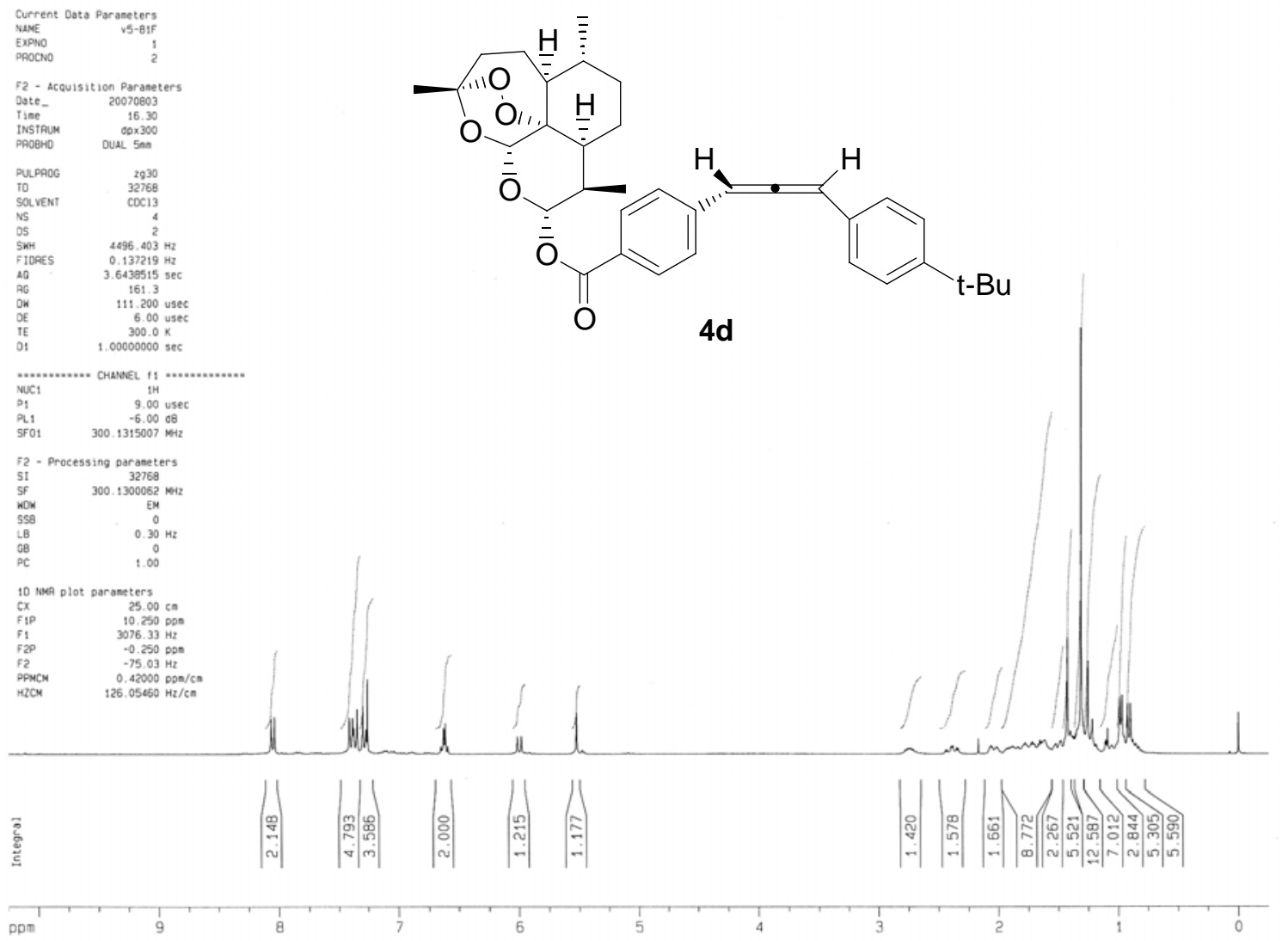

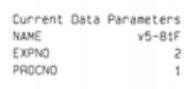

F2 - Acquisition paraneters

$\begin{array}{lr}\text { Date- } & 20070802 \\ \text { Time } & 19.200\end{array}$

PAOARO OUAL $5 \mathrm{~mm}$

\begin{tabular}{lr} 
PU.PFOG & $290 \mathrm{C}$ \\
TD & 32768 \\
SOLVENT & COC13 \\
\hline W V V & 120
\end{tabular}

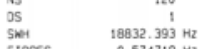

$\begin{array}{ll}\text { Thefes } & 0.5747919 \mathrm{~Hz} \\ 40 & 0.8700404 \mathrm{sec}\end{array}$

$\begin{array}{lrl}\text { AG } & 8192 \\ \text { ON } & 26.550 \text { usec } \\ \text { OE } & 5.00 \text { use }\end{array}$

$\begin{array}{ll}\text { TE } & 300.0 \mathrm{~K} \\ 01 & 2.50000000 \mathrm{sec}\end{array}$

N.............. OANEEL 14 ...............

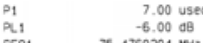

.............. Crevel. 12 ...............

CPOPAG2 Naltez16
NuC?

$\begin{array}{ll}\text { PCPO2 } & 100.00 \text { usec } \\ \text { P.L2 } & 120.0006 \\ \text { P.t.12 } & 18.00060\end{array}$

The

$\begin{array}{lc}\text { F2 - Processing parameters } \\ \text { S1 } & 32778 \\ \text { SF } & 75.4677479 \mathrm{NHz} \\ \text { WOW } & E M \\ \text { SSB } & 0 \\ \text { L8 } & 1.00 \mathrm{~Hz} \\ \text { GB } & 0\end{array}$

10 NAR plot paraneters

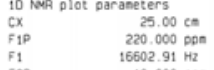

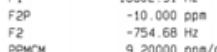

Wariond

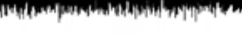

ppm $200 \quad 180$

160

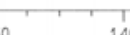

60

$\frac{1}{20}$ 
${ }^{1} \mathrm{H}$ and ${ }^{13} \mathrm{C}$ NMR Spectra of 5a-b, $6 a$
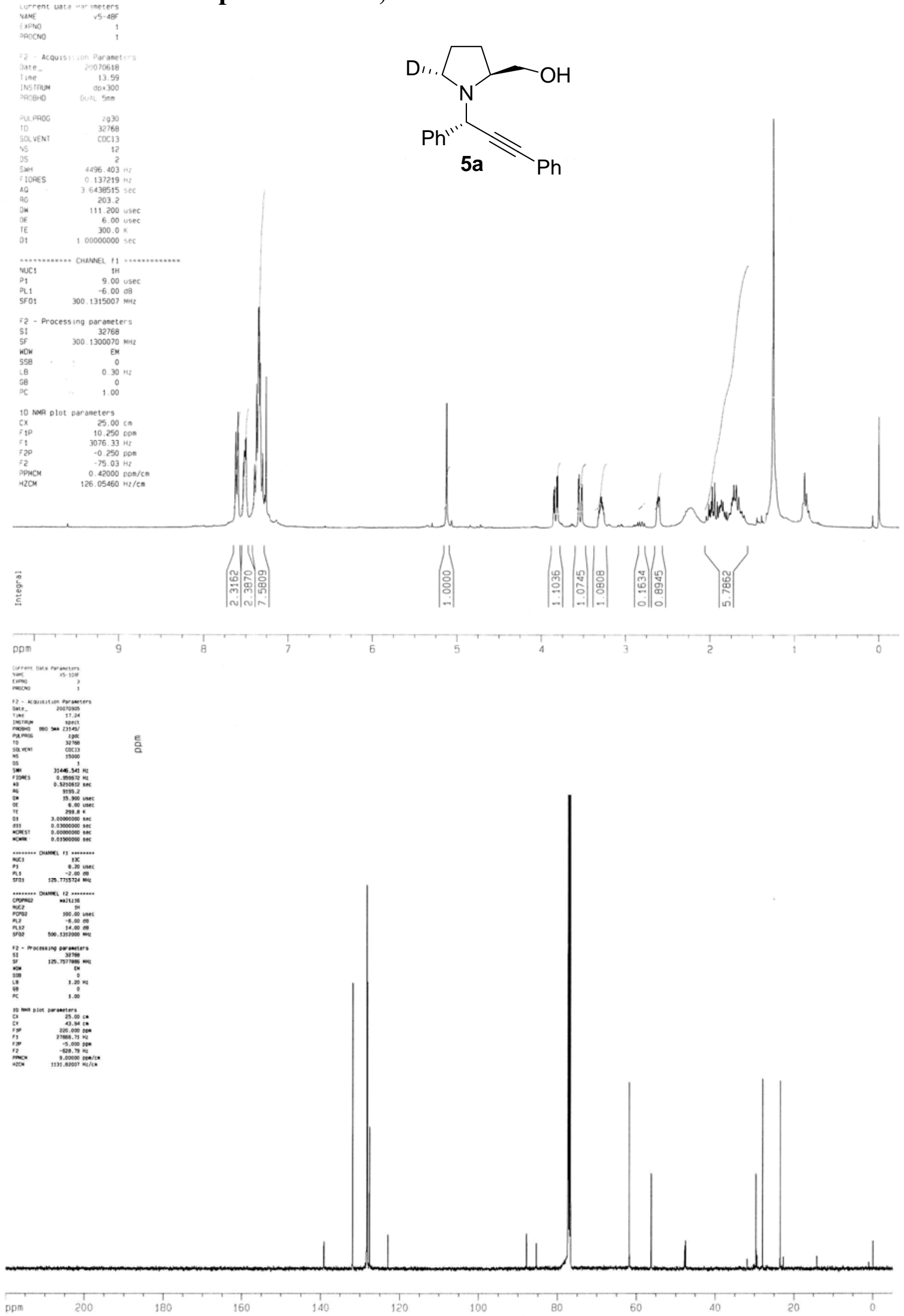

S80 


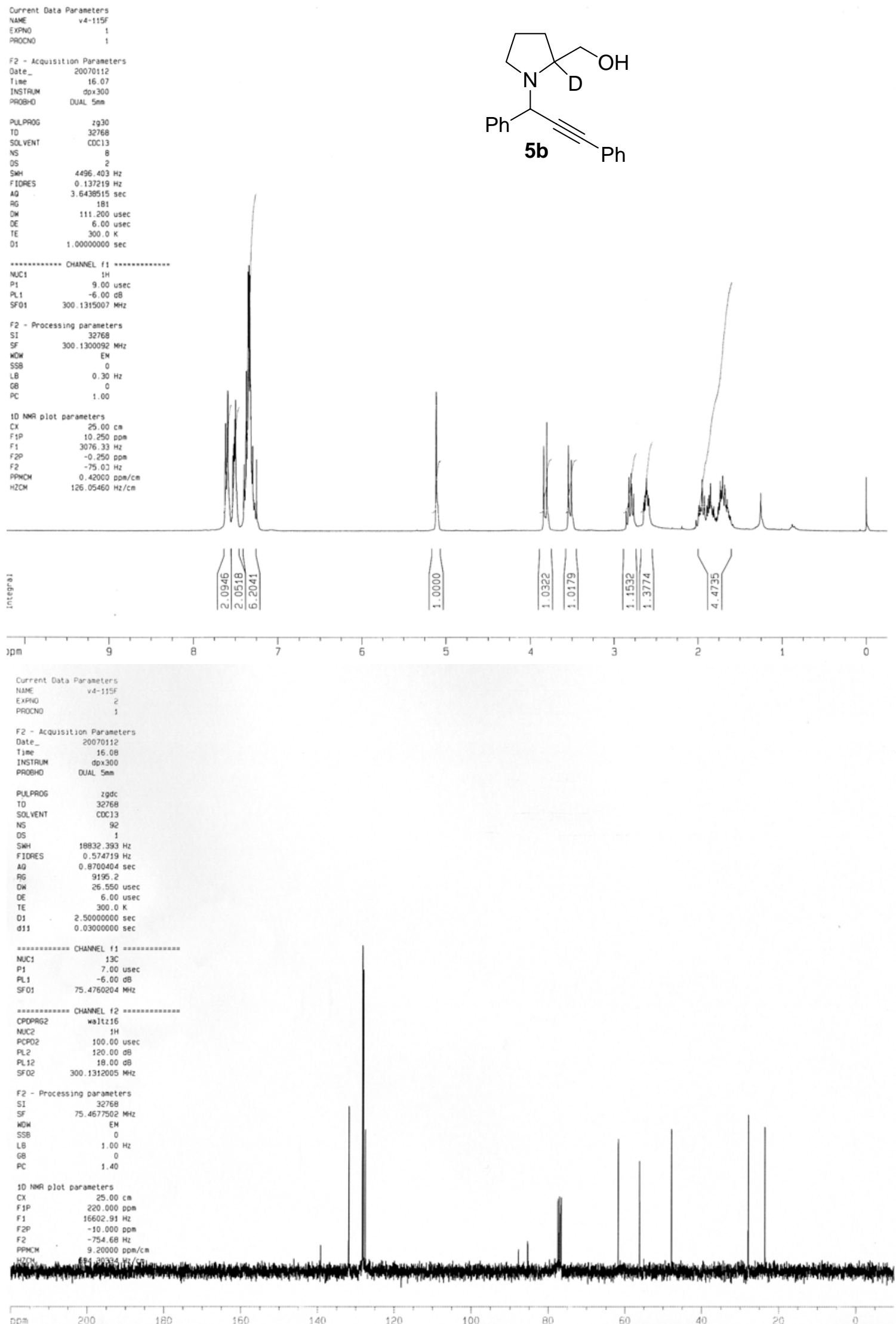




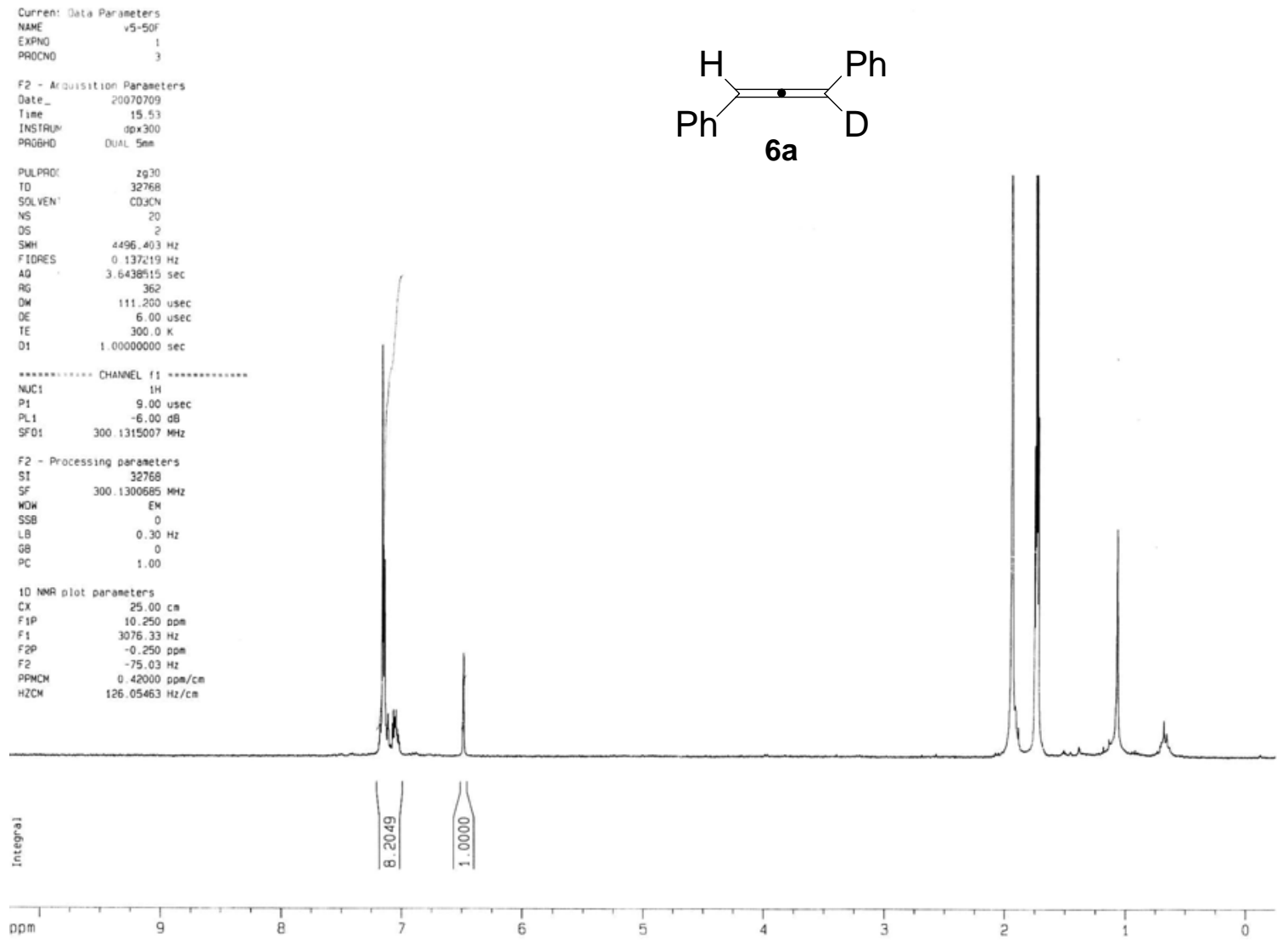




\section{${ }^{1} \mathrm{H}$ and ${ }^{13} \mathrm{C}$ NMR Spectra of $7 \mathrm{~b}, 8 \mathrm{~b}-\mathrm{c}$}
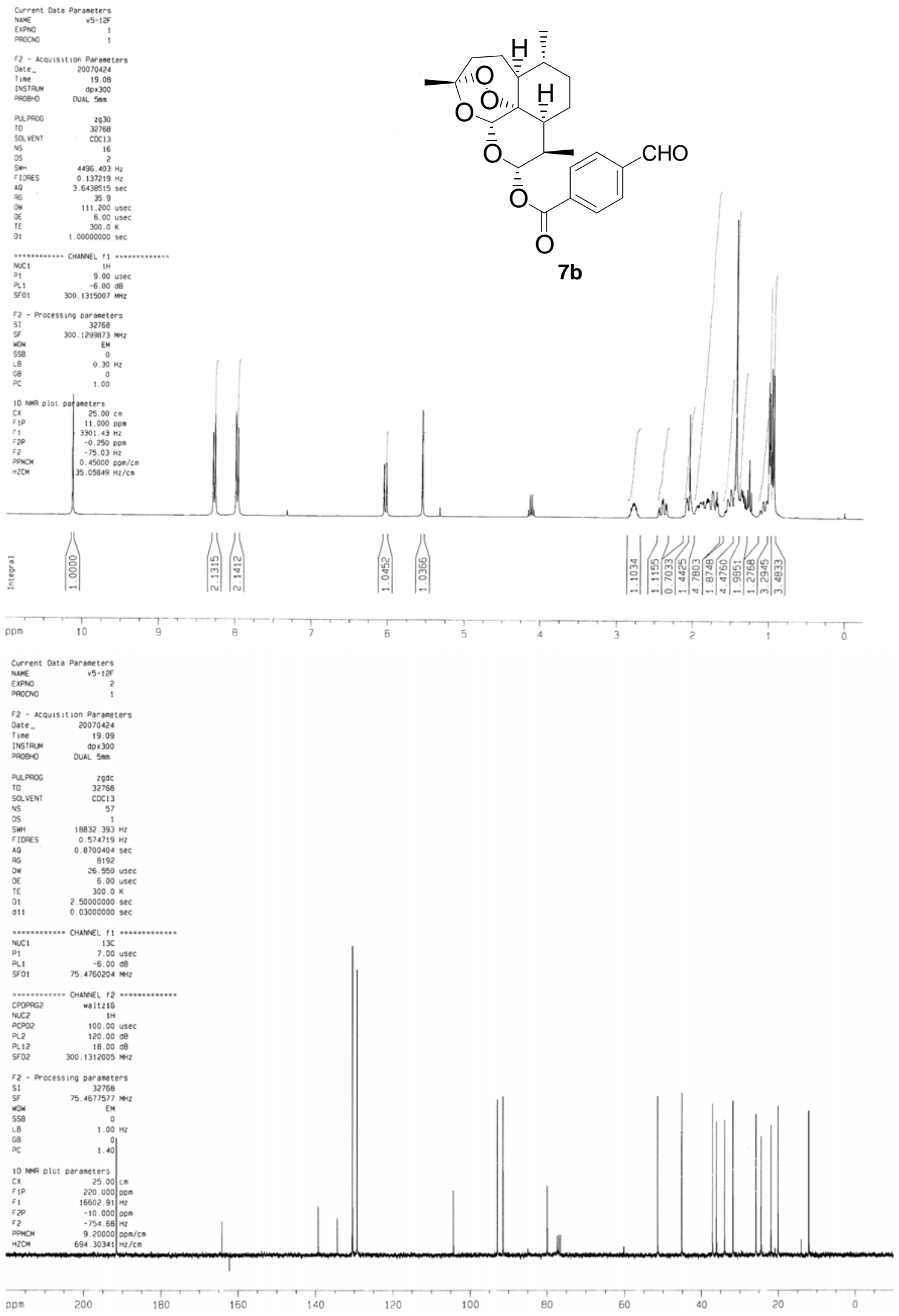

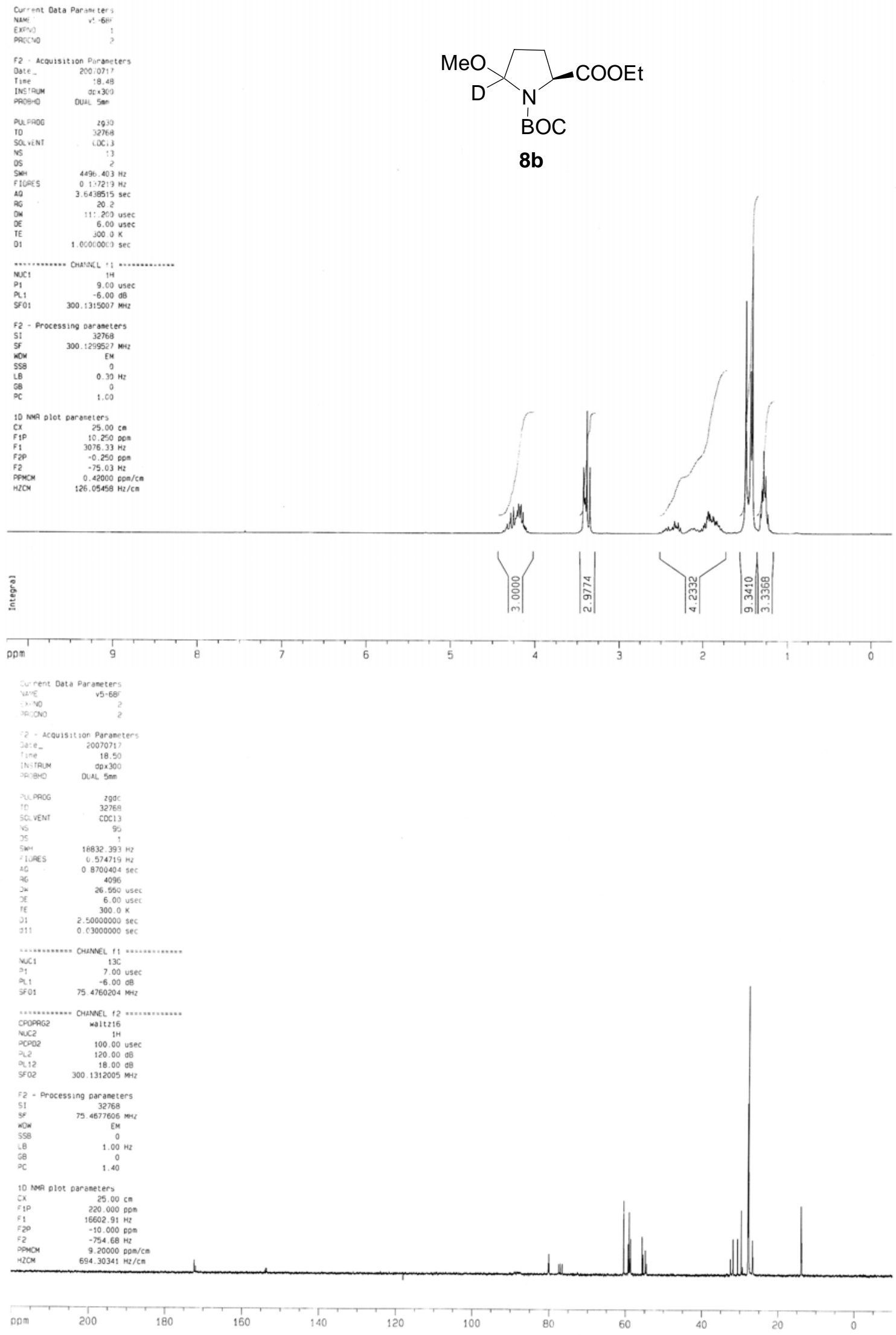

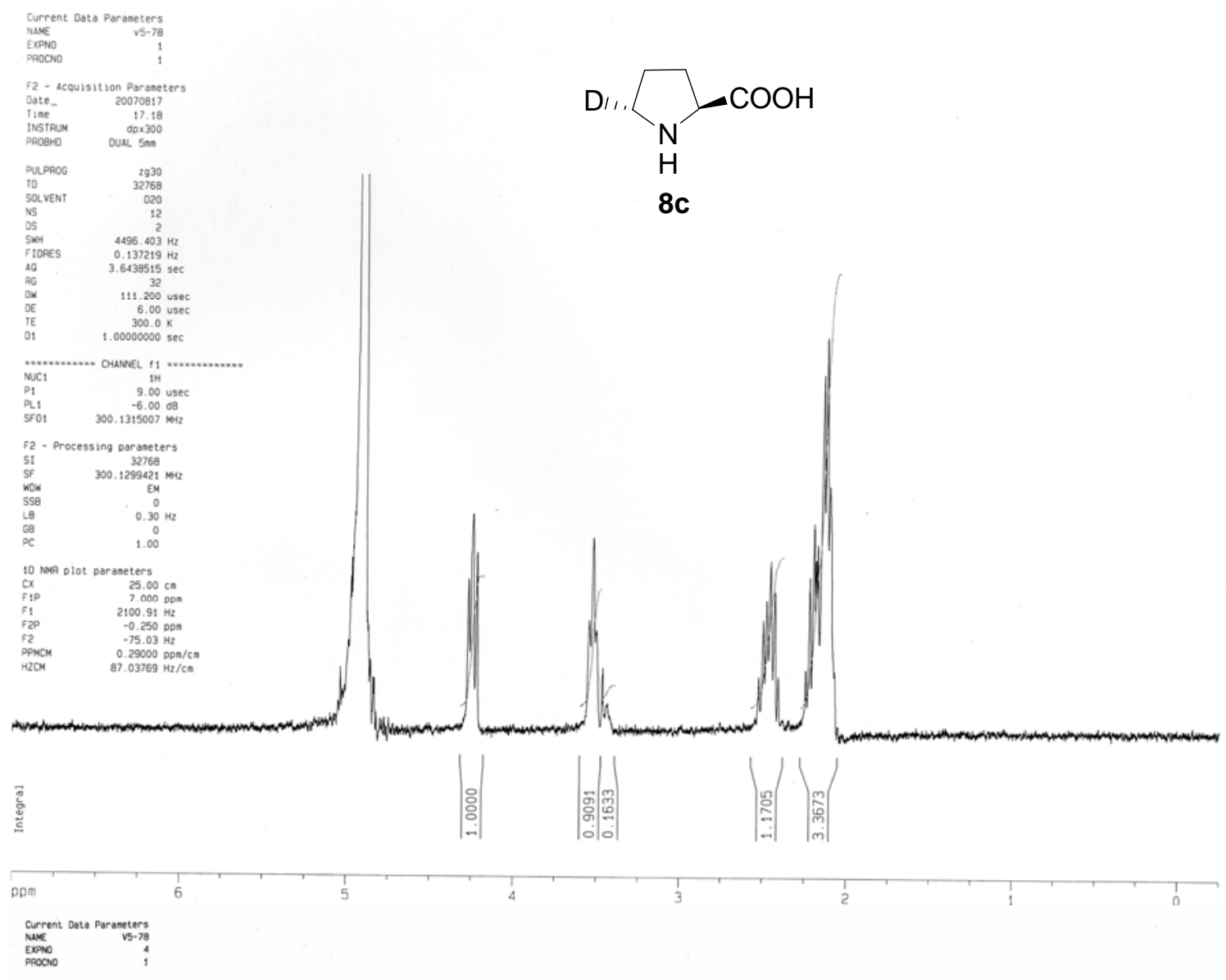

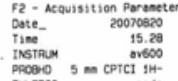

Th

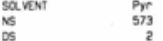

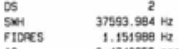

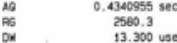

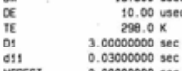

$\begin{array}{ll}\text { MOEST } & 0.00000000 \mathrm{sec} \\ \text { MOAX } & 0.01500000 \mathrm{sec}\end{array}$

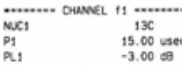

150. 9193963 .

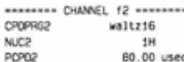

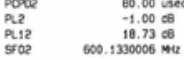

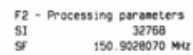

$\begin{array}{lc}\text { NOW } & \text { ER } \\ \text { SSP } & 0 \\ \text { LB } & 1.00 \mathrm{~Hz} \\ \text { GB } & 0 \\ \text { PC } & 1.00\end{array}$

10 Not plot persosters

$\begin{array}{ll}c r & 12.02 \mathrm{~cm} \\ \text { Fip } & 220.000\end{array}$

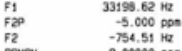

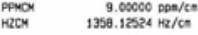
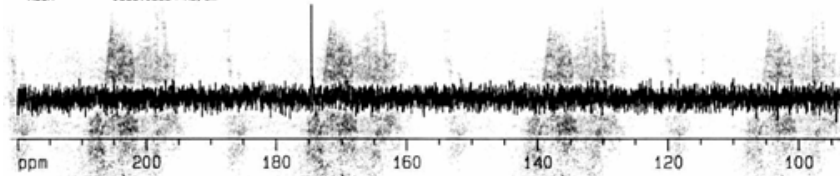